Mauricio Watanabe Ribeiro

\title{
AVALIAÇÃO MULTIMODAL DA FISIOLOGIA DE PILOTOS DE AERONAVES DE ASAS ROTATIVAS DURANTE MANOBRA DE POUSO EM SITUAÇÃO CRÍTICA
}

Tese apresentada à Faculdade Israelita de Ciências da Saúde Albert Einstein para obtenção do Título de Doutor em Ciências da Saúde. 
Mauricio Watanabe Ribeiro

\section{AVALIAÇÃO MULTIMODAL DA FISIOLOGIA DE PILOTOS DE AERONAVES DE ASAS ROTATIVAS DURANTE MANOBRA DE POUSO EM SITUAÇÃO CRÍTICA}

Tese apresentada à Faculdade Israelita de Ciências da Saúde Albert Einstein para obtenção do Título de Doutor em Ciências da Saúde.

Orientadora: Profa. Dra. Elisa Harumi Kozasa

Coorientador: Prof. Dr. Birajara Soares Machado 


\section{$\mathrm{R} 484 \mathrm{a}$}

Ribeiro, Mauricio Watanabe

Avaliação multimodal da fisiologia de pilotos de aeronaves de asas rotativas durante manobra de pouso em situação crítica / Mauricio Watanabe Ribeiro. -- São Paulo, 2019.

xiv, $66 \mathrm{f}$.

Tese (Doutorado) - Faculdade Israelita de Ciências da Saúde Albert Einstein. Instituto Israelita de Ensino e Pesquisa Albert Einstein. Programa de Pós-Graduação em Ciências da Saúde.

Título em inglês: Multimodal assessment of physiology of pilots of rotating wings aircrafts during landing maneuver in critical situation.

1. Carga de trabalho. 2. Resposta galvânica da pele. 3. Frequência cardíaca. 4. Taxa respiratória. 5. Frequência de piscadas.

NLM - WD 700

Elaborada pelo Sistema Einstein Integrado de Bibliotecas 
FACULDADE ISRAELITA DE CIÊNCIAS DA SAÚDE ALBERT EINSTEIN

Coordenador do Curso de Pós-Graduação: Prof. Dr. Luiz Vicente Rizzo 
Mauricio Watanabe Ribeiro

\title{
AVALIAÇÃO MULTIMODAL DA FISIOLOGIA DE PILOTOS DE AERONAVES DE ASAS ROTATIVAS DURANTE MANOBRA DE POUSO EM SITUAÇÃO CRÍTICA
}

Presidente da banca: Profa. Dra. Elisa Harumi Kozasa

\author{
BANCA EXAMINADORA
}

Membros titulares:

Dra. Joana Bisol Balardin

Prof. Dr. Luiz Eugenio Araujo de Moraes Mello

Prof. Dr. Edgard Morya

Membros suplentes:

Prof. Dr. Luís Otávio Sales Ferreira Caboclo

Prof. Dr. André Mascioli Cravo

Aprovada em: 17/02/2020. 


\section{Dedicatória}

Aos meus pais, Fumika Watanabe e Angelim Ribeiro, pois foram eles os verdadeiros gigantes que ofereceram os ombros para que eu pudesse enxergar mais longe. 


\section{Agradecimentos}

Aos meus pais, Fumika e Angelim, pelo cuidado compassivo, carinho e apoio durante toda minha vida. À minha irmã, Mariana, por seu apoio incondicional e pela paciência nos momentos de tensão e ausência.

À minha companheira, Kel, agradeço por sempre me lembrar de que o caminho é muito mais importante do que a chegada, e por fazer esse caminho ser tão mais leve e divertido. A Lílian, Frida e Brisa, agradeço por tudo o que vocês me ensinaram nesses anos todos, todo o apoio, o carinho e a saudade que sinto de vocês.

Aos orientadores, Profa. Dra. Elisa Harumi Kosaza e Prof. Dr. Birajara Soares Machado, que tanto ensinaram e orientaram no decorrer desta jornada, servindo como grandes exemplos de conduta científica ética e correta.

Ao Brig. José Elias Matieli e ao Prof. Dr. Luiz Vicente Rizzo por terem viabilizado a parceria interinstitucional entre o Instituto Tecnológico da Aeronáutica e a Sociedade Beneficente Israelita Brasileira Albert Einstein.

Ao Ten. Cel. José Ricardo Scarpari, ao Prof. Dr. Roberto Gil Annes da Silva e ao Prof. Dr. Carlos Henrique Forster pela parceria sem a qual este projeto não seria possível.

Muitos outros companheiros permaneceram ao meu lado durante este período maravilhoso da minha vida, como flores que encontramos durante uma trilha difícil que ajudam a alegrar o caminho. Foram muitos aprendizados com cada amigo que levo para além da vida acadêmica: Camilinha, Carlos, Cássia, Rui, Fábio, Nadja, lago, Josi, Madé e minha irmã vajra, Camilona.

Para além da academia, muitos outros amigos ampliaram meu conhecimento de vida: os amigos do Amor, que vejo com mais ou menos frequência, aqueles que estão espalhados pelo mundo, aqueles que moram do lado de casa, todos grandes companheiros de caminhada de tantos anos e que me ensinaram e ensinam tanto.

Agradeço ao Instituto de Pesquisas e Ensaios em Voo (IPEV) e ao Instituto Israelita de Ensino e Pesquisa (IIEP) e à Coordenação de Aperfeiçoamento de Pessoal de Nível Superior (CAPES), pelo apoio financeiro para a realização deste estudo, número do processo $88882.366120 / 2019-01$. O presente trabalho foi realizado 
com apoio da Coordenação de Aperfeiçoamento de Pessoal de Nível Superior - Brasil (CAPES) - Código de Financiamento 001. 
"A vida resiste a definições."

Elizabeth Mattis Namgyel (O poder de uma pergunta aberta, 2019) 


\section{Sumário}

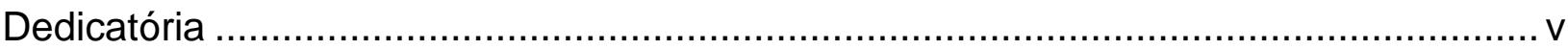

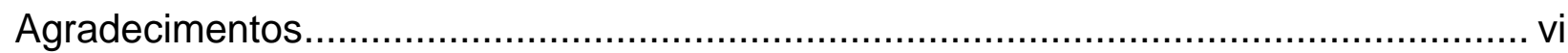

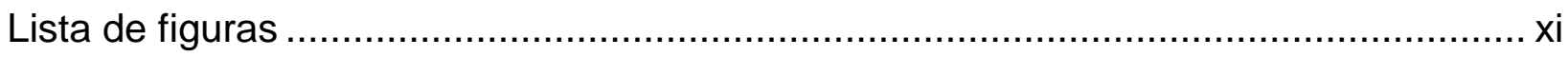

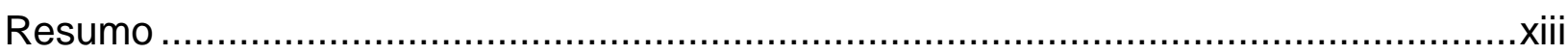

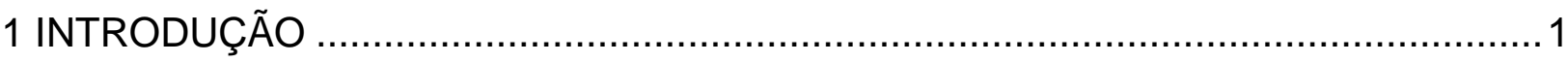

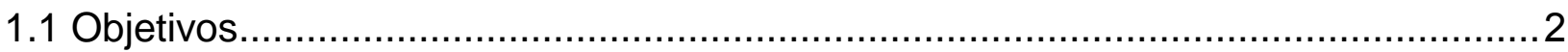

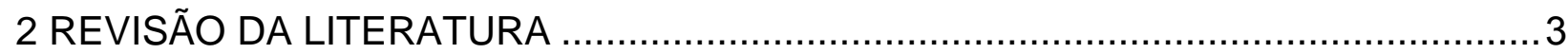

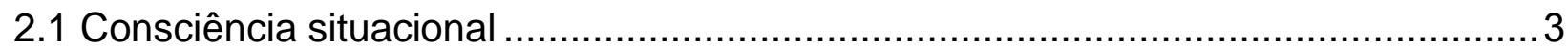

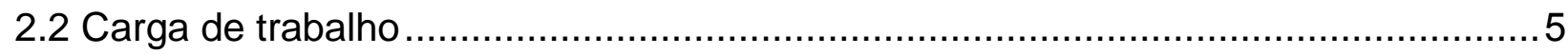

2.3 A pilotagem de helicópteros e a curva do homem morto ....................................... 6

2.4 Medições de carga de trabalho subjetivas........................................................ 8

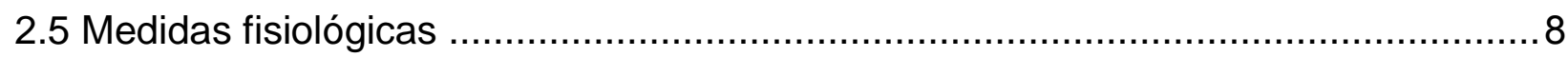

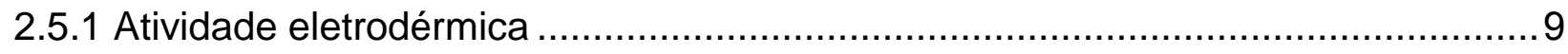

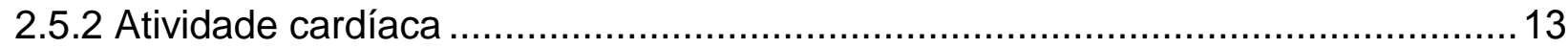

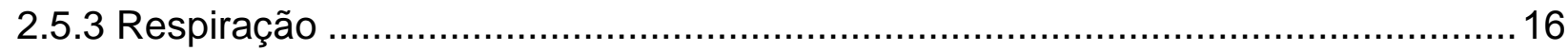

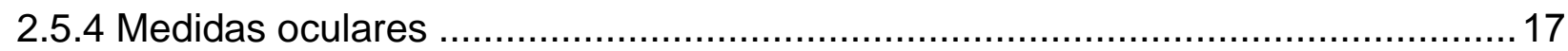

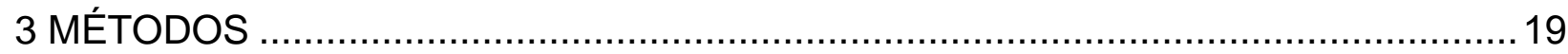

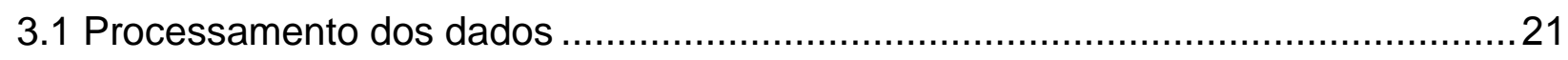

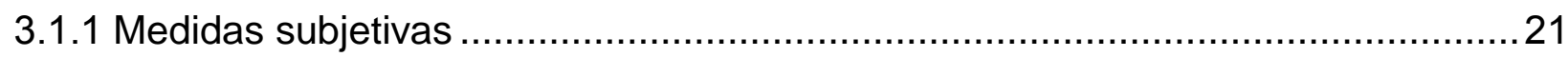

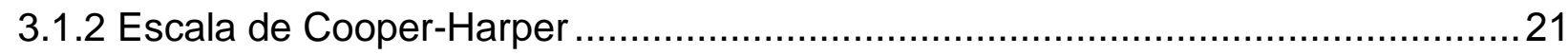

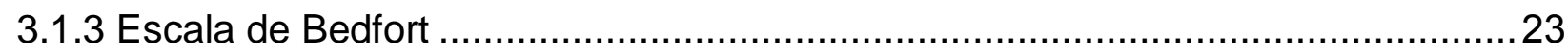

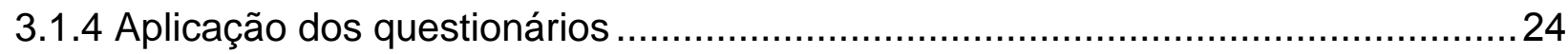

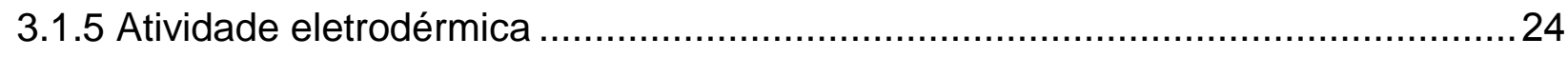

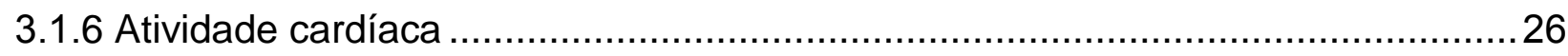

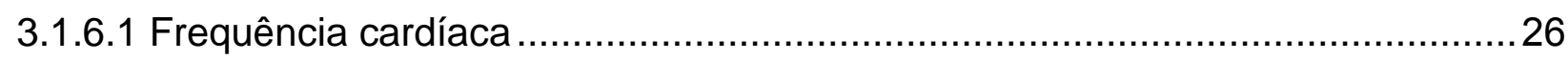

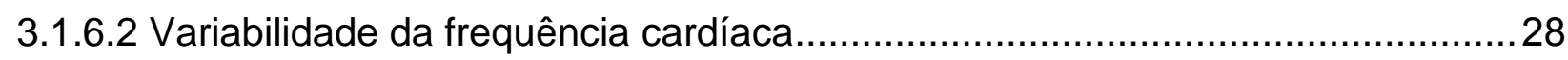

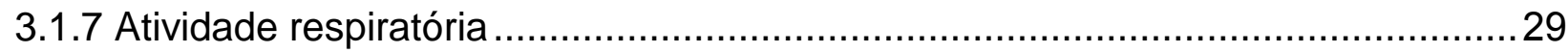

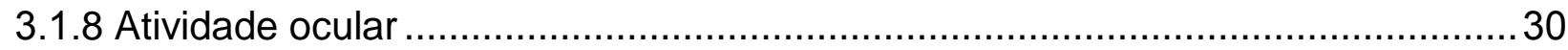

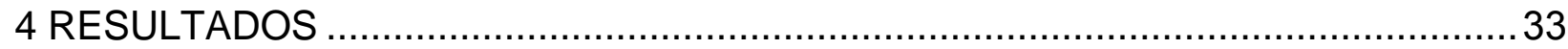

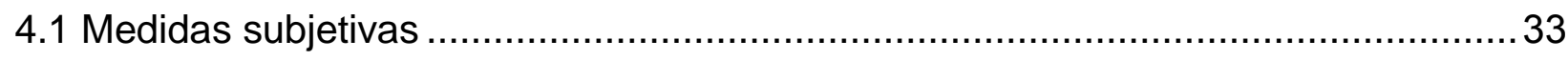

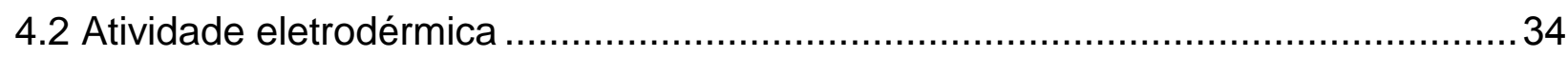




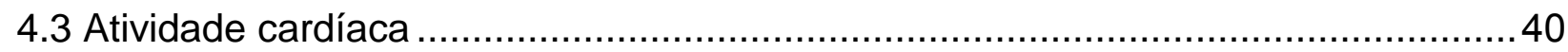

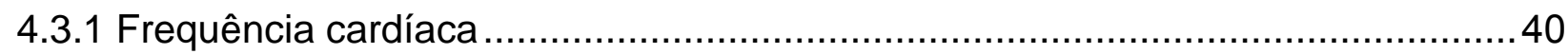

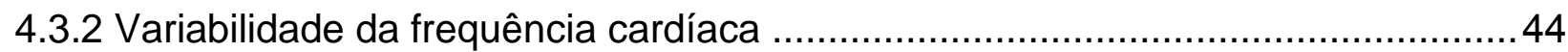

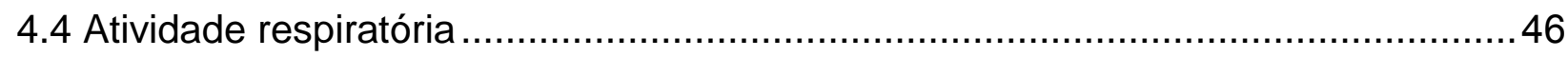

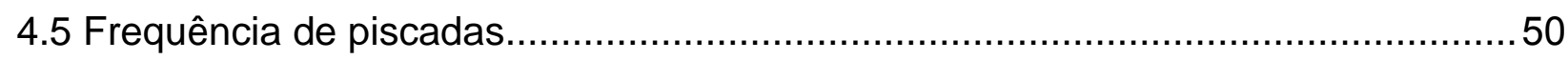

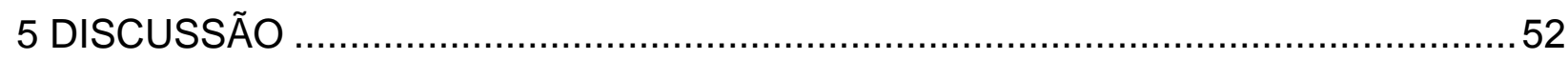

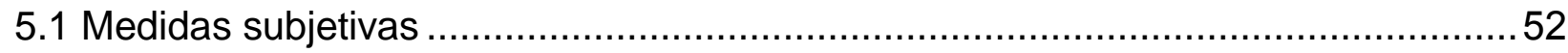

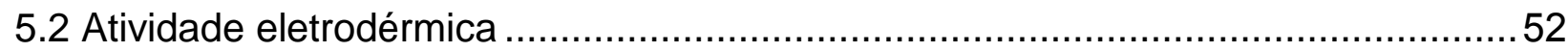

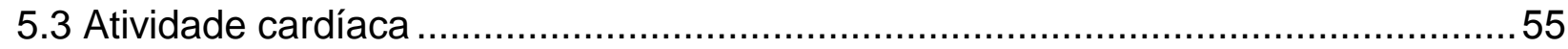

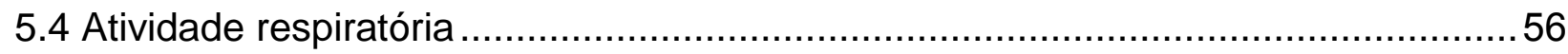

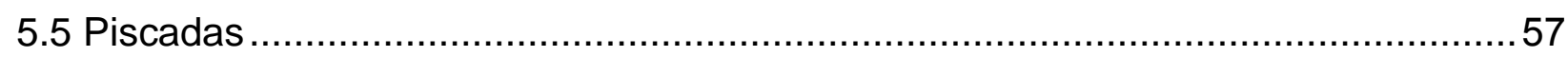

5.6 Discussão sobre os resultados em conjunto ................................................... 58

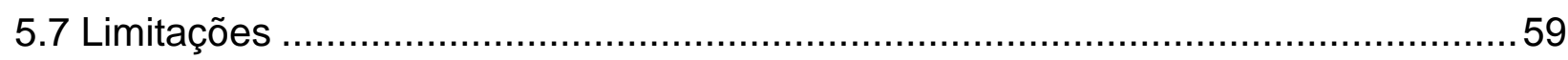

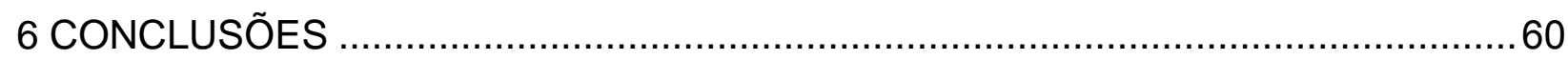

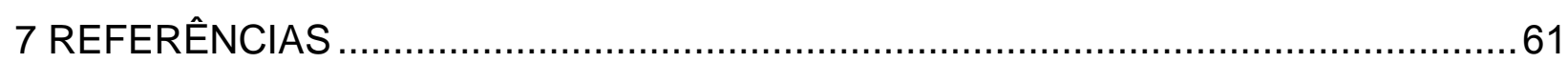

Abstract 


\section{Lista de figuras}

Figura 1. Modelo de consciência situacional em tomada de decisão dinâmica. 4

Figura 2. A curva do homem morto e a variação de risco da manobra de autorrotação em suas redondezas .7

Figura 3. Resposta Eletrodérmica canônica com medição exossomática . 11

Figura 4. Representação do ciclo cardíaco no eletrocardiograma. 14

Figura 5. Conjunto multimodal de sensores fisiológicos utilizados neste trabalho. 20

Figura 6. Pontos de execução da manobra de autorrotação em relação à curva do homem morto .20

Figura 7. Escala de Cooper-Harper..... .22

Figura 8. Exemplo de variação de condutância ao redor da manobra. .25

Figura 9. Exemplo de extração de dados de batimentos por minuto a partir do sinal de ECG gravado .26

Figura 10. Exemplo de correção manual do intervalo entre batimentos 27

Figura 11. Exemplo de espectrograma e área de interesse ao redor da manobra .......30

Figura 12. Exemplo de resultado de análise de componentes independentes .............31

Figura 13. Histograma das cargas de trabalho. 33

Figura 14. Médias dos relatos subjetivos das cargas de trabalho por local de manobra 34

Figura 15. Exemplo de sinais brutos da atividade eletrodérmica, demonstrando a modulação logo após a falha de motor. .35

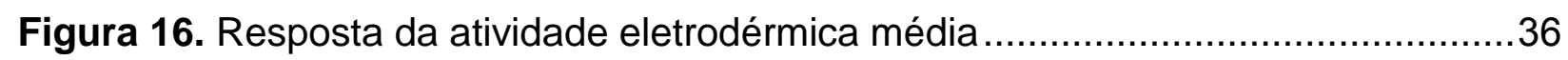

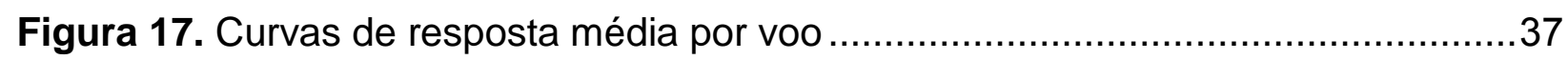

Figura 18. Exemplo da modificação da amplitude percentual no decorrer de um voo..38

Figura 19. Amplitude percentual média das respostas da atividade eletrodérmica com relação ao local da manobra 39

Figura 20. Média e erro padrão do Log da resposta da atividade eletrodérmica agrupada por posição em relação à curva do homem morto. .39

Figura 21. Frequência cardíaca ao redor da falha do motor.

Figura 22. Curvas de frequência cardíaca normalizada em relação aos cinco segundos anteriores a falha do motor por voo

Figura 23. Integrais da frequência cardíaca ao redor das manobras. .43 
Figura 24. Valor médio e erro padrão das integrais da frequência cardíaca por local da manobra 43

Figura 25. Resultado da relação entre as potências de alta e baixa frequência da variabilidade cardíaca obtidas com o modelo de processamento de pontos

Figura 26. Relação entre as potências de alta e baixa frequência da variabilidade cardíaca obtidas com o modelo de processamento de pontos 45

Figura 27. Valor bruto do sinal de respiração de uma manobra ao redor da falha do motor .46

Figura 28. Valor bruto médio do sinal da respiração ao redor da falha do motor .46

Figura 29. Frequência respiratória promediada média .48

Figura 30. Frequência respiratória promediada média por voo de cada piloto .49

Figura 31. Frequência de piscadas média ao redor da manobra .50

Figura 32. Número de piscadas e derivada com dois tamanhos diferentes de bins.....51 


\section{Resumo}

Introdução: Voos de helicóptero devem se situar fora da denominada curva do homem morto, de forma a possibilitar um pouso seguro em caso de falha no motor. Isso permite a realização em segurança da manobra de pouso em autorrotação, quando não há o funcionamento do motor. Em caso de falha do motor em uma região dentro da curva do homem morto não há energia residual o suficiente para a execução dessa manobra, o que levaria a um acidente fatal. O padrão para mensurar a carga de trabalho durante a manobra de pouso em autorrotação consiste em medidas subjetivas, que são suscetíveis a diversos vieses e reportam o valor médio da carga de trabalho durante a execução da manobra. A mensuração objetiva através de marcadores fisiológicos pode ajudar na caracterização no decorrer do tempo da execução da manobra, aumentando assim a resolução da medida e podendo explicitar os momentos de maior demanda por parte dos pilotos. Ao compreender melhor os passos de maior demanda, o treinamento dos pilotos pode ser melhorado e a demanda ao qual o piloto está submetido durante estas manobras melhor avaliada. Objetivos: Estudar a viabilidade da gravação de sinais eletrofisiológicos durante manobras de autorrotação em voos reais. Analisar suas correlações com 4 diferentes níveis de dificuldade paras as manobras: aquelas realizadas fora da curva, na região limítrofe da curva ou dentro da curva do homem morto, com aviso prévio ou ainda pontos fora da curva, mas ocorrendo sem aviso prévio (surpresa). Métodos: Foram analisadas a atividade eletrodérmica, o eletrocardiograma, a respiração e frequência de piscadas de onze pilotos, durante manobras de autorrotação em diferentes pontos em relação à curva do homem morto. Cada piloto realizou diversas manobras em cada ponto em relação à curva, com diferentes alturas e velocidade, separados em dois voos distintos. Para levar em conta as repetições e aumentar o poder estatístico, cada medida foi avaliada com a utilização de modelo linear de efeitos mistos. Resultados: A atividade eletrodérmica, a frequência cardíaca e a frequência de piscadas apresentaram sinais robustos na comparação entre voos e com padrões similares ao reportado na literatura. O sinal da respiração não apresentou um sinal robusto comparando dois diferentes voos dos pilotos. O modelo linear de efeitos mistos mostrou que as variações percentuais da atividade eletrodérmica eliciadas nas manobras dentro da curva $(p<0,05)$ e surpresa $(p<0,05)$ foram maiores do que das manobras fora da curva, 
conforme o esperado. Todos os sinais analisados, inclusive a respiração, apresentaram em seu valor médio dois momentos distintos de modulação de resposta, um logo após a falha do motor e outro alguns segundos depois. Conforme o esperado, já que os dois momentos de maior demanda são a entrada na manobra de autorrotação e o pouso (flare). Conclusões: Os sinais fisiológicos podem ser utilizados mesmo num ambiente real com muitas fontes de ruído. Estas análises mostraram que estes sinais, em especial a atividade eletrodérmica, podem ser úteis para complementar a avaliação da demanda que os pilotos estão submetidos durante a execução desta manobra.

Descritores: Carga de trabalho; Resposta galvânica da pele; Frequência cardíaca; Taxa respiratória; Frequência de piscadas 


\section{INTRODUÇÃO}

A sobrevivência do ser humano sempre esteve relacionada com sua capacidade de extrair informações relevantes do meio ambiente. Desde a época em que éramos basicamente caçadores coletores, necessitamos dessa capacidade para podermos ser bem-sucedidos em termos de espécie. Atualmente, a quantidade de informações disponível é cada vez maior, e a necessidade de uma boa percepção e compreensão tornam-se um desafio. $\mathrm{O}$ maior problema consiste em distinguir quais informações são necessárias e em qual momento. Dentro desse contexto, a consciência situacional, definida como "a percepção dos elementos no ambiente dentro de um volume de tempo e espaço, a compreensão de seus significados e a projeção de seu status no futuro próximo",(1) ganha cada vez mais importância em campos como treinamentos e desenvolvimento de interfaces de operação. ${ }^{(2)}$

Em qualquer ambiente, apenas ter uma consciência situacional do que está acontecendo não garante uma execução adequada da ação necessária para atingir os objetivos pretendidos. Em ambientes sujeitos a variações rápidas das condições e cujos erros na execução da ação desejada podem levar a fatalidades há um aumento na necessidade de se levar em conta fatores que influenciam na execução dessa ação, como a carga de trabalho a que o operador está submetido. A carga de trabalho no construto teórico de Endsley é considerada um fator externo à consciência situacional, mas que influencia na transformação entre uma boa consciência situacional e a execução adequada de uma ação para atingir um objetivo estabelecido. A carga de trabalho pode ser definida como a quantidade de processamento de informação (especialmente atencional e de memória de trabalho) demandada durante um período de tempo específico, isto é, o esforço mental necessário para a execução de uma tarefa. ${ }^{(3)}$

Neste trabalho, temos como objeto a análise multimodal da fisiologia de pilotos de helicóptero durante a execução de uma manobra de pouso em situação de falha do motor. Essa é uma situação limítrofe, na qual os pilotos têm uma janela de tempo curta para executar uma manobra difícil e cuja ocorrência é rara.

Não há na literatura nenhum relato de avaliação objetiva, através de marcadores fisiológicos, da carga de trabalho a qual os pilotos de helicóptero estão sujeitos durante a execução de manobras de autorrotação em voos reais. Esses 
marcadores podem ajudar a guiar os treinamentos ao indicar os pontos de maior dificuldade para a realização da manobra. Além disso, há a possibilidade de verificar se há alteração da resposta fisiológica dos pilotos com o aumento da dificuldade em realizar a manobra, o que ocorre ao movermos o ponto de execução em direção à região limite de operação, conhecida como curva do homem morto.

Nossa hipótese é a de que há uma distribuição não uniforme da dificuldade durante a execução do pouso em situação crítica, que será observada por maiores respostas fisiológicas dos pilotos. Além disso, as variações fisiológicas (arousal) serão maiores conforme nos aproximamos da área limite de operação segura, também chamada de curva do homem morto, e ainda maiores caso elas ocorram de maneira inesperada (surpresa).

\subsection{Objetivos}

1. Avaliar a viabilidade da aquisição de dados fisiológicos (condutância da pele, eletrocardiograma, respiração e piscadas) durante a execução de manobras de autorrotação em ambiente real;

2. Analisar possibilidades de associações entre as variações dos sinais gravados em diferentes pontos de execução da manobra: fora, próximo ao limite, dentro do perímetro da curva e as ocorrências surpresa. 


\section{REVISÃO DA LITERATURA}

\subsection{Consciência situacional}

A formação da consciência situacional pode ser entendida como a construção do conhecimento do que está ocorrendo ao seu redor. No modelo de Endsley, ${ }^{(3)}$ a consciência situacional é dividida em três níveis: percepção, compreensão e projeção. A percepção seria o primeiro nível, pois se o operador não for capaz de perceber quais são as informações importantes em determinado momento, as chances de ele formar uma interpretação incorreta da situação atual são muito altas. O segundo nível, a compreensão, baseia-se nas informações coletadas no primeiro nível. Após perceber os sinais do ambiente, o operador precisa combinar, interpretar, armazenar e reter as informações. Ou seja, é necessário integrar os diversos pedaços de informação e determinar a relevância de cada um deles para o seu objetivo. Isso é o análogo à diferença entre compreender um texto e simplesmente ler as palavras. No terceiro nível, a projeção, o operador deve ter a habilidade de prever para onde a situação vai caminhar, os possíveis eventos futuros e sua dinâmica. Essa capacidade de fazer projeções a partir de eventos atuais, sua dinâmica e implicações são as bases que permitem uma tomada de decisão adequada.

No entanto, apenas entender as diversas fontes de informação pelas quais se forma a consciência situacional não ajuda a entender as complexidades de como as pessoas ativamente escolhem as informações, as colocam juntas e as interpretam em um ambiente dinâmico, formando um estado de consciência desse ambiente onde tanto as situações quanto os objetivos do operador estão em constante mudança. Existe, portanto, um processo, um método de aquisição de informação, e diferentes indivíduos podem utilizar processos distintos para chegar ao mesmo estado de conhecimento. Porém, eles também podem se utilizar do mesmo processo e chegar a conclusões distintas devido a diferenças na compreensão e projeção da informação adquirida, ou ainda por conta de diferenças em seus modelos ou esquemas mentais do ambiente. ${ }^{(2)}$

$\mathrm{Na}$ figura 1 ilustra-se a proposta de Endsley ${ }^{(3)}$ da relação entre a consciência situacional, a tomada de decisão e a execução. Essa separação pode ser útil no entendimento das condições necessárias para a execução bem-sucedida de 
uma ação. Nessa proposta, a consciência situacional é considerada um componente do modelo interno que determinado operador cria do seu ambiente. Esse modelo é então utilizado pelo operador para embasar suas decisões. Dessa forma, a consciência situacional seria um precursor da tomada de decisão e pode haver uma conexão direta entre elas, especialmente à medida que aumenta o nível de experiência do indivíduo. Isso é natural, já que entender a situação leva à seleção de uma ação apropriada da memória, como em uma jogada já estudada em uma partida de xadrez.

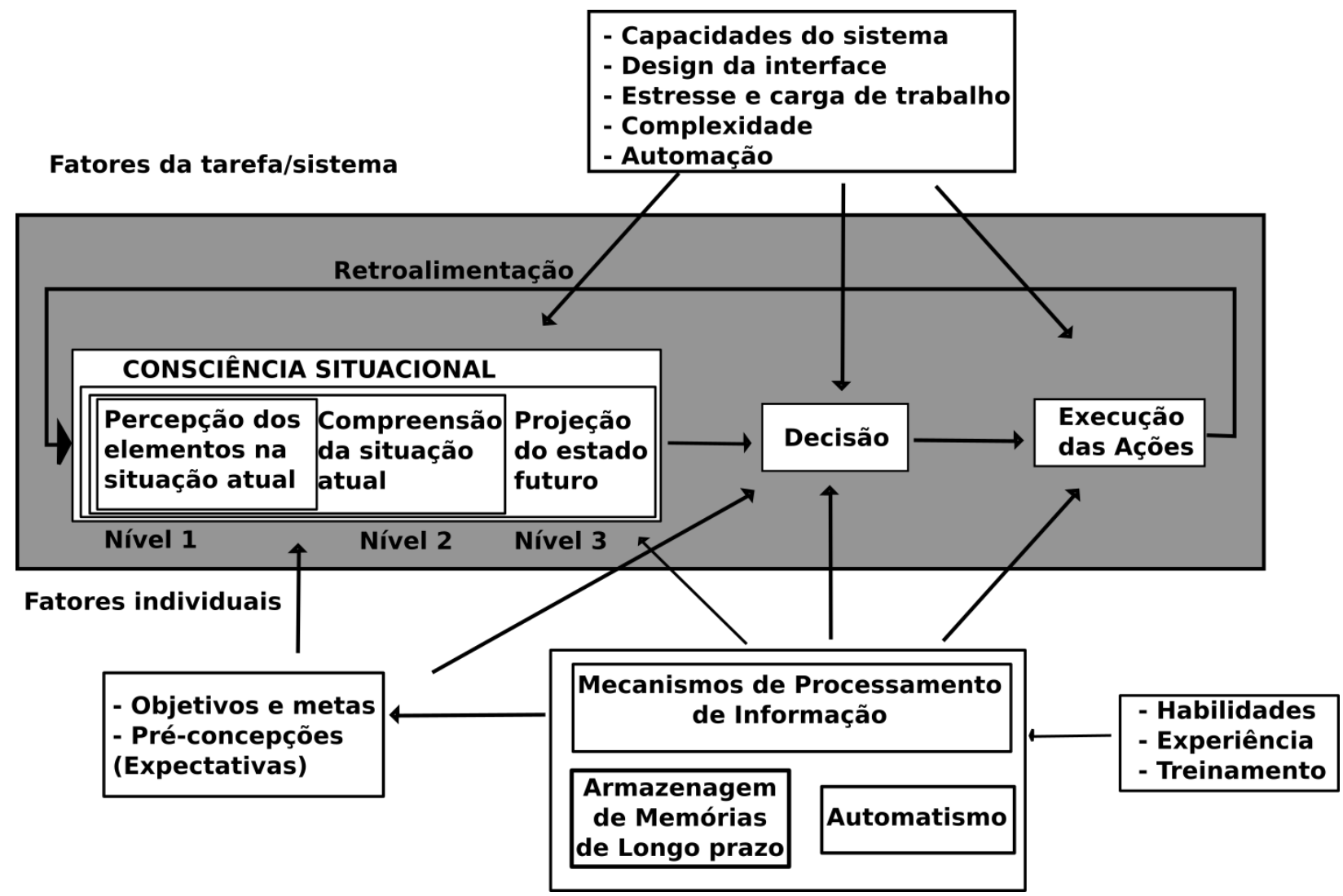

Fonte: Traduzido de Endsley MR. Toward a theory of situation awareness in dynamic systems. Hum Factors. 1995;37(1):32-64. Figure 1, Model of situation awareness in dynamic decision making; p. 36. ${ }^{(3)}$

Figura 1. Modelo de consciência situacional em tomada de decisão dinâmica

No entanto, muitos outros fatores são necessários para transformar uma boa consciência situacional em uma boa decisão, pois uma decisão ruim pode ser tomada mesmo com uma boa consciência situacional. Podemos imaginar um exemplo de decisão incorreta o caso de um comandante em uma batalha, que saiba onde está seu inimigo e as capacidades dele, mas que ainda assim não escolhe a estratégia correta ou adequada para seu ataque. Uma decisão incorreta pode ocorrer por diversos 
fatores, desde um treinamento inadequado que leva a estratégias inadequadas no processo de decisão a restrições organizacionais ou até mesmo técnicas. ${ }^{(2)}$

Portanto, a relação entre consciência situacional e desempenho pode ser vista como uma conexão probabilística, ou seja, uma boa consciência situacional aumenta a probabilidade de boas decisões e bom desempenho, mas não as garante. De modo inverso, deficiências na consciência situacional aumentam a probabilidade de um desempenho ruim, entretanto, em muitos casos, isso não cria um erro sério. Por exemplo, perder a orientação em uma aeronave pode levar mais facilmente a um acidente quando se está voando a baixas altitudes do que a altas altitudes. Assim, o comportamento e o desempenho são apenas indicadores indiretos da consciência situacional do operador. Uma ação desejada pode também ser executada de maneira incorreta devido a um erro físico, outras demandas, treino inadequado ou problemas no sistema. ${ }^{(2)}$

\subsection{Carga de trabalho}

Embora consciência situacional e carga de trabalho sejam, em geral, inter-relacionadas, elas também podem variar de maneira independente. Somente quando a demanda de carga de trabalho excede o máximo da capacidade humana é que a consciência situacional está em risco, pois problemas de consciência situacional também podem ocorrer sob baixas ou moderadas cargas de trabalho (devido a problemas de vigilância, por exemplo). ${ }^{(4)}$

A carga de trabalho é em geral mensurada através de testes subjetivos, ${ }^{(5,6)}$ e nesta tese utilizamos os testes de Cooper Harper ${ }^{(7)}$ e o de Bedford. ${ }^{(8,9)}$ Além da questão da subjetividade intrínseca a esse tipo de teste, eles são momentâneos, ou seja, há uma única mensuração após a realização da tarefa. Um fator relevante é justamente definir o momento mais adequado para a aplicação desses testes, se logo após a tarefa (no nosso caso após a manobra), se quebrando a tarefa no meio para mensuração (que não é possível no nosso caso) ou após o término da atividade (que seria no nosso caso após o termino do voo).

Outra possibilidade bastante promissora na mensuração da carga de trabalho envolve a diminuição da subjetividade da medida através da obtenção de medidas objetivas, tais como as obtidas através da fisiologia do operador durante a 
execução da tarefa. Nesse tipo de avaliação, busca-se por uma interface entre a cognição e a fisiologia, ou seja, entender como a atividade cognitiva da pessoa se relaciona ou resulta em mudanças na fisiologia. Nesses casos, é importante que as medidas fisiológicas sejam obtidas da maneira menos intrusiva possível para não interferir no desempenho do operador. Além disso, como essas medidas são contínuas, podem ser particularmente relevantes em situações em que um evento de interesse ocorra de maneira não planejada ou não controlada, pois permitem avaliar as condições que o antecederam. ${ }^{(2)}$

Neste trabalho, pilotos de helicóptero altamente treinados tiveram suas respostas fisiológicas registradas durante a execução de manobras com diferentes graus de dificuldade em uma situação de voo real.

Aquisições fisiológicas multimodais efetuadas em ambientes reais podem ajudar na validação de treinamentos em ambientes com simuladores, e a fornecer critérios complementares para a avaliação e para o desenvolvimento de programas de treinamentos. Os resultados podem também embasar a escolha do melhor momento para a aplicação de testes subjetivos.

\subsection{A pilotagem de helicópteros e a curva do homem morto}

Um dos requisitos de segurança para aeronaves de asas rotativas (helicópteros) é que o voo esteja restrito a regiões onde haja a possibilidade de execução de uma manobra de autorrotação. A autorrotação é definida como um modo de operação no qual a aeronave de asas rotativas é sustentada sem a transmissão de torque do motor para o rotor. Isso pode ocorrer em virtude de uma falha no motor, ou por conta de uma ruptura e/ou perda do controle direcional que torne necessário se eliminar o torque aplicado na transmissão. ${ }^{(10)}$

Nesse cenário, a rotação autossustentada do rotor do helicóptero ocorre sem torque residual do motor, realizando uma transformação energética de energias potencial gravitacional e cinética de translação em energia cinética de rotação das pás do rotor, cuja potência utilizada para manter a rotação é resultado do fluxo ascendente do escoamento pelo rotor, função da razão de descida do helicóptero pelo ar. $^{(11)}$ 
Durante os voos, para cada ponto de operação dentro da curva de altura versus velocidade, há um risco envolvido, conforme mostrado na figura 2. A operação segura de aeronaves de asas rotativas passa então pela manutenção contínua de condições de voo que não se enquadrem dentro da chamada "curva do homem morto", a parte hachurada (região em 100\% de risco) do gráfico. Essa curva é descrita para cada aeronave e compreende uma região na qual seria muito difícil evitar um acidente em caso de parada do motor. ${ }^{(12,13)}$

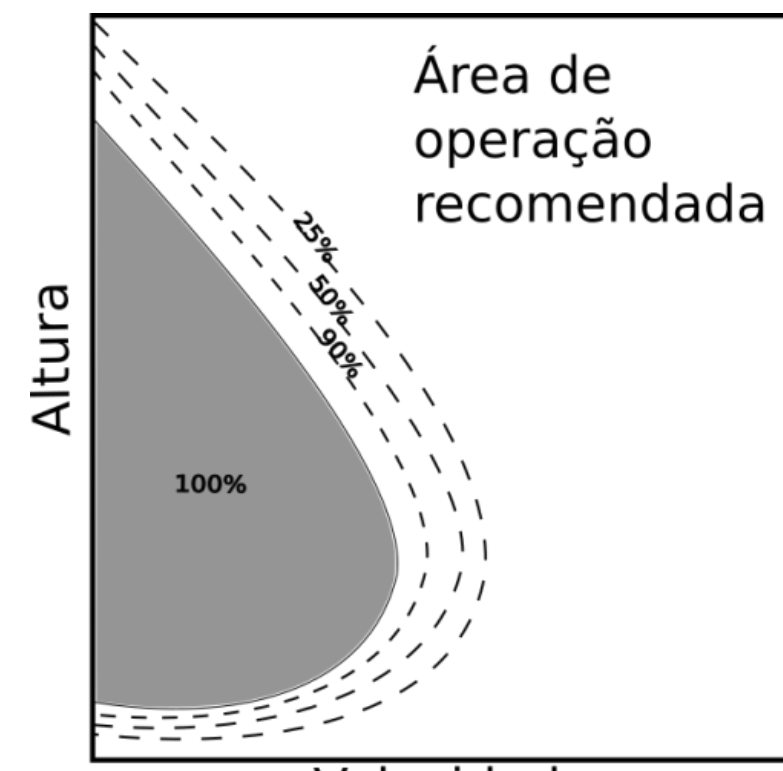

Velocidade

Fonte: Traduzido de Shapley JJ Jr, Kyker RA, Ferrell KR. The development of an improved method of conducting height-velocity testing on rotary wing aircraft. J Am Helicopter Soc. 1969;15(2):30-8. Figure 7, Proposed heightvelocity diagram; p. $37 .^{(12)}$

Figura 2. A curva do homem morto e a variação de risco da manobra de autorrotação em suas redondezas

A carga de trabalho não pode ser diretamente observada, pois ela é uma propriedade abstrata que emerge da interação do operador com o meio e dos recursos de processamento de informação à sua disposição durante a execução de uma tarefa. Ela pode ser inferida através de múltiplos métodos, incluindo medidas subjetivas, psicofisiológicas e do próprio desempenho do operador..$^{(14-16)}$

Nas próximas seções, serão abordados em maiores detalhes os estudos com as medidas subjetivas e fisiológicas que foram utilizadas neste trabalho para a aquisição multimodal de nosso conjunto de dados. 


\subsection{Medições de carga de trabalho subjetivas}

As medições subjetivas são frequentemente utilizadas para medição da carga de trabalho por incluírem vantagens de ordem prática, como a facilidade de executá-la e o fato de não serem intrusivas. Além disso, elas são largamente utilizadas na literatura. ${ }^{(17)}$

No entanto, há alguns problemas em sua utilização, tais como a possibilidade de vieses (principalmente em ambientes de alto risco), o risco de que muitas facetas importantes da carga de trabalho não sejam endereçadas pelo questionamento e a não possibilidade de aplicação de uma avaliação contínua da carga de trabalho. ${ }^{(5)}$ Assim, medidas subjetivas medem a experiência geral dos procedimentos, e não é possível observar mudanças que ocorrem durante as diferentes etapas de uma tarefa. ${ }^{(18)}$ Além disso, essas medições são ainda dependentes de valores culturais. ${ }^{(19)}$

Dentre as medidas mais utilizadas para medição de carga de trabalho em aeronaves estão a escala de Cooper-Harper ${ }^{(7)}$ e a escala de Bedford, ${ }^{(8,9)}$ que foram as escolhidas para serem utilizadas neste trabalho.

\subsection{Medidas fisiológicas}

Ao contrário das medidas de desempenho e relatos subjetivos, as medidas fisiológicas permitem uma medição contínua durante a tarefa e não demandam uma resposta comportamental declarada. ${ }^{(20,21)}$

Um dos maiores problemas com os correlatos fisiológicos da carga de trabalho é que eles podem ser gerados por muitos sistemas do corpo (como o simpático e o parassimpático), que podem estar interconectados entre si. ${ }^{(22)}$ Portanto, não deveria ser esperado que uma única medida pudesse dar uma noção completa da natureza multifacetada de tarefas complexas como a pilotagem. ${ }^{(23)}$ 


\subsubsection{Atividade eletrodérmica}

A atividade eletrodérmica da pele é um dos marcadores psicofisiológicos mais utilizados, devido à facilidade de se obter uma resposta nítida, cuja intensidade parece se relacionar com a intensidade e/ou o significado psicológico do estímulo apresentado. ${ }^{(24)}$ As bases da medição da atividade eletrodérmica são as mudanças na atividade elétrica nas glândulas sudoríparas écrinas, que são controladas pelo sistema nervoso autonômico simpático e que não possuem inervações parassimpáticas. ${ }^{(25)} \mathrm{A}$ atividade das glândulas sudoríparas é controlada por um conjunto de diferentes áreas do sistema nervoso central. A atividade simpática pode ser eliciada a partir de áreas do córtex, núcleos da base, estruturas do diencéfalo como tálamo e hipotálamo, sistema límbico, e de áreas do tronco encefálico. ${ }^{(24)}$

Há dois tipos principais de suor: i) o termorregulatório, que ocorre em todo o corpo em resposta a mudanças no ambiente; e ii) o emocional, presente principalmente nas palmas das mãos e nas solas dos pés. ${ }^{(26)}$ Há ainda uma fonte complementar de atividade eletrodérmica eliciada por áreas dos núcleos da base e por áreas corticais pré-motoras, cuja atividade ocorre de maneira concomitante ao preparo para ações motoras. ${ }^{(24)}$

O suor termorregulatório tem suas origens no sistema nervoso central, mais especificamente no hipotálamo posterior, com muitas fibras sendo retransmitidas na parte tegmentar da ponte e no núcleo medular (reticular), descendo até os neurônios pré-ganglionares simpáticos. ${ }^{(25)}$ Já o suor emocional resulta de um aumento da atividade das glândulas sudoríparas, concomitante a um estado psicológico/emocional que aparece em momentos de grande excitação (arousal) ou sob estresse, por exemplo. ${ }^{(24)}$ Estudos anatômicos sugerem que um maior controle da excitação simpática e da atividade eletrodérmica é fomentado por uma matriz neural envolvendo os córtices pré-frontal e parietal, e estruturas límbicas, que incluem o cíngulo e o lobo temporal medial com um grau de lateralização para o hemisfério direito. $^{(25)}$

É importante ressaltar que os circuitos que regulam o suor emocional e o termorregulatório não são completamente independentes: há uma interação através de regiões hipotalâmicas. ${ }^{(24)}$ Os poucos estudos sistemáticos sobre a relação entre atividade eletrodérmica e temperatura da pele indicam que os parâmetros 
da atividade eletrodérmica podem ser consideravelmente influenciados por acréscimos ou decréscimos de temperatura. ${ }^{(24)}$ O suor emocional, por exemplo, não ocorre a baixas temperaturas. ${ }^{(26)}$

As medições da atividade eletrodérmica são divididas em dois grupos, a depender se elas são ou não realizadas com a aplicação de uma corrente externa. As que não utilizam uma corrente externa mensuram a atividade endossomática, enquanto as com fonte externa de corrente associam-se à atividade exossomática. A imensa maioria dos trabalhos utiliza sensores com fontes de correntes para medir a atividade eletrodérmica. ${ }^{(24)}$

A atividade exossomática pode ser medida através de uma corrente contínua ou alternada. Quando a medida é efetuada à voltagem constante, obtém-se a condutância da pele, e quando à corrente contínua, a resistência da pele. Analogamente, quando se aplica uma corrente alternada à voltagem constante, a resultante é a admitância da pele, e ao mantermos a corrente efetiva constante, obtémse a impedância da pele. (24) $^{24}$

A série temporal obtida pela gravação da atividade eletrodérmica pode ser descrita por duas componentes, a primeira um processo tônico de variação lenta, e a segunda uma resposta à atividade fásica rápida, cuja amplitude consiste num marcador da atividade do sistema autonômico simpático. ${ }^{(27)}$ Um dos parâmetros mais utilizados para quantificação da resposta da atividade eletrodérmica exossomática é a amplitude do sinal bruto. ${ }^{(28)}$ Já a janela de latência para o início da resposta fásica é tradicionalmente considerada entre um e cinco segundos após o estímulo. ${ }^{(24)}$

A atividade eletrodérmica é, em geral, um marcador confiável, com grande sensibilidade e especificidade, portanto, muitos trabalhos a utilizam para avaliar o estado psicofisiológico ou para entender diferenças entre participantes saudáveis e pacientes, em particular na caracterização de estados depressivos e de tendências e comportamentos suicidas. ${ }^{(29-32)}$

Neste projeto, o maior interesse é a caracterização da atividade eletrodérmica no processamento de estímulos externos (Figura 3). Em particular, queremos caracterizar como ela se comporta durante a manobra de autorrotação nas imediações da curva do homem morto. Isso é interessante, pois as respostas eletrodérmicas são facilmente eliciadas por estímulos ameaçadores, tais como som alto ou faces raivosas, sendo sensíveis a um amplo espectro de variações nas componentes do estímulo, tais como significado motivacional, grau de abstração 
cognitiva, novidade e familiaridade, potencial ameaça ou recompensa, ganhos e perdas, amor e ódio, antecipação e resultado, recuperação de memórias e trabalho cognitivo. Salientamos também que a atividade eletrodérmica incorpora aspectos subjetivos, tais como a saliência subjetiva, que se relaciona com importância motivacional. ${ }^{(25)}$

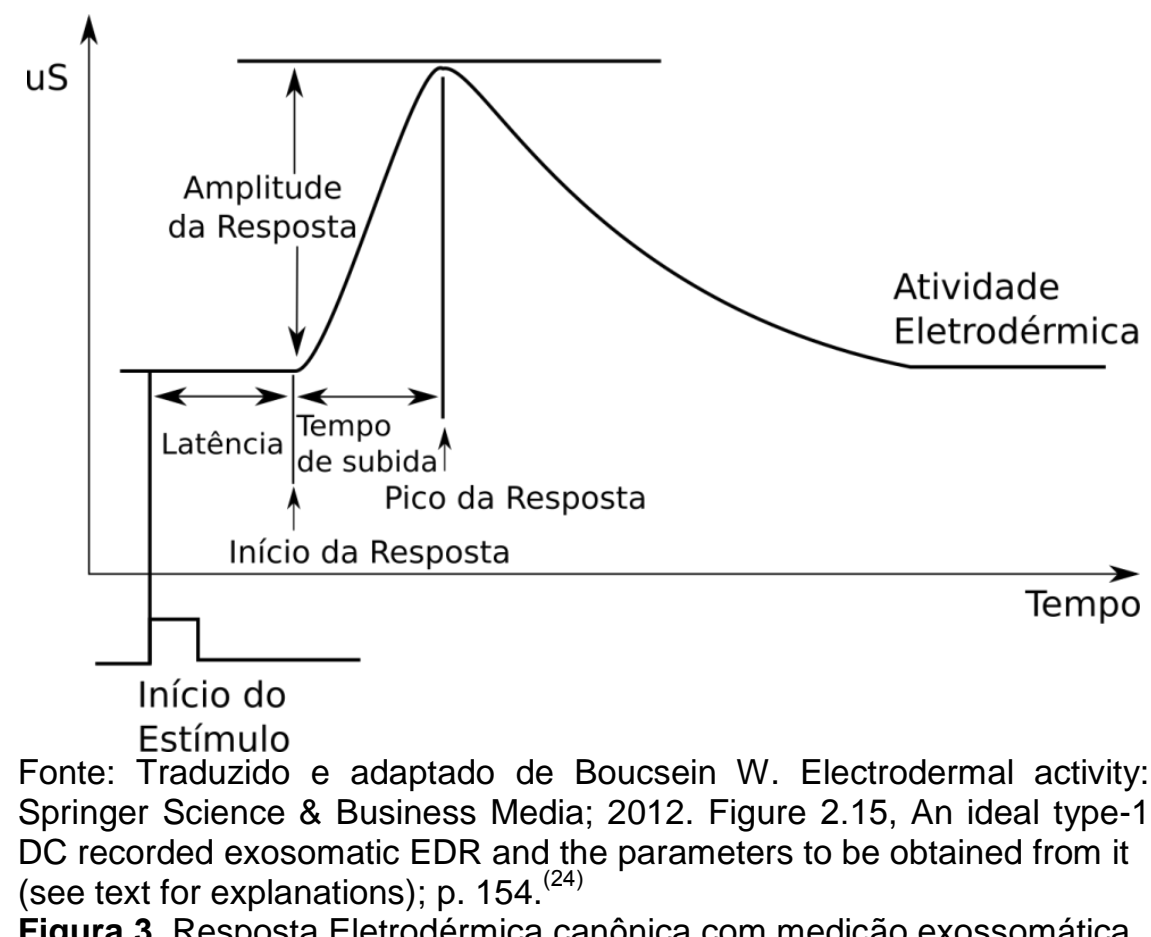

Figura 3. Resposta Eletrodérmica canônica com medição exossomática

Alguns sinais fisiológicos são utilizados para distinguir entre tipos de resposta autonômica a um estímulo saliente: resposta de orientação (orienting response), resposta defensiva (defensive response) e resposta de sobressalto (startle response). ${ }^{(33)} \mathrm{A}$ resposta de orientação pode ser entendida como sendo envolvida com o direcionamento da atenção para um estímulo novo ou significativo, enquanto o sobressalto representaria um desengajamento da atividade em andamento (uma interrupção) devido à ocorrência de um estímulo abrupto ou altamente inesperado, que é então seguido por um engajamento (luta) ou então evitar e fugir (fuga), dependendo da natureza do estímulo eliciante. ${ }^{(34)}$

A resposta de orientação ocorre após uma mudança ambiental e direciona a atenção em direção ao estímulo, provocando uma desaceleração da frequência cardíaca, além de evocar o padrão característico da atividade eletrodérmica (Figura 3). Aqui, a amplitude da atividade eletrodérmica relacionada ao evento diminui 
com a repetição do estímulo, em um processo conhecido como habituação. ${ }^{(35-37)}$ Por outro lado, a amplitude da atividade eletrodérmica na resposta de orientação pode ser amplificada se o estímulo estiver relacionado a uma ação cognitiva ou motora. ${ }^{(24,38)}$ Apesar disso, ressaltamos que uma resposta eletrodérmica não ocorre exclusivamente na presença de estímulos ambientais; ela pode também ser evocada através de modulação interna, intrínseca aos processos cognitivos do indivíduo, tais como pensamentos e expectativas. ${ }^{(39)}$ A resposta defensiva, por sua vez, coloca o organismo no modo de luta ou fuga, e é caracterizado por aumento da frequência cardíaca. Nesse caso, a habituação da atividade eletrodérmica não é considerável. ${ }^{\left({ }^{33}\right)}$ Finalmente, a resposta de sobressalto é eliciada por um estímulo breve e intenso, resultando em uma aceleração na frequência cardíaca. Aqui, a habituação ocorre após um pequeno número de repetições, e é possível observar uma latência menor entre a ocorrência do estímulo e o aumento na atividade eletrodérmica, mas esse intervalo de tempo nunca é inferior a 0,5 segundo. ${ }^{(24)}$

A atividade eletrodérmica também é utilizada para avaliar a tomada de decisão, o que é particularmente interessante no contexto de nosso trabalho. A difusão da medida advém em grande parte devido à hipótese do marcador somático, proposta por Damásio para explicar déficits típicos na tomada de decisão em pacientes com lesões no córtex pré-frontal ventromedial. ${ }^{(40)}$ Antes da tomada de decisão em situação de risco, isto é, associada a uma possibilidade de punição, participantes saudáveis mostram uma atividade eletrodérmica antecipatória elevada, ausente em pacientes com lesão no córtex pré-frontal ventrolateral. ${ }^{(41)}$ No entanto, os pacientes continuam apresentando uma resposta eletrodérmica ao resultado de suas ações, de ganho ou perda em uma tarefa de apostas. ${ }^{(42)}$

Assim, o uso da atividade eletrodérmica se torna interessante devido a seu potencial de incorporar critérios subjetivos em uma medida objetiva. No contexto da avaliação de carga de trabalho, observou-se em motoristas de ônibus, assistidos ou não por um sistema de estacionamento automático, que a atividade eletrodérmica possuía menor duração quando o sistema estava desligado do que quando eles estacionavam com auxílio. Entretanto, a duração da resposta eletrodérmica foi sendo reduzida conforme os motoristas se familiarizavam com o sistema automático, indicando que a atividade eletrodérmica parece estar ligada ao esforço mental e não à demanda física. ${ }^{(43)}$ 
Em um simulador, foi avaliado se a duração da atividade eletrodérmica é sensível a diferentes cargas de trabalho. Assim, tarefas secundárias de diferentes níveis de dificuldade foram adicionadas aos operadores. Foi observado que a diferença entre a atividade basal e a multitarefa atinge um valor máximo, o que sugere que essa medida pode apresentar problemas em cargas de trabalho elevadas, atingindo um efeito teto. ${ }^{(44)}$

Com relação à utilização do sensor para mensurar a carga de trabalho em ambientes realísticos e, portanto, mais similares aos descritos neste trabalho, alterações significativas na resposta eletrodérmica foram observadas durante segmentos de decolagem, arremetida e pouso final, em que houve um maior número de respostas, maiores valores tônicos e menores tempos de recuperação. Já a amplitude e os tempos de subida praticamente não apresentaram diferenças. ${ }^{(23)}$

Esses achados em conjunto mostram que a atividade eletrodérmica é um potencial marcador fisiológico para estimativa da carga de trabalho do operador durante a realização de uma tarefa, mesmo em ambientes reais. No entanto, alguns estudos alertam que as diferenças entre cargas de trabalho têm que ser grandes para ser possível observar variações na atividade eletrodérmica. Mas há o risco de um efeito teto nessas medidas em cenários de carga de trabalho extrema. Neste projeto, avaliaremos a viabilidade desse sensor, tentaremos verificar a presença ou não do efeito teto e se há alguma variabilidade nas grandezas da atividade eletrodérmica com relação à dificuldade da manobra.

\subsubsection{Atividade cardíaca}

O controle da frequência cardíaca é um processo complexo, que envolve interações neurológicas, bioquímicas e hidromecânicas. O coração é inervado pelas divisões simpática e parassimpática do sistema nervoso autonômico, que exercem um controle dinâmico na modificação da frequência de batimentos. O sistema parassimpático atua no coração através de ramos do nervo vago, atuando por meio da secreção de acetilcolina e causando uma diminuição na frequência cardíaca. Já a inervação simpática secreta majoritariamente noradrenalina, que, por sua vez, estimula a secreção de adrenalina nas glândulas suprarrenais ou adrenais, aumentando a frequência cardíaca. ${ }^{(45)} \mathrm{O}$ relaxamento do controle simpático (vagal) é provavelmente 
mais importante para causar um aumento moderado na frequência cardíaca do que um aumento do tônus simpático. O hipotálamo contribui para o controle cardiovascular ao integrar os componentes somático e autonômico de vários padrões comportamentais. Estimulações nas regiões posteriores e póstero-lateral do hipotálamo, de certas estruturas mediais do tálamo e da formação reticular causam uma taquicardia sinusoidal. O córtex cerebral parece modular os efeitos no hipotálamo, via sistema límbico, provavelmente relacionado com a excitação (arousal). ${ }^{(46)}$

Existem muitas medidas de atividade cardíaca, e a seleção da mais adequada varia com base nas necessidades do pesquisador. Para mais detalhes, observe a figura 4 a seguir.

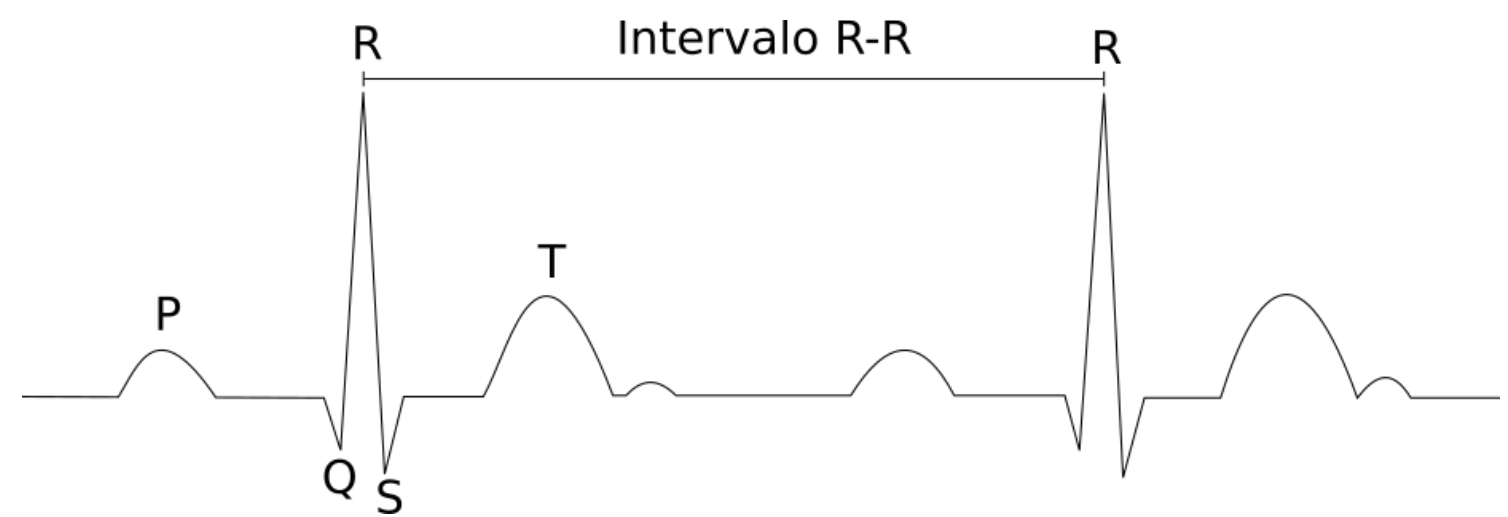

Fonte: Traduzido de Charles RL, Nixon J. Measuring mental workload using physiological measures: a systematic review. Appl Ergon. 2019;74:221-32. Figure 1, The cardiac cycle; $p$. $222 .(47)$

Figura 4. Representação do ciclo cardíaco no eletrocardiograma

O período cardíaco, também conhecido como intervalo entre batimentos (interbeat interval), corresponde ao tempo médio em milissegundos entre batimentos cardíacos, e é em geral relativo ao intervalo entre picos $\mathrm{R}$ consecutivos. Consequentemente, uma medida derivada, a frequência cardíaca, é obtida através da divisão do período cardíaco por 60000 (milissegundo para minuto).

A variabilidade da frequência cardíaca é a medida da variação nos padrões dos intervalos entre batimentos, e pode ser calculada de diversas maneiras, incluindo métricas no domínio do tempo e da frequência. ${ }^{(48)}$ As de domínio da frequência envolvem a análise do sinal eletrocardiográfico por densidade espectral, em geral através da transformada de Fourier. As componentes mais comumente utilizadas são as baixas $(0,02-0,06 \mathrm{~Hz})$, médias $(0,07-0,14 \mathrm{~Hz})$ e altas frequências $(0,15-$ 
$0,5 \mathrm{~Hz}$ ). A razão entre baixas e altas frequências também pode ser utilizada como um marcador do nível de atividade simpática em relação à atividade parassimpática. ${ }^{(47)}$

As medidas de eletrocardiograma são as mais utilizadas dentre o universo de sensores fisiológicos para avaliação de carga de trabalho cognitivo. ${ }^{(47)} \mathrm{A}$ variabilidade da frequência cardíaca, a frequência cardíaca, a período cardíaco e a pressão sanguínea são sensíveis a variações na carga de trabalho. ${ }^{(48)}$

A resposta inicial típica da atividade cardíaca ao aumento da carga de trabalho é associada à ativação do sistema simpático, aumentando a frequência cardíaca, a pressão e diminuindo as medidas de variabilidade de frequência cardíaca e de pressão sanguínea. Esse padrão é semelhante à chamada resposta para fuga ou luta. ${ }^{(49)}$

Os estudos relacionando frequência cardíaca com carga de trabalho em aviação (voo reais de aeronaves de asas fixas) reportam que a frequência cardíaca apresenta o máximo durante fases de voo mais demandantes, tais como decolagens e pousos. ${ }^{(23,50,51)}$ Isso também ocorre em simuladores de voo, onde se observou um aumento da frequência durante uma manobra de interceptação em relação ao dado basal em repouso. A variação incremental (nominal) da frequência cardíaca entre os pilotos mais experientes e menos experientes não foi estatisticamente relevante. Além disso, não houve correlação entre o desempenho e a variação cardíaca, mas sim entre o desempenho e a experiência em voo. ${ }^{(52)}$ Em um simulador de um avião comercial, também se observou sensibilidade suficiente para separar algumas fases do voo entre si, com picos na decolagem e pouso, e uma correlação positiva entre a variação incremental dos batimentos cardíacos com os resultados subjetivos do questionário de carga de trabalho, o NASA-TLX, que não foi utilizado neste trabalho. ${ }^{(53)}$ No entanto, as variações na frequência cardíaca em voos simulados não são um consenso na literatura, ${ }^{(54,55)}$ com indicações de que a diferença no contraste voo versus repouso em voos reais é maior do que em simuladores. ${ }^{(56)}$

Uma medida de variabilidade cardíaca baseada em curtos períodos de tempo (aproximadamente 30s) pode ajudar a estimativa da carga de trabalho quando efeitos de longo prazo (como fatiga) entram em ação. ${ }^{(49)} A$ efetividade dessas análises são baseadas em observações de que as reações cardiovasculares a aumentos temporários nas demandas da tarefa são somente marginalmente afetadas pelos efeitos compensatórios de longo prazo do barorreflexo, mas são sensíveis o suficiente a mudanças na carga da tarefa. ${ }^{(57)} \mathrm{A}$ análise de curtos períodos já foi testada 
em simuladores de voo ${ }^{(58)}$ e de direção, ${ }^{(59)}$ mostrando que a análise da variabilidade cardíaca com 30 segundos já fornece informações sensíveis e estáveis, desde que computadas sob um número suficiente de repetições das atividades. A influência compensatória do barorreflexo em uma escala de tempo curta (30-40s, por exemplo) pode estar presente, mas é relativamente pequena, como reportado em um modelo de simulação de barorreflexo. ${ }^{(60)}$ Um estudo em um simulador de direção mostrou que a abordagem de curto período foi capaz de mensurar uma diminuição da variabilidade cardíaca em uma situação de aumento de carga de trabalho, com o surgimento de neblina em caso de baixo trânsito, mas não apontou diferenças a trânsito intenso, indicando que pode haver um efeito teto. ${ }^{(57)}$

Esses resultados sugerem que há uma alteração na frequência cardíaca a depender da fase de voo, mas que, em geral, só é possível analisar a diferença entre as tarefas com grandes contrastes de nível de dificuldade. ${ }^{(61)}$ Neste trabalho, o objetivo é verificar se a diferença de carga de trabalho entre os diferentes pontos de manobra de autorrotação serão grandes o suficiente para gerar uma mudança mensurável na frequência cardíaca. O que pode ajudar na diminuição da subjetividade ao se avaliar o nível de dificuldade que o piloto estava sujeito durante a execução da manobra de pouso após a ocorrência de uma falha de motor.

\subsubsection{Respiração}

A respiração é o processo fisiológico primariamente envolvido com a troca de oxigênio e dióxido de carbono entre os tecidos do corpo e a atmosfera. A quantidade de oxigênio requerida pelo corpo é determinada pelo nível de atividade ou metabolismo nos vários tecidos, e o aumento na demanda é suprido pelo aumento da frequência e/ou da profundidade da respiração. Durante períodos de estresse e esforço mental intenso, o aumento da frequência respiratória pode acarretar no processo conhecido como hiperventilação. ${ }^{(46)}$ Tradicionalmente, a frequência respiratória é medida através de um cinto posicionado ao redor do peito sensível às expansões e contrações da caixa torácica. ${ }^{(62)} \mathrm{Um}$ dos principais desafios envolvidos na medição da respiração é a possibilidade de contaminação devido à movimentação e à fala, que alteram a frequência respiratória. ${ }^{(46,63,64)}$ Particularmente na caracterização de fases de 
voo, ressaltamos que a fala ocorre na maior parte das situações operacionais associadas com grande carga de trabalho. ${ }^{(46)}$

Alguns poucos trabalhos conseguiram empregar a medida da respiração com sucesso na caracterização da carga de trabalho. Em estudos com simulação de controle de tráfego aéreo foi observado que a amplitude das respirações não é um bom marcador de aumento de carga de trabalho, mas sim a frequência respiratória, que aumenta com a complexidade da tarefa ${ }^{(65,66)}$ e que pode possibilitar a diferenciação entre altas e baixas demandas cognitivas. ${ }^{\left({ }^{66)}\right.}$ Já em um estudo com simulação de tarefas de voo, a frequência respiratória também se mostrou maior durante a execução das tarefas em relação à linha de base. ${ }^{(67)} \mathrm{Em}$ voos simulados, houve um aumento da frequência respiratória no voo considerado mais difícil, apesar de a distinção de fases de voo não ser possível com base nessa medida. ${ }^{(62)}$

Esses resultados indicam que há a possibilidade de se obter informações a respeito da carga de trabalho a qual os operadores estão submetidos durante a execução de uma tarefa, mas que há desafios em ambientes reais, em especial devido à presença de fala.

\subsubsection{Medidas oculares}

Há diversas medidas oculares para avaliar a carga de trabalho. Dentre elas podemos citar a frequência, duração e latência das piscadas e o tamanho da pupila. ${ }^{(47)}$ A dilatação da pupila aumenta com o aumento da carga de trabalho. ${ }^{(68)} \mathrm{A}$ frequência de piscadas apresenta dois comportamentos opostos, por um lado a frequência tende a aumentar em tarefas de maior carga de trabalho, mas por outro lado a frequência diminui em tarefas com alta demanda visual. ${ }^{(69)}$

Em um estudo em simulação de emergência em plantas de produção de energia nuclear, se obteve como resultado que durante o período de execução de um plano operacional de emergência a frequência de piscadas na tarefa mais complexa era maior do que na tarefa menos complexa. Mas em relação aos passos do plano, o período anterior ao pico de complexidade tinha mais picadas do que durante o pico. Após o pico de complexidade a frequência de piscadas também aumentava em relação aos instantes que compreendiam o pico. ${ }^{(18)}$ Outro estudo com 
planta de energia nuclear e também mostrou uma menor frequência de piscadas nas fases de maior complexidade da tarefa. ${ }^{(70)}$

Em um simulador de voo de aeronave de asas fixas as menores taxas de piscadas foram obtidas durante momentos de voo mais visualmente demandantes. ${ }^{(23,71)} \mathrm{E}$ em uma simulação de aeronave de asas rotativas as menores taxas de piscadas foram obtidas durante a modalidade de voo visual, em contraste com a auditiva. ${ }^{(72)}$

Esses resultados indicam que a frequência de piscadas pode ser um marcador para a identificação dos momentos de maior demanda visual durante a execução de um procedimento composto por diversos passos, como é o caso da manobra estudada neste trabalho. 


\section{MÉTODOS}

Foram recrutados para esta campanha de voo pilotos de teste e instrutores de voo de helicóptero da Força Aérea Brasileira e pilotos de teste do Exército Brasileiro. Atenderam a este recrutamento seis pilotos de teste da aeronáutica, um piloto de teste do exército e quatro instrutores de voo de helicóptero da aeronáutica. De 23 de novembro a sete de dezembro de 2017 dados multimodais destes 11 pilotos foram coletados por uma série de sensores fisiológicos sincronizados com um sistema de telemetria completa de uma aeronave de asas rotativas, que incluía um sistema de câmeras, GPS, além de todos os dados de voo. Essa campanha de ensaio em voo já ocorreria mesmo sem a aquisição de dados fisiológicos, e o escopo do trabalho e a sua relevância foram analisados e aprovados pelo Comitê de Ética em Pesquisa do Instituto Israelita de Ensino e Pesquisa do Hospital Albert Einstein (CAAE 72744717.7.0000.0071). Os pilotos foram recrutados entre os pilotos de teste da aeronáutica, do exército e ex-instrutores de voo de helicóptero da aeronáutica. Todos os pilotos concordaram voluntariamente em participar da aquisição de dados fisiológicos após ler o termo de consentimento livre e esclarecido, que foi assinado pelos participantes. A paramentação fisiológica envolveu sensores de eletromiografia, eletrocardiografia, condutância da pele, eletroencefalografia, movimentação dos olhos e taxa respiratória, conforme apresentado na figura 5.

Cada piloto realizou entre 12 e 27 manobras distribuídas entre pontos situados fora da curva do homem morto, próximo ao limite da curva e dentro da curva, conforme pode ser observado nos pontos em vermelho da figura 6 . A envoltória dessa curva é definida para cada aeronave e equivale à área de $100 \%$ de risco apresentada na figura 2. Houve ainda até quatro manobras consideradas "surpresa" em cada voo, que haviam sido previamente combinadas tanto com o centro de controle do tráfego aéreo, quanto com os pilotos instrutores e os engenheiros de voo, mas desconhecidas para os pilotos. As manobras foram, em geral, divididas em dois voos, com exceção de um piloto, que precisou executar todas em apenas um voo, devido a falhas e imprevistos com o sistema da aeronave. Além disso, todos executaram um voo prévio, de familiarização com a aeronave, os sistemas fisiológicos e o aeroporto local.

Todos os pilotos participantes do estudo são muito experientes, porém possuem diferentes expertises no que tange à manobra de autorrotação em 
particular, como mostrado na tabela 1. A média de idade dos pilotos é de 40 anos e os dois pilotos de maior idade tomavam medicamentos para pressão à época da campanha (Lasartana e Candesartana). Após o término de cada manobra de autorrotação, o piloto passava o controle da aeronave para o instrutor, e o engenheiro de voo aplicava as escalas de medição de carga de trabalho (a de Cooper-Harper e a de Bedford). Nas manobras surpresa, esses questionários não foram aplicados.

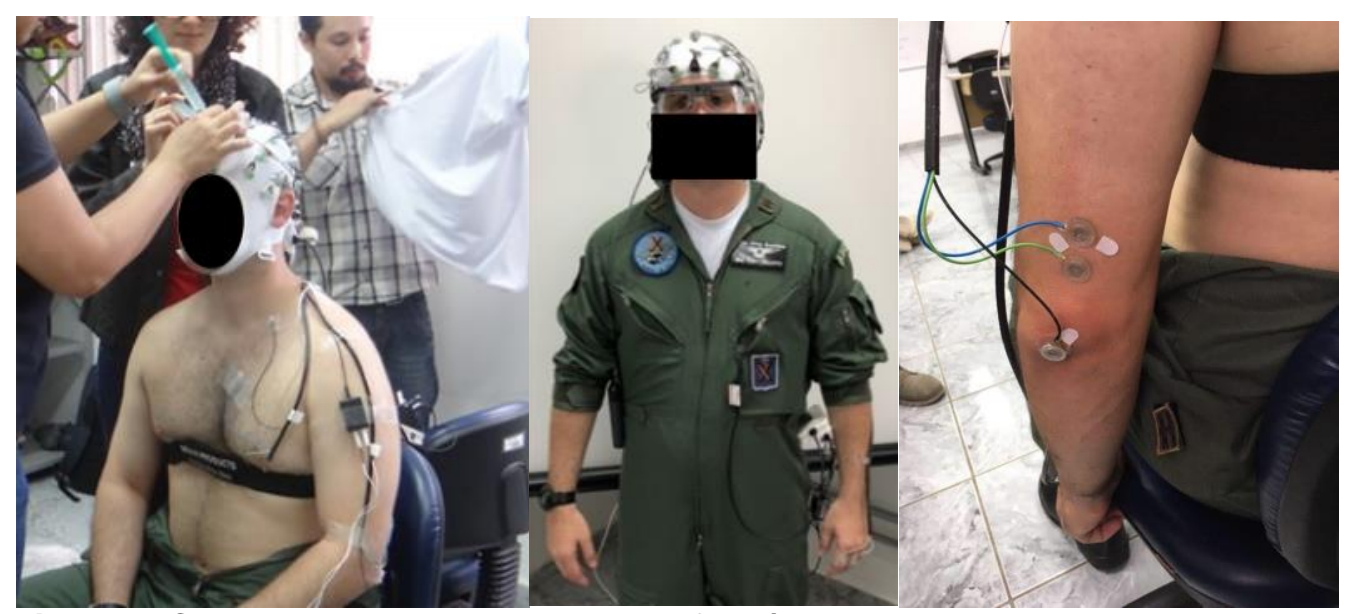

Figura 5. Conjunto multimodal de sensores fisiológicos utilizados neste trabalho

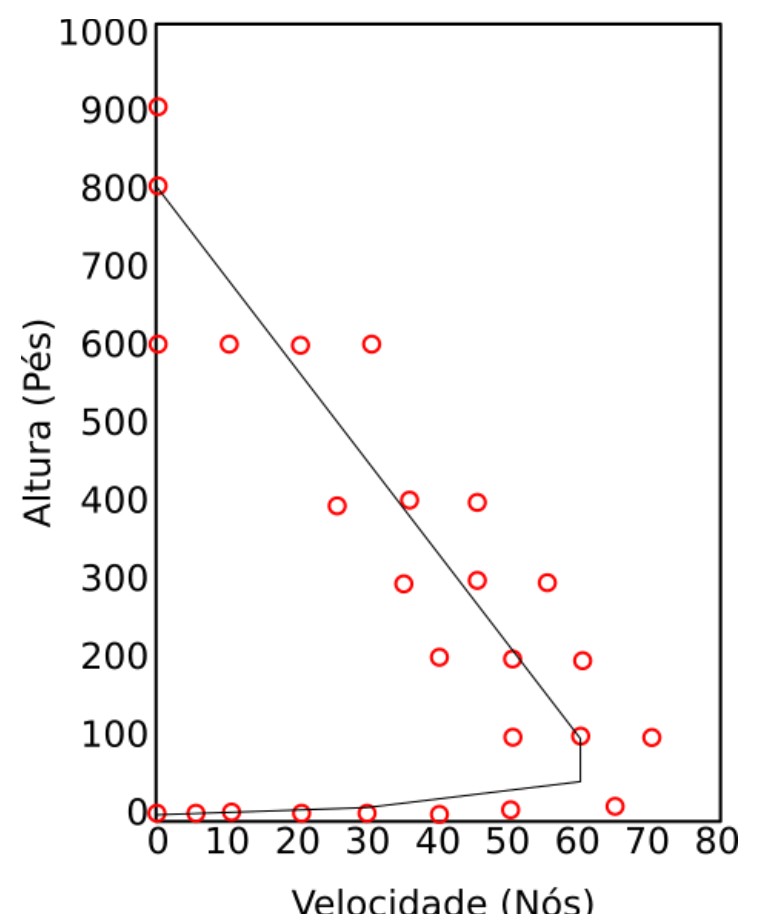

Figura 6. Pontos de execução da manobra de autorrotação em relação à curva do homem morto 
Com relação aos sistemas fisiológicos, todos os dados foram coletados em um sistema integrado (Brain Products, Alemanha) a $500 \mathrm{~Hz}$. Os eletrodos de medição de atividade eletrodérmica (Brain Products, Alemanha) foram colocados no dorso da mão esquerda, na parte medial dos dedos indicador e médio. A área foi gentilmente limpa com álcool $70 \%$ antes da aplicação do gel eletrolítico. A atividade cardíaca foi analisada através de um conjunto de três eletrodos, colocados aproximadamente na região das vértebras dois e seis (para aquisição de sinal) e na clavícula (referência). Uma cinta elástica foi posicionada ao redor do peito de cada participante para medir o movimento torácico durante as respirações (Brain Products, Alemanha).

Tabela 1. Tabela da separação entre os clusters esperados de experiência

\begin{tabular}{|c|c|c|c|c|c|c|c|}
\hline \multirow{2}{*}{ Identificação } & \multicolumn{3}{|c|}{ Horas de voo } & \multirow{2}{*}{$\begin{array}{l}\text { Instrutor } \\
\text { AS-350 }\end{array}$} & \multirow{2}{*}{$\begin{array}{l}\text { Piloto de } \\
\text { teste }\end{array}$} & \multirow{2}{*}{$\begin{array}{l}\text { Experiência em } \\
\text { autorrotação }\end{array}$} & \multirow{2}{*}{ Idade } \\
\hline & Total & Helicóptero & H50 & & & & \\
\hline Piloto 1 & 4006 & 2660 & 1441 & Sim & Sim & Avançado & 41 \\
\hline Piloto 2 & 2592 & 2337 & 1740 & Sim & Sim & Avançado & 37 \\
\hline Piloto 3 & 3308 & 1411 & 178 & Não & Sim & Intermediário & 37 \\
\hline Piloto 4 & 1746 & 1588 & 133 & Não & Sim & Intermediário & 38 \\
\hline Piloto 5 & 3500 & 1988 & 1479 & Sim & Sim & Avançado & 46 \\
\hline Piloto 6 & 3730 & 2580 & 1725 & Sim & Sim & Avançado & 48 \\
\hline Piloto 7 & 1755 & 1755 & 1430 & Não & Sim & Intermediário & 37 \\
\hline Piloto 8 & 2242 & 1037 & 234 & Não & Não & $2^{\mathrm{a}}$ vez & 37 \\
\hline Piloto 9 & 1384 & 1219 & 722 & Não & Não & $1^{a}$ vez & 35 \\
\hline Piloto 10 & 2750 & 2155 & 1120 & Não & Não & $1^{\mathrm{a}} \mathrm{vez}$ & 41 \\
\hline Piloto 11 & 3650 & 2350 & 1130 & Não & Não & $1^{\mathrm{a}}$ vez & 42 \\
\hline
\end{tabular}

\subsection{Processamento dos dados}

As médias tanto das medidas subjetivas quanto das medidas fisiológicas foram realizadas de maneira global e posteriormente agrupadas por tipo de manobra (fora, na linha ou dentro da curva do homem morto ou surpresa).

\subsubsection{Medidas subjetivas}

\subsubsection{Escala de Cooper-Harper}

A escala de Cooper-Harper foi uma das primeiras para a avaliação da carga de trabalho na aviação, e é amplamente utilizada. ${ }^{(73-75)}$ Ela é uma escala 
subjetiva que combina uma abordagem de árvore de decisão com uma escala ordinal que vai de 1-10.

Pode-se verificar que as notas dependem do julgamento do operador em relação ao voo, e é necessário que as terminologias usadas na escala sejam padronizadas. Nessa escala há quatro níveis ou categorias, como pode ser visto na figura 7. A melhor categoria é chamada de desempenho desejado ou claramente adequada, associada a um nível satisfatório de carga de trabalho do piloto, com valores que variam de um a três. A segunda melhor é definida como desempenho adequado, pois o piloto compensou as deficiências com o aumento de sua carga de trabalho, com valores de quatro a seis. Nessa categoria, o desempenho é tolerável, mas o piloto almeja uma melhora. A terceira categoria envolve deficiências importantes, pois o piloto julga impossível atingir um desempenho adequado mesmo que compense com toda carga de trabalho disponível. Nessa categoria, os valores variam entre sete e nove. $O$ quarto nível é denominado incontrolável, no qual a preocupação com o desempenho é total, com valor dez na escala.

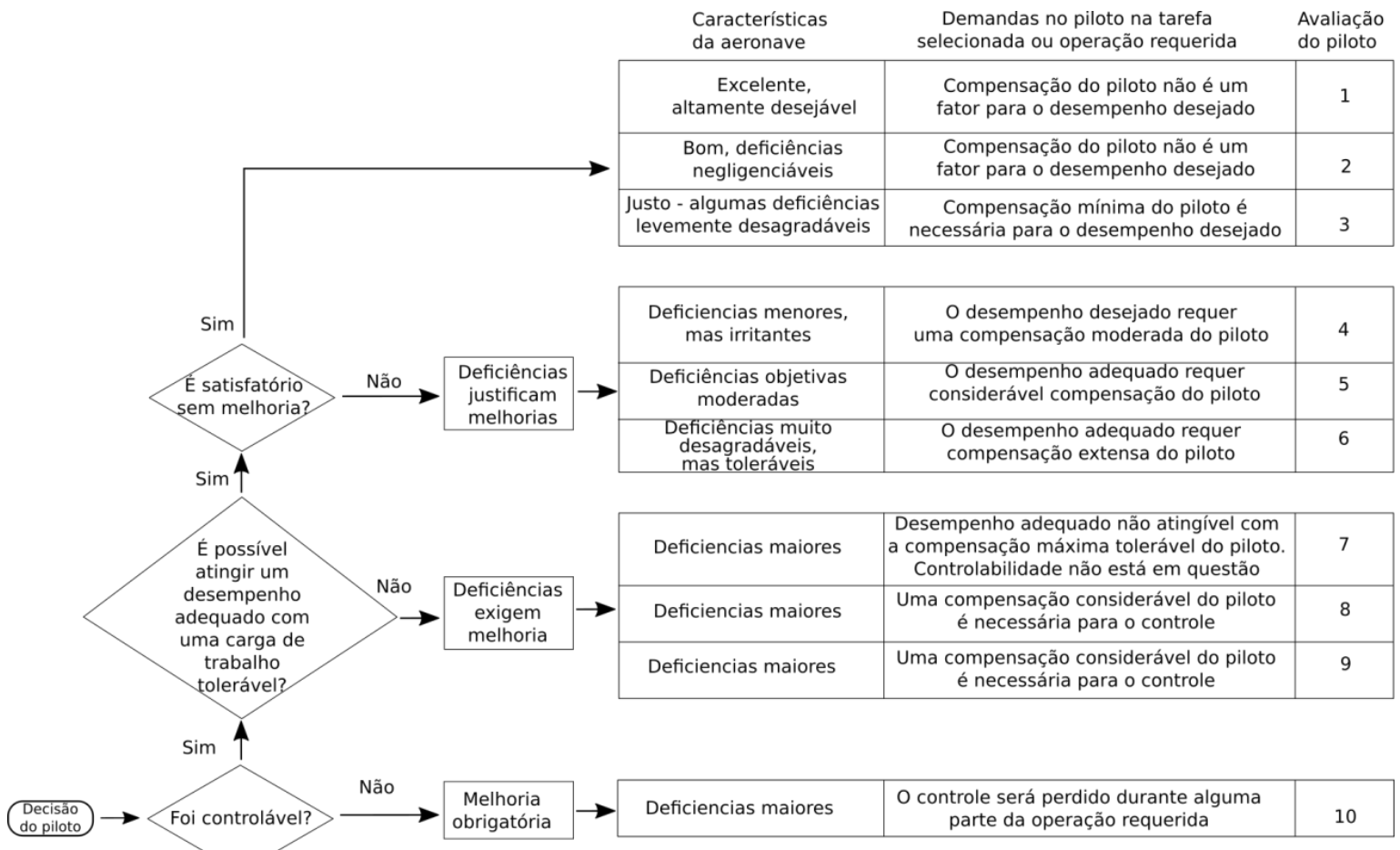

Fonte: Traduzido de Cooper GE, Harper RP Jr. The use of pilot rating in the evaluation of aircraft handling qualities. Paris: Advisory Group for Aerospace Research and Development; 1969. Figure 7, Handling qualities rating scale; p. $12 .^{(7)}$

Figura 7. Escala de Cooper-Harper 
Os autores definem o uso do termo "compensação" como um indicativo de que o piloto precisa aumentar sua carga de trabalho para melhorar 0 desempenho da aeronave. Pode ser entendida também como uma medida de esforço e atenção adicionais para manter um dado nível de desempenho em face a condições menos favoráveis ou deficiências de pilotagem.

Tanto no artigo original da proposta de escala ${ }^{(7)}$ quanto em manuais

subsequentes $^{(76)}$ é possível encontrar as definições de cada um dos termos principais, o que permite uma terminologia homogênea entre os participantes.

\subsubsection{Escala de Bedfort}

Roscoe ${ }^{(8)}$ propôs uma modificação na escala de Cooper-Harper. Ela continuou apresentando um modelo de árvore de decisão e separação em quatro níveis de carga de trabalho, com subdivisões em três desses níveis, mas ainda numa escala de um a dez. A principal mudança em relação à escala de Cooper-Harper foi a introdução da noção de "capacidade-livre" (em tradução livre de spare capacity), que seria a capacidade que o participante teria para poder realizar alguma outra tarefa em adição à tarefa principal, como, por exemplo, responder ao rádio enquanto realiza determinada tarefa. ${ }^{(8,9)}$

As três categorias de separação propostas na escala de Bedford são: i) se foi possível completar a tarefa, em caso negativo a carga de trabalho é considerada dez; ii) se a carga de trabalho foi tolerável para a tarefa, em caso negativo a carga de trabalho ficaria entre sete e nove; e iii) se a carga de trabalho foi satisfatória sem redução, em caso negativo a carga de trabalho ficaria entre quatro e seis, e, em caso positivo, entre um e três. Os autores dessa escala modificada dizem que a escala de Cooper-Harper parece mais adequada para avaliar as qualidades de manobrabilidade (handling qualities), enquanto a modificação proposta conseguiria endereçar os níveis de carga de trabalho. 


\subsubsection{Aplicação dos questionários}

Os questionários foram aplicados pelos engenheiros de voo logo após o término da execução da manobra de pouso, com exceção daquelas que ocorreram de maneira surpresa. Logo após o final da manobra o piloto passava o controle da aeronave para o piloto instrutor e respondia aos questionários em forma de árvore de decisão apresentados anteriormente.

Para garantir que as terminologias seriam utilizadas de maneira uniforme antes do início da campanha de autorrotação foram realizadas reuniões entre os pilotos e os engenheiros de teste envolvidos. E após os voos havia uma reunião para repassar cada uma das manobras e para que o piloto pudesse conversar com o engenheiro de voo sobre suas escolhas.

\subsubsection{Atividade eletrodérmica}

A atividade eletrodérmica foi primeiramente analisada em cada um dos voos, para avaliar a presença do padrão característico (Figura 3) no sinal bruto. A curva de resposta média foi obtida através da normalização de resposta utilizando-se o valor médio da condutância da pele nos 5 segundos anteriores àquela manobra, resultando numa variação percentual da curva de resposta associada. Outra análise foi a partir da amplitude percentual após cada manobra de falha do motor (Figura 8) para comparação. Ressaltamos que o sinal não foi filtrado para manter seu valor inicial original. Os sinais de resposta da condutância da pele foram considerados válidos se começassem entre 0,5 e 5 segundos após a ocorrência da falha do motor e apresentasse uma variação de amplitude mínima de $1 \%$. Todas as análises foram realizadas com o software MatLab®. 


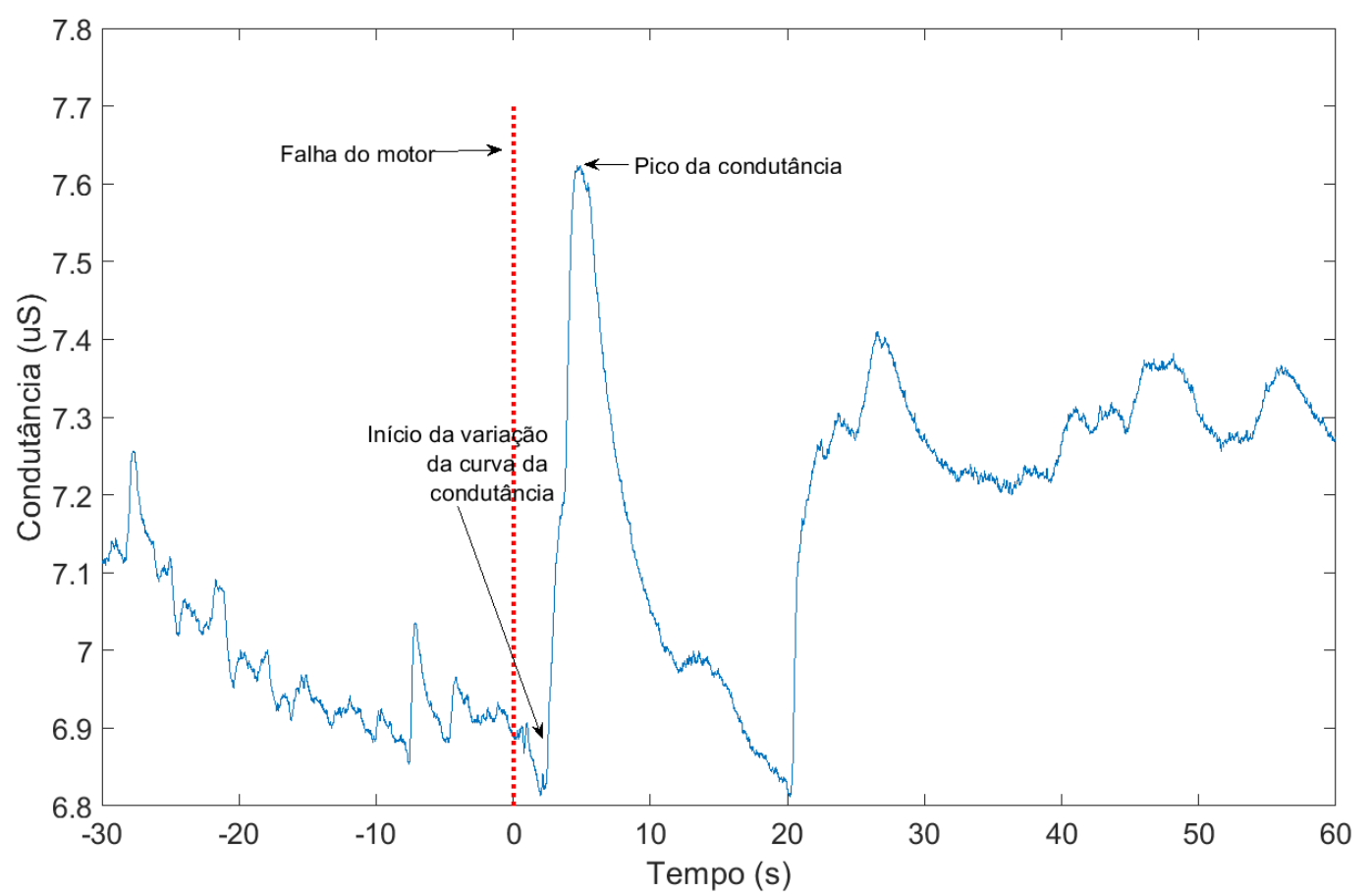

Figura 8. Exemplo de variação de condutância ao redor da manobra

Para avaliar se as diferenças entre as amplitudes das respostas eram estatisticamente significativas, foram utilizados modelos lineares mistos. Foram analisadas como efeitos fixos a localização da manobra em relação à curva do homem morto.

$$
R_{E D A} \sim-1+\text { Curva }+(1 \mid \text { Piloto }) .
$$

Como é possível observar na equação 1 , optou-se por ignorar o valor do intercepto, buscando a relação entre o ponto de manobra e a curva do homem morto (fora, linha ou dentro, ou surpresa) através de um modelo linear misto (efeito fixo) e agrupando as manobras de cada piloto como parte da variação nos dados que não se consegue explicar pelo modelo (efeito aleatório). Como os resíduos retornados pelo modelo na primeira tentativa não eram normalmente distribuídos, aplicou-se 0 logaritmo na variação percentual das respostas da atividade eletrodérmica. 


\subsubsection{Atividade cardíaca}

\subsubsection{Frequência cardíaca}

O sinal de eletrocardiograma foi filtrado para retirada do sinal DC com um filtro de resposta infinita, ${ }^{(77)}$ no domínio da frequência, na faixa de $1-100 \mathrm{~Hz}$ e sem latência de fase. O valor filtrado foi invertido para que os picos RR ficassem no sentido positivo. Em seguida, foi estabelecido um limiar para detecção dos picos (duas vezes o desvio padrão) e a frequência cardíaca calculada a partir do inverso dos intervalos entre batimentos cardíacos. Uma análise de regressão linear de ordem 3 foi utilizada, através da toolbox de variação da atividade cardíaca de Kaplan, para avaliar a presença de picos faltantes ou anomalias no batimento cardíaco. Todas as análises foram realizadas com o software MatLabß. Um exemplo do pré-processamento pode ser visto na figura 9.

a)

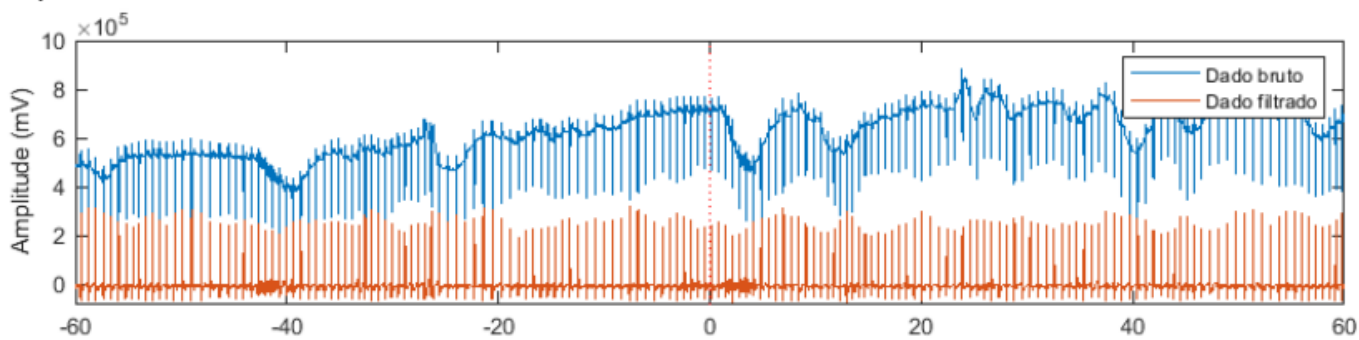

b)

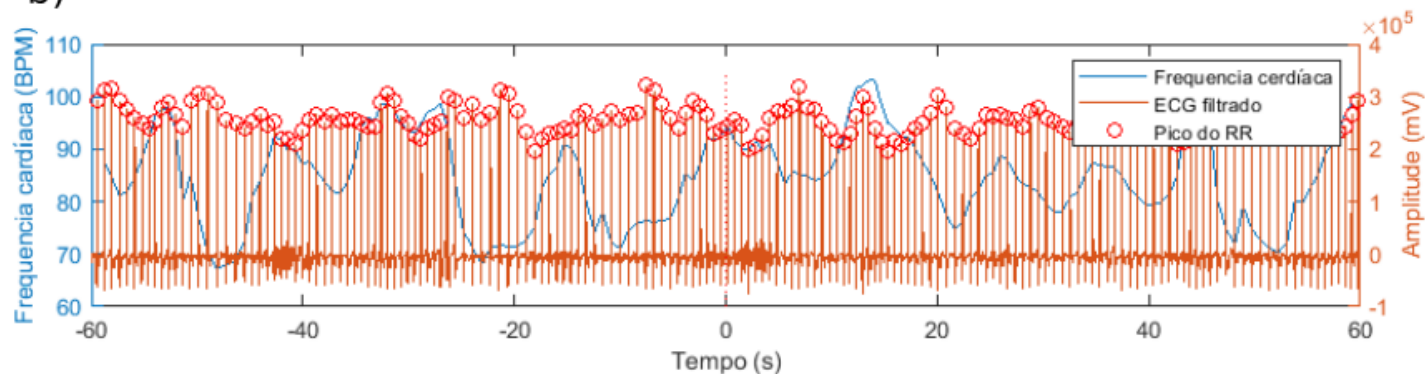

Em a) temos a retirada da componente $\mathrm{DC}$ do sinal. Em b) a detecção dos picos $\mathrm{R}$ e a frequência cardíaca resultante.

Figura 9. Exemplo de extração de dados de batimentos por minuto a partir do sinal de ECG gravado

Em casos em que houve uma não detecção pelo método automático, ela foi manualmente corrigida. Além disso, quando houve algum tipo de batimento anormal, houve uma correção adotando o tempo entre os dois picos RR 
adjacentes à arritmia como sendo a ocorrência do pico $\mathrm{R}$ para cálculo do intervalo entre batimentos, como mostrado nos momentos destacados pelas setas na figura 10.

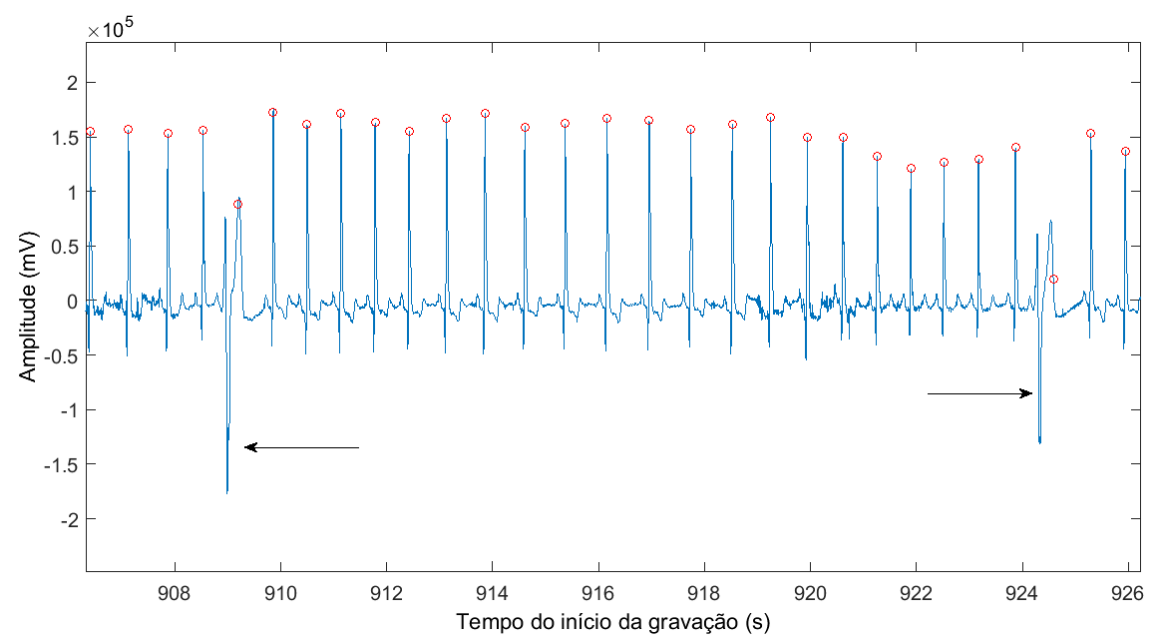

Figura 10. Exemplo de correção manual do intervalo entre batimentos

Como cada piloto apresentava uma atividade basal diferente, para fins de comparação, a frequência cardíaca foi normalizada pela frequência média nos 5 segundos anteriores à falha do motor. Para comparação entre as respostas cardíacas foi utilizada como métrica a integral da frequência cardíaca normalizada no período entre a falha do motor (tempo 0 segundo) e 40 segundos após a falha, pois isso permite avaliar o retorno da atividade cardíaca ao patamar que antecedeu a autorrotação.

Assim como para a amplitude da atividade eletrodérmica, a diferença entre a integral da frequência cardíaca normalizada também foi avaliada através de modelos lineares mistos, como descrito pela equação 2 abaixo. A equação 2 avalia a variação da integral da frequência cardíaca normalizada em relação à posição da manobra em relação à curva do homem morto, deixando as repetições entre os pilotos como variável de explicação para os efeitos aleatórios. Novamente desconsiderou-se o efeito do intercepto. Nesse caso, o modelo retornou uma distribuição de resíduos na qual a hipótese de normalidade não foi rejeitada e, portanto, ele não foi corrigido pelo operador logaritmo.

$$
R_{\text {IntFreqCard }} \sim-1+\text { Curva }+(1 \mid \text { Piloto }) .
$$




\subsubsection{Variabilidade da frequência cardíaca}

A variabilidade da frequência cardíaca foi analisada a partir da série de intervalos $R R$, que passaram pelas correções manuais descritas na seção anterior. A análise de variabilidade cardíaca foi então realizada através do modelo de processamento de pontos (point processing). Esse modelo assume uma distribuição gaussiana inversa para os batimentos cardíacos, adicionando o efeito do histórico recente do sistema autonômico no coração, sendo então denominado de um modelo gaussiano inverso dependente do histórico.

Em linhas gerais este modelo estabelece gaussiano a partir de um modelo autorregressivo de ordem $\mathrm{n}$ e do histórico dos dados. Inicialmente, um fator de ponderação é aplicado ao histórico e ele é ajustado pelo modelo autorregressivo. A seguir, a resultante é utilizada na estimativa de um modelo gaussiano inverso que geraria esse conjunto de dados. Finalmente, este modelo estima o valor do próximo intervalo entre batimentos. A partir dos parâmetros do modelo gaussiano inverso obtém-se os valores da variabilidade cardíaca. Maiores informações sobre o modelo podem ser encontradas nos artigos de Barbieri e colaboradores. ${ }^{(78,79)}$

Assim, testamos intervalos entre batimentos - RR - de cada voo, com um conjunto de históricos, variando de 30 a 180 segundos, num passo de 15 segundos. Cada intervalo foi associado a um dos seguintes valores de ponderação 0,$99 ; 0,98 ; 0,95$ e 0,90. Com relação à ordem, testamos as ordens pares entre 2 e 12 . Isso gerou 264 resultados de modelos para cada voo, que foram então analisados a partir das métricas sugeridas pelos autores para os resíduos: i) o gráfico de teste de erro de Kolmogorov-Smirnov, cuja métrica é a variação máxima em relação à diagonal; para verificar a normalidade da distribuição e ii) o valor máximo da autocorrelação nos primeiros 60s do modelo ajustado.

Com base nesses dados, ordenamos o valor médio de cada uma das métricas nos 19 voos analisados, e o modelo com menor valor nas duas métricas (Kolmogorov-Smirnov e autocorrelação dos resíduos) ordenadas foi escolhido. 


\subsubsection{Atividade respiratória}

O sinal da cinta respiratória foi filtrado através de um filtro de resposta infinita, ${ }^{(77)}$ no domínio da frequência, na faixa de $0,5-35 \mathrm{~Hz}$ e sem latência de fase. Buscamos padrões significativos no sinal filtrado em torno da ocorrência da falha do motor. Em seguida, estimamos o espectrograma com o uso da transformada em ondeletas, utilizando a ondeleta mãe de Morlet. Optamos por essa transformada em função da sua capacidade de representar o sinal por meio de funções localmente definidas e adequadas para uma representação de processos não estacionários. ${ }^{(80)}$

Em seguida, calculamos a frequência característica correspondente a cada instante, na janela de tempo ao redor da manobra de falha do motor a partir do somatório de cada frequência ponderada pela densidade espectral dividido pela energia total instantânea, nas frequências de 0,05 a $0,5 \mathrm{~Hz}$, conforme descrito pela equação 3.

$$
f_{\text {promediada }}(t)=\frac{\sum_{i=0,05}^{0,5} \text { Densidade Especratal }_{i, t} \times \text { freq }_{i}}{\sum_{i=0,05}^{0,5} \text { Densidade Especratal }_{i, t}}
$$

Onde t é o tempo ao redor da manobra, sendo analisado em uma janela de tempo de 50 segundos antes e depois da manobra. Um exemplo de espectrograma calculado e a área utilizada para o cálculo da frequência pró-mediada pode ser visto na figura 11. 


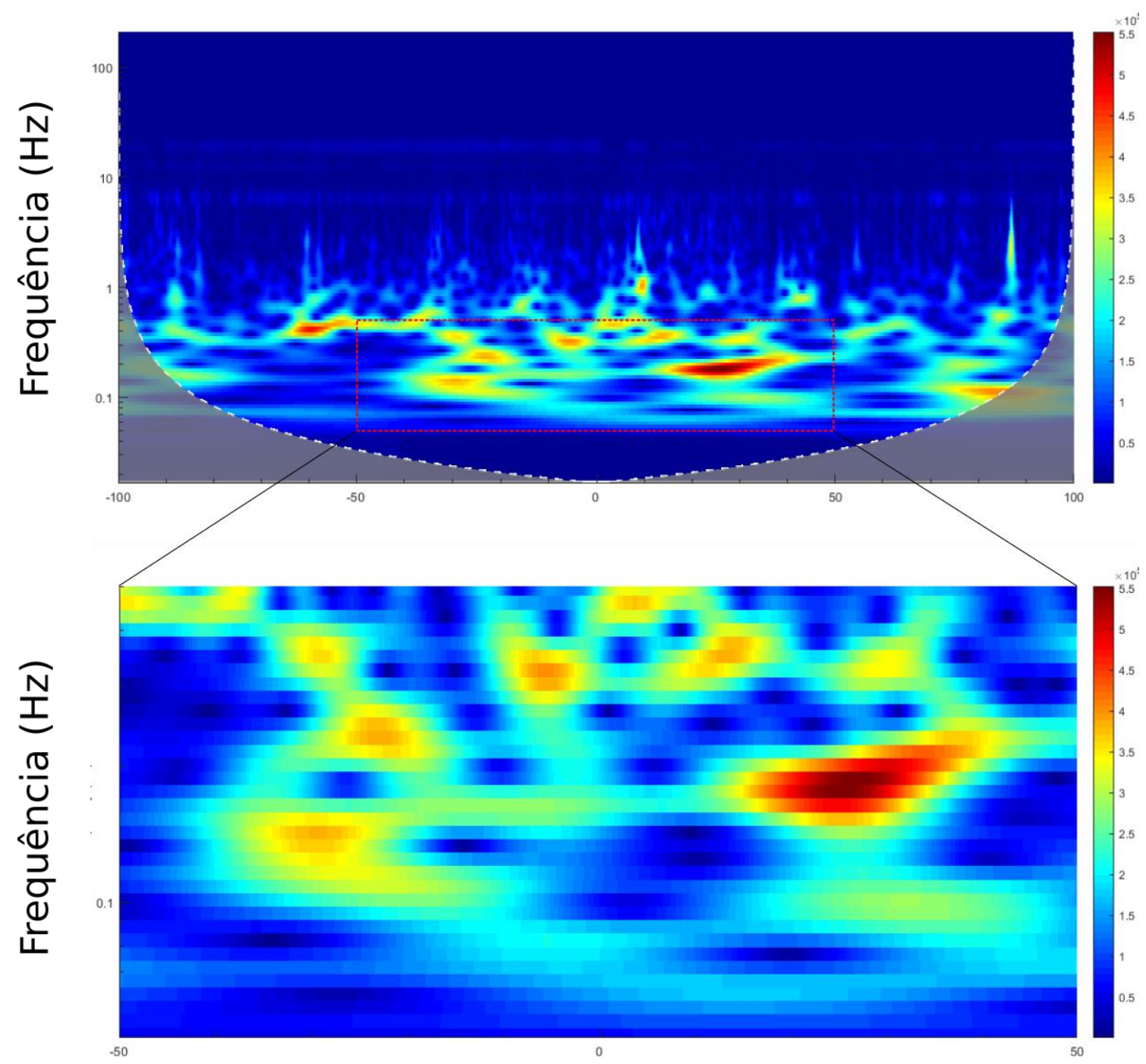

Tempo (s)

As cores em azul são aquelas com menor magnitude e as em vermelho as maiores magnitudes.

Figura 11. Exemplo de espectrograma e área de interesse ao redor da manobra

\subsubsection{Atividade ocular}

Dentre os sensores utilizados para a aquisição de dados fisiológicos dos pilotos, não foram adicionados eletrodos específicos para a medição da atividade ocular. Assim, utilizamos uma análise indireta, através das componentes independentes do eletroencefalograma. Sabe-se que a atividade, principalmente nos eletrodos Fp1 e Fp2, contém interferência da atividade dos músculos ao redor dos olhos, e a análise de componentes independentes é bastante utilizada na demarcação deste sinal. Portanto, neste trabalho utilizamos a atividade dessa componente como uma medida indireta da ocorrência de piscadas. 
Para esta análise, o sinal bruto do EEG foi filtrado (passa-banda de $0,1$ à $50 \mathrm{~Hz})$ e então foi feita a análise de componentes independentes, como demonstrado na figura 12. Neste cenário utilizamos a toolbox do EEGLAB. ${ }^{(77)}$

Para cada manobra realizamos a análise de componentes independentes em 60s de dado, e buscamos por aquela cujo padrão mais se assemelhava ao demonstrado na figura 12, no qual a maior atividade da componente é centrada nos eletrodos Fp1 e Fp2 (Figura 12a), com eventos distribuídos no tempo e duração da ordem de $50 \mathrm{~ms}$ (Figura 12b).

a)

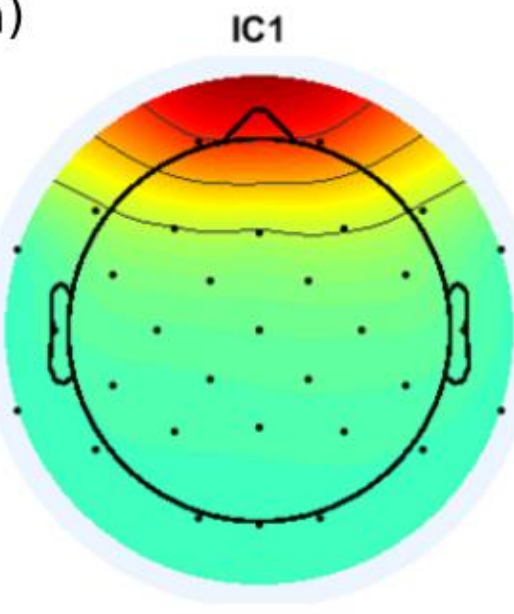

b)

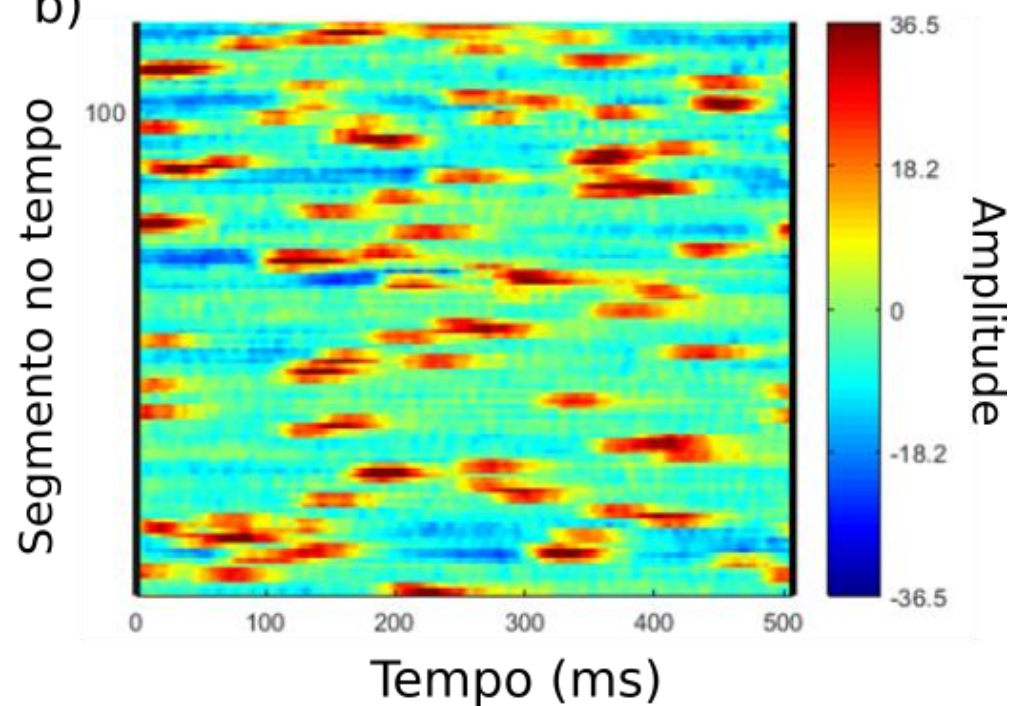

A topografia da componente é representada em a) e a projeção do sinal nesta direção no decorrer do tempo em b).

Figura 12. Exemplo de resultado de análise de componentes independentes

A ocorrência de cada evento de piscada, foi considerado sempre que o valor da projeção do dado na direção da componente excedesse o limiar definido a partir de sua média somado a dois desvios padrão. A ocorrência de piscadas foi então agrupada em janelas de tempo ("bins"), cujo tamanho foi definido a partir da minimização de uma função custo:

$$
C_{i}=\frac{2 k-v}{n \Delta^{2}}
$$

Onde $\mathrm{k}$ é a média e $\mathrm{v}$ a variância das $\mathrm{k}_{\mathrm{i}}$ ocorrências de eventos nas $\mathrm{n}$ manobras analisadas, ${ }^{(81)}$ com o tamanho variando de $100 \mathrm{~ms}$ a 12 segundos. 
Para verificar a ocorrência de uma variação na frequência de piscadas, foi utilizado o teste de Kruskal-Wallis com a distribuição da frequência de piscadas por manobra em cada bin. 
4 RESULTADOS

\subsection{Medidas subjetivas}

A primeira análise realizada foi para avaliar se havia diferenças entre as avaliações subjetivas (Cooper-Harper e escala de Bedford). Observa-se nos histogramas abaixo, considerando as duas métricas, que a variação da carga de trabalho quando analisada por Cooper Harper tem um valor mais provável de cinco, caracterizado por um desempenho adequado, pois o piloto compensou as deficiências com o aumento de sua carga de trabalho. Já na escala de Bedford, observa-se um valor mais provável em sete (caracterizando que a carga de trabalho não foi tolerável para a tarefa), e uma grande concentração em 10, o máximo da escala, o que poderia sugerir uma saturação (Figura 13a). Em seguida, separou-se os histogramas em janelas correspondentes aos quatro níveis de agrupamento das respostas, onde observa-se uma mesma tendência visual nas duas métricas, com maior probabilidade na faixa entre 4-6, com declínio mais acentuado na escala de Cooper-Harper do que na escala de Bedford (Figura 13b), mas ressalta-se que não houve avaliações estatísticas nestas métricas.

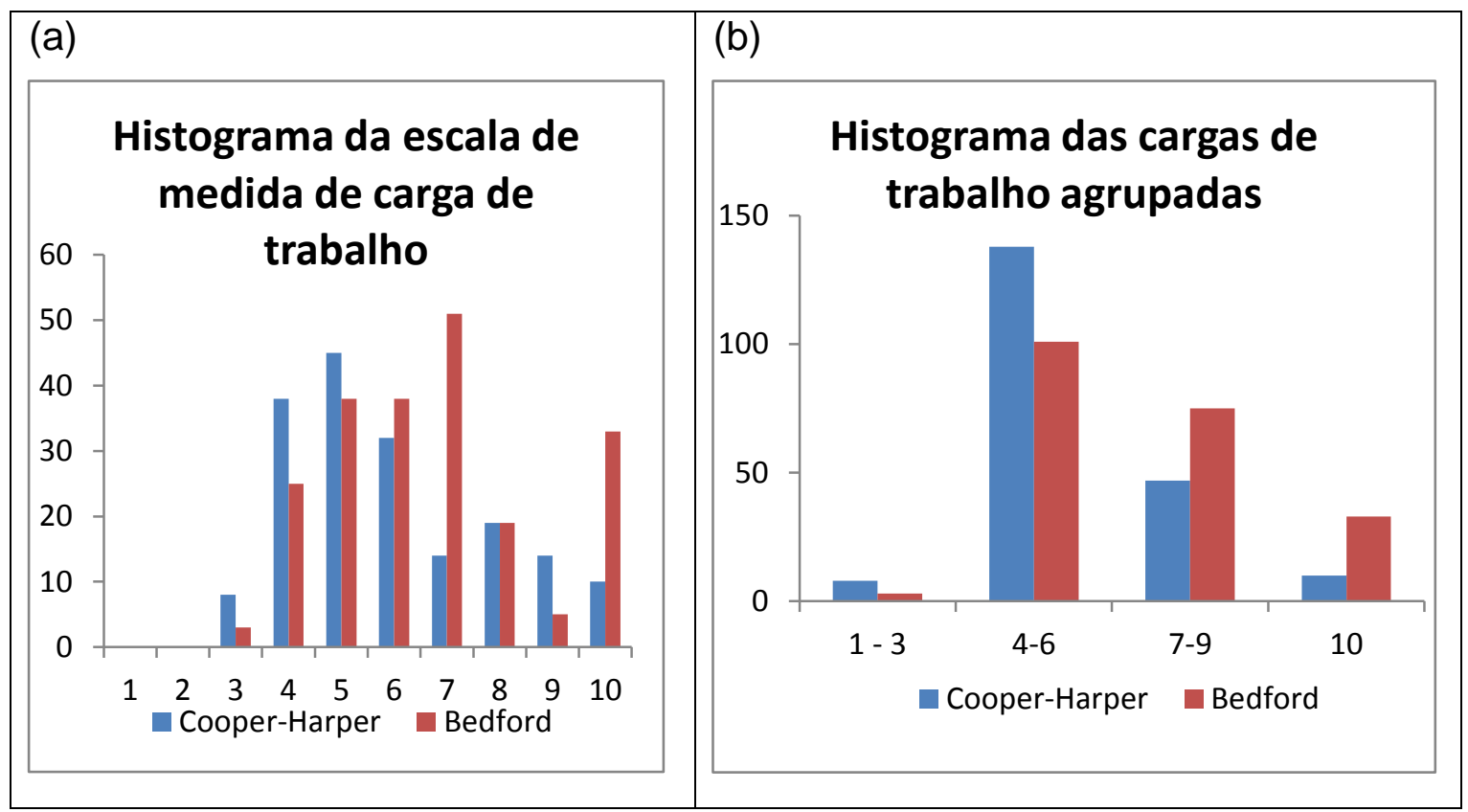

Figura 13. Histograma das cargas de trabalho 
Quando analisamos o valor médio de carga de trabalho reportado por ambas as métricas, verificou-se que em ambas o perfil esperado foi obtido, ou seja, a menor média nas manobras fora da curva do homem morto e aumentando conforme se caminhou para dentro da curva, conforme apresentado na figura 14, sendo que estes dados não foram submetidos a análises estatísticas para averiguar se estes valores diferiam estatisticamente entre si.

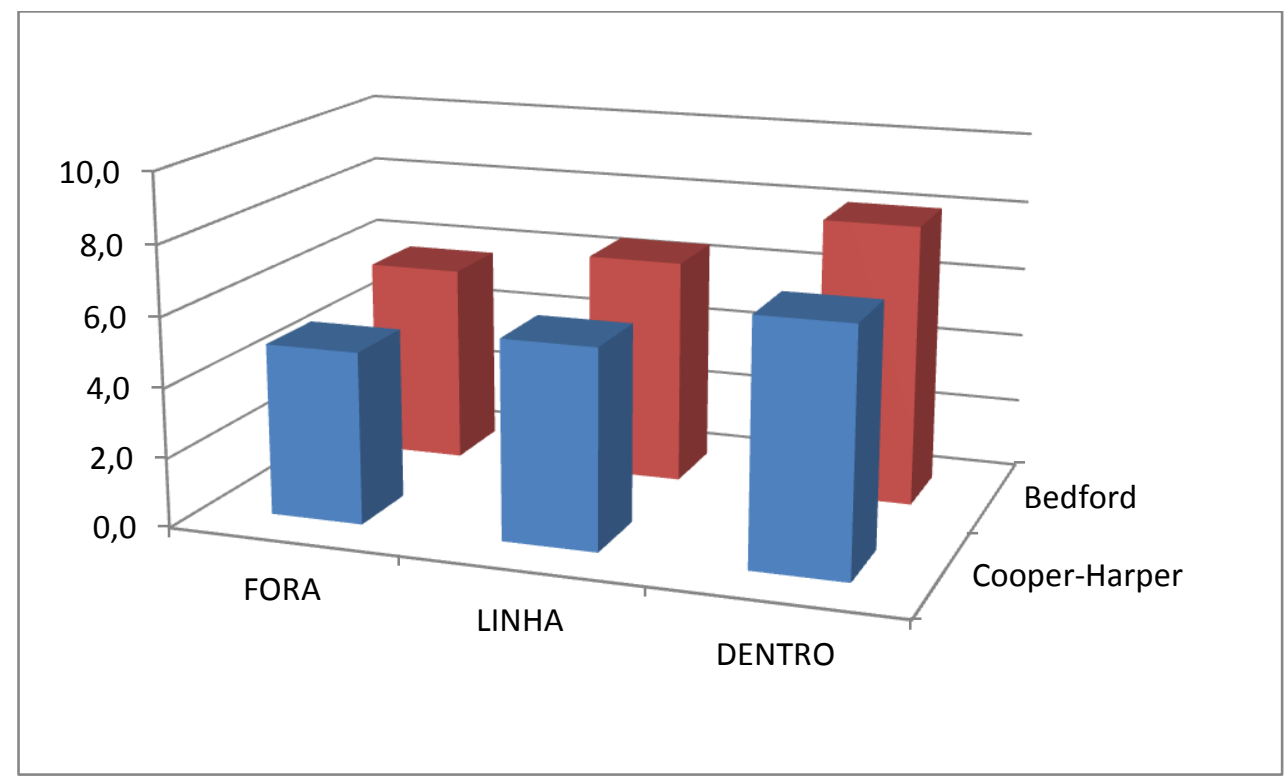

Figura 14. Médias dos relatos subjetivos das cargas de trabalho por local de manobra

\subsection{Atividade eletrodérmica}

O primeiro passo para avaliar a viabilidade da gravação da atividade eletrodérmica foi a análise do sinal bruto dos voos, apresentados na figura 15 . As linhas tracejadas (em vermelho) mostram os momentos em que houve uma falha do motor. É possível observar uma variação positiva na atividade eletrodérmica, bem evidente logo após cada uma das manobras. No gráfico apresentado na figura 15a, podemos verificar um drift no decorrer do tempo, o que não é observado no dado da figura $15 b$. 
a)

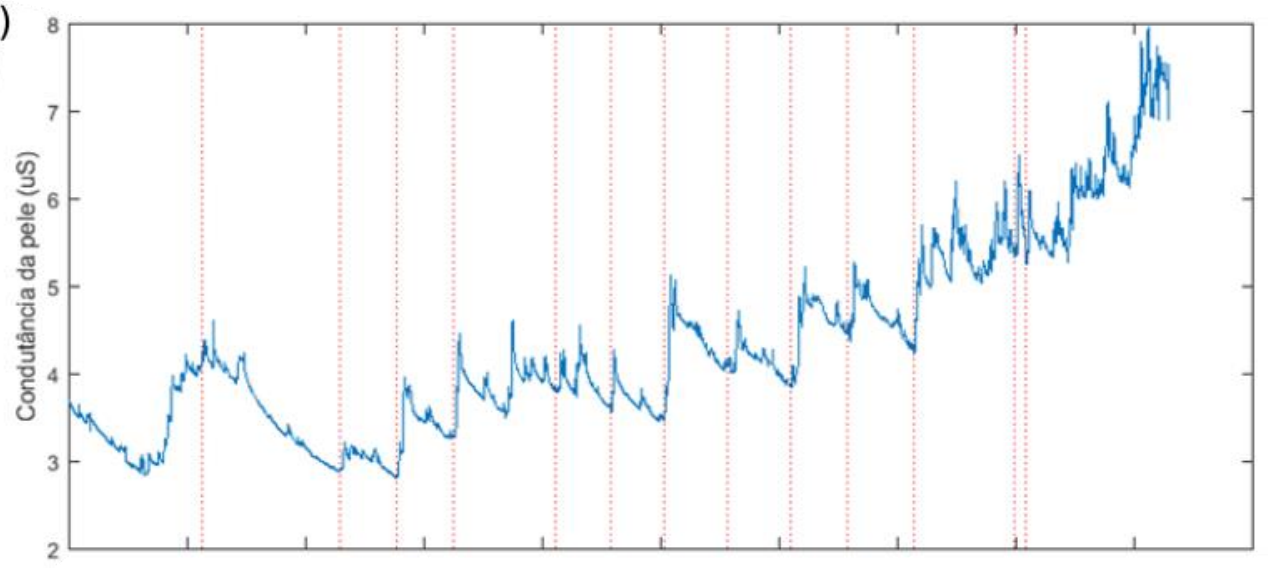

b)

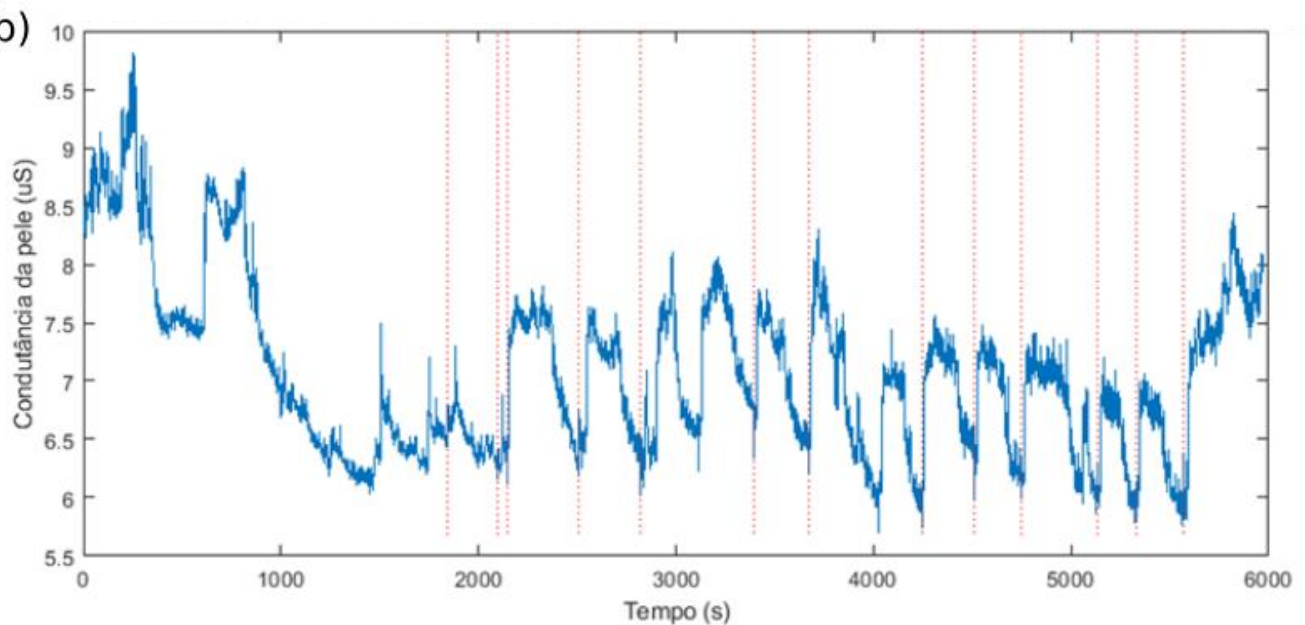

Em a) a gravação completa da atividade eletrodérmica do piloto 2 no único voo gravado (segundo voo de autorrotação). Em b) a gravação completa da atividade eletrodérmica do piloto 7 no seu segundo voo de autorrotação.

Figura 15. Exemplo de sinais brutos da atividade eletrodérmica, demonstrando a modulação logo após a falha de motor

A seguir, nosso objetivo foi verificar se o formato da curva de resposta após a falha do motor correspondia ao formato característico (Figura 3). Na figura 16a é apresentado o valor médio da curva de resposta, em janelas de 120 segundos, centradas na falha do motor. O instante zero corresponde ao ponto no qual o motor atinge uma marca inferior a 360 rotações por minuto (onde a aeronave perde sua sustentação) e o alarme sonoro é disparado automaticamente. Observa-se que as variações percentuais médias por nível de experiência e o formato da curva estão de acordo com o padrão característico descrito na literatura (Figura 3). 
a)

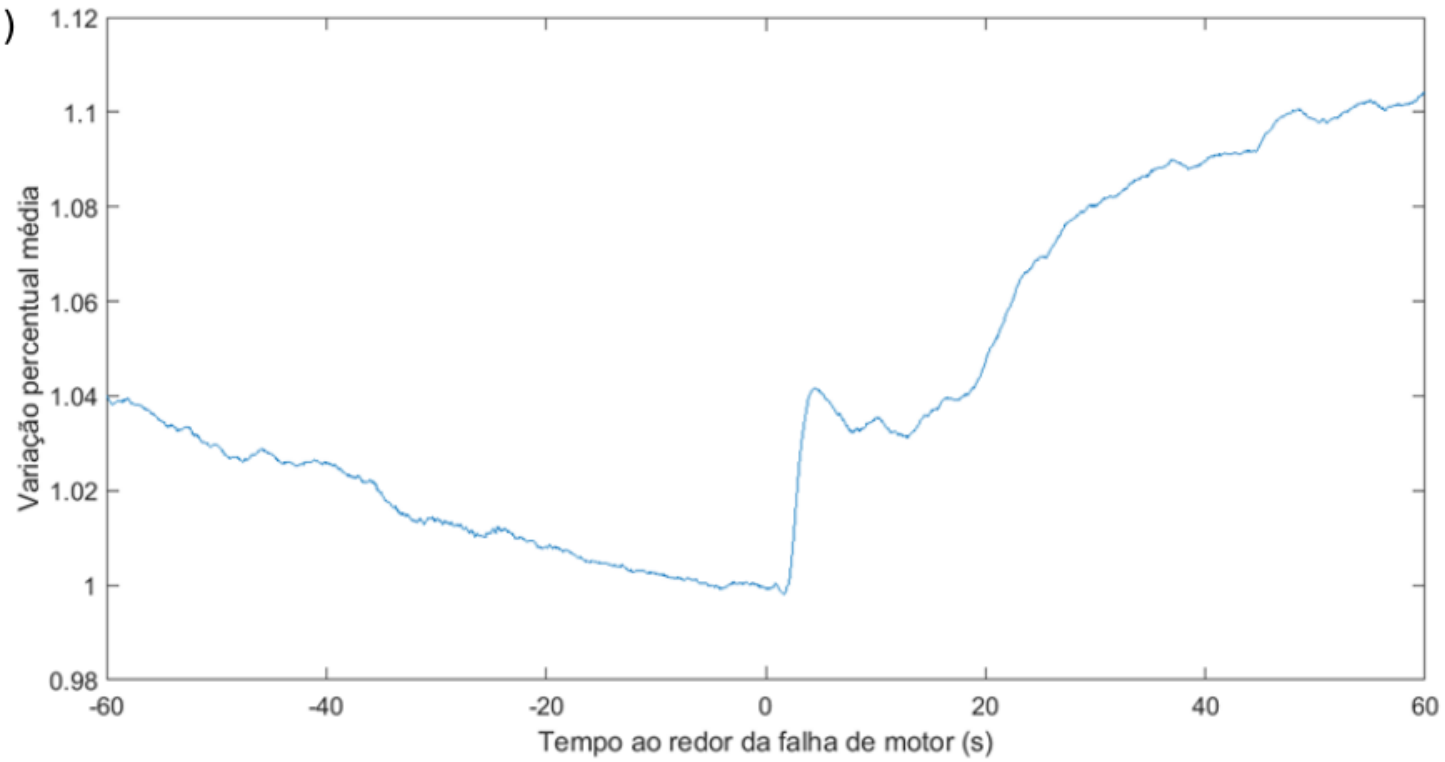

b)

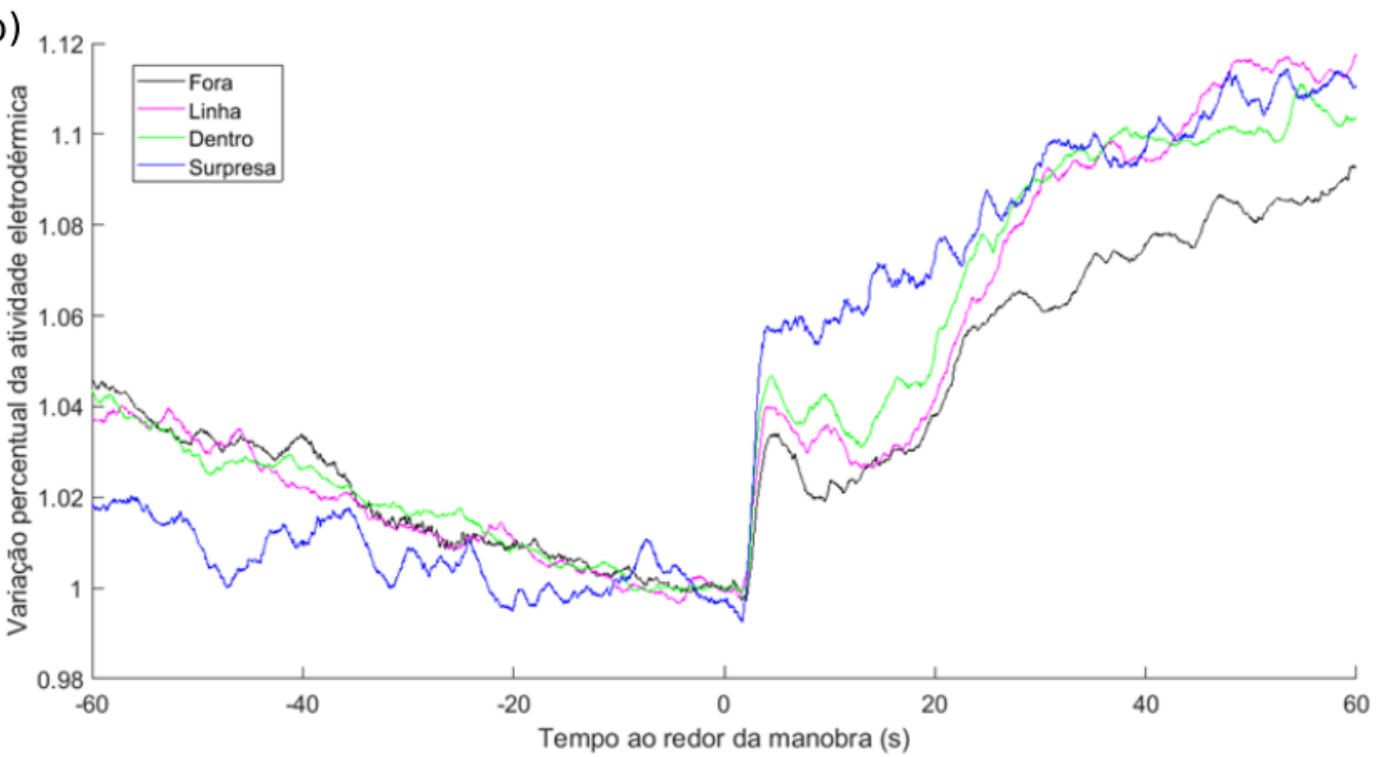

Em a) temos a média global de todas as manobra. Em b) as médias agrupadas por local de ocorrência.

Figura 16. Resposta da atividade eletrodérmica média

As curvas referentes à resposta média de cada voo por cada piloto podem ser vistas na figura 17. É possível verificar uma grande variabilidade nas formas de onda entre diferentes pilotos, mas que há uma elevada consistência no formato entre os dois voos do mesmo participante. 

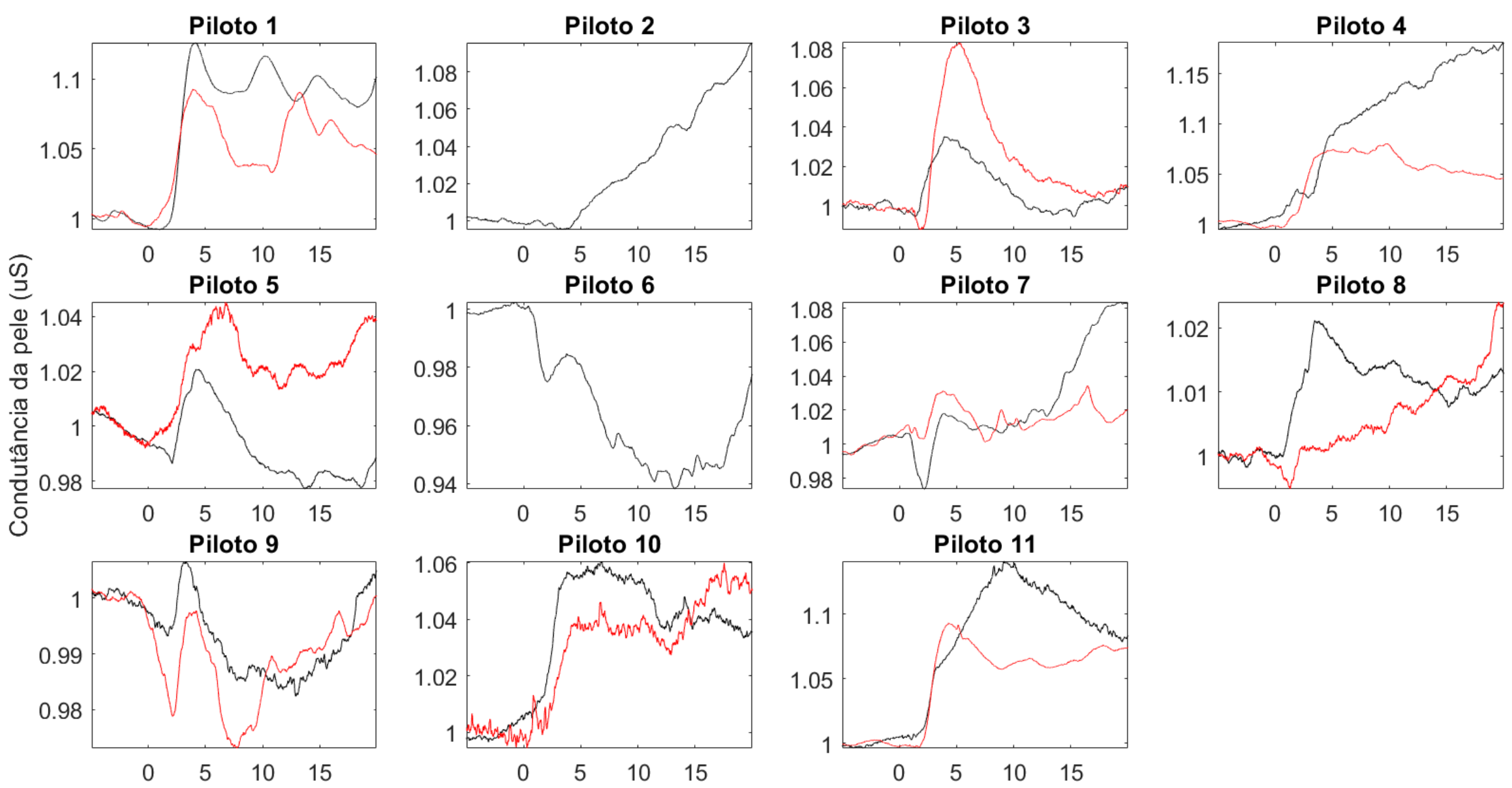

Tempo ao redor da falha de motor (s)

Pode-se observar a semelhança entre as respostas do mesmo participante em voos distintos.

Figura 17. Curvas de resposta média por voo 
A seguir, efetuamos uma análise da variação das amplitudes percentuais da resposta eletrodérmica ao longo dos voos, para observar a presença ou não de habituação. As amplitudes das respostas apresentaram em geral uma variação negativa no decorrer do voo, conforme pode ser observado na figura 18. Dos 20 voos em que adquirimos dados, apenas quatro apresentaram um coeficiente angular positivo (sendo que um deles terminou abruptamente com apenas quatro manobras, devido a um problema técnico na aeronave).

Das 232 manobras gravadas, 214 (91\%) apresentaram uma resposta dentro dos critérios adotados (Seção 3.1.5), sendo 18 (8\%) delas com tempo de latência inferior a um e maior que 0,5 segundos. Apenas dois voos tiveram mais de duas manobras cuja resposta não se adequou aos critérios estabelecidos.

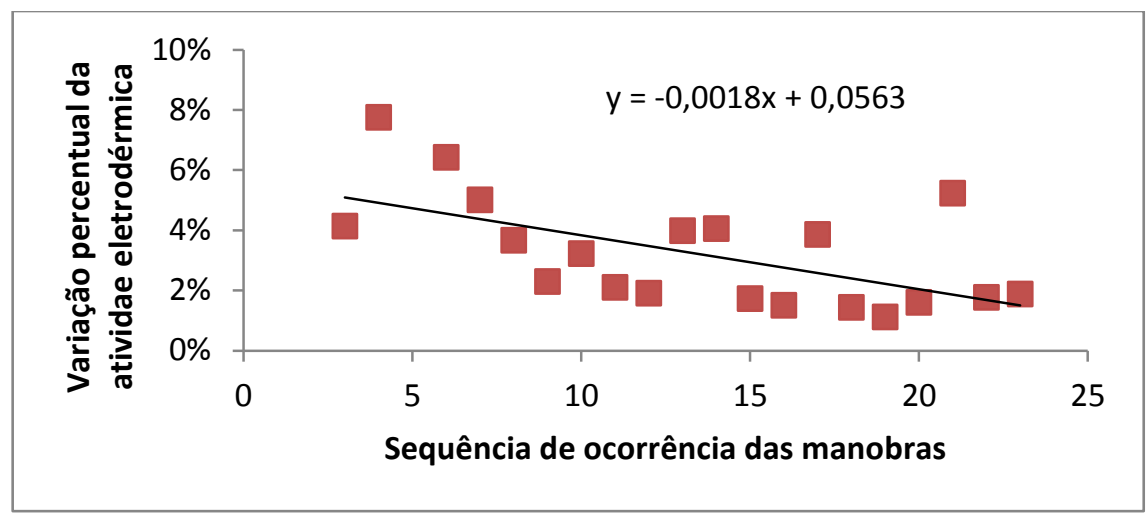

Observe que há uma tendência de diminuição ao longo do tempo, sugerindo a habituação.

Figura 18. Exemplo da modificação da amplitude percentual no decorrer de um voo

As amplitudes foram então agrupadas por local de manobra em relação à curva do homem morto (fora, na linha e dentro e surpresa). A média dos voos de cada piloto foi então agrupada por nível de experiência e o resultado é apresentado na figura 19. 


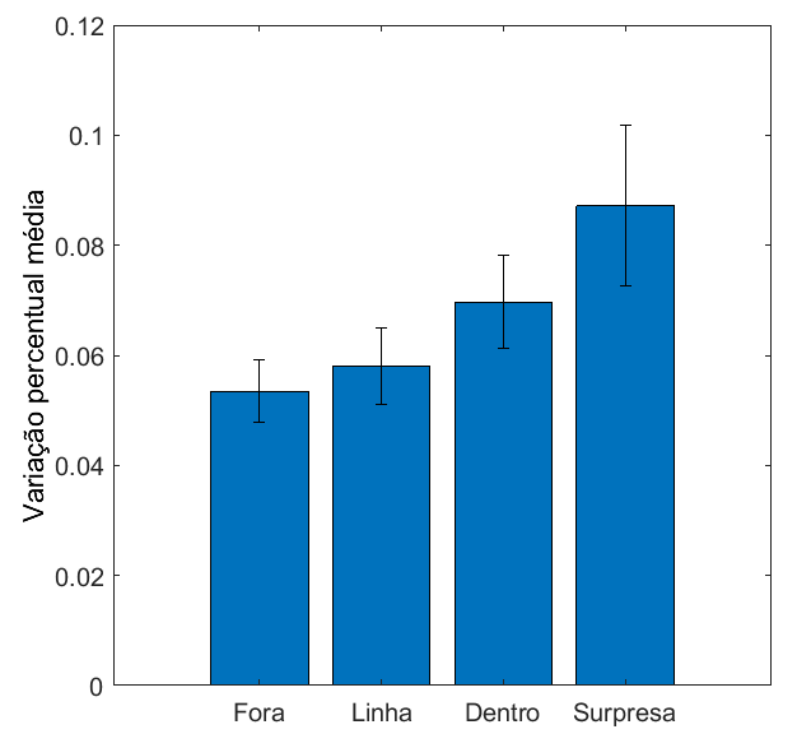

Figura 19. Amplitude percentual média das respostas da atividade eletrodérmica com relação ao local da manobra

Quando utilizamos uma versão do modelo ponderada pelos pontos de manobra (Equação 1), observamos diferenças significativas entre as manobras dentro da curva e surpresa em comparação com as manobras fora da curva, conforme apresentado na figura 20, o que, como o esperado, aponta para um aumento da excitação (arousal).

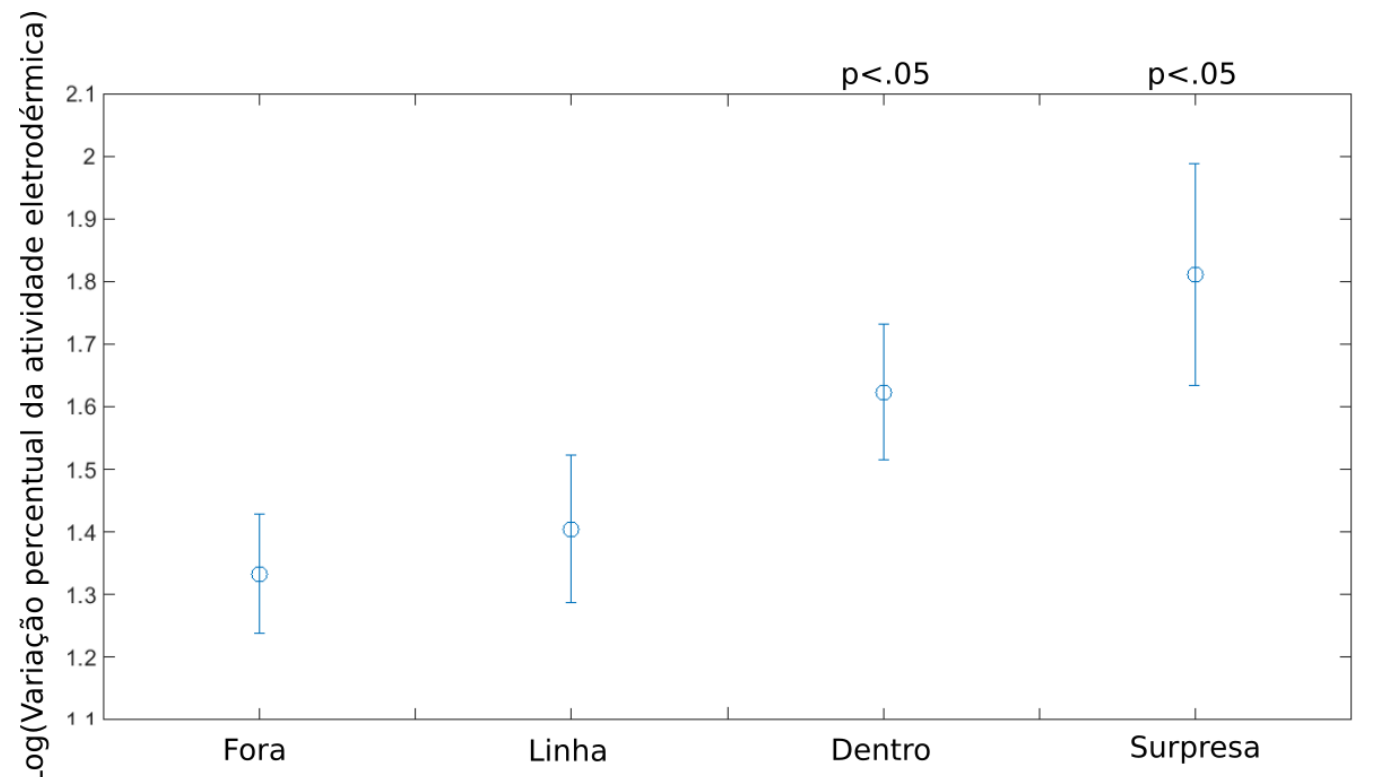

A significância estatística é em relação as manobras fora da curva do homem morto, que foi usado como o padrão no modelo linear misto (Eq. 1).

Figura 20. Média e erro padrão do Log da resposta da atividade eletrodérmica agrupada por posição em relação à curva do homem morto 


\subsection{Atividade cardíaca}

\subsubsection{Frequência cardíaca}

Dentre os 20 voos gravados, houve problema na aquisição do eletrocardiograma em apenas um. A frequência cardíaca normalizada ao redor de todas as manobras é apresentada na figura 21. Nesta figura, é possível observar a presença de dois picos de frequência cardíaca: o primeiro ao redor de três segundos e o segundo próximo de 12-13 segundos.

Quando separamos as manobras por local de ocorrência, numa primeira análise visual, observa-se que a primeira elevação da frequência cardíaca normalizada é temporalmente próxima para as manobras independente do local de execução, por volta dos 3,5-4 segundos. Este primeiro pico tem valores próximos, em especial para os cenários de fora e dentro da curva. Já o segundo pico ocorre em momentos diferentes para as manobras: ele ocorre ao redor dos 12 segundos para as manobras de fora e dentro da curva do homem morto, mas o valor da variação percentual dentro é nominalmente maior do que nas manobras fora. As manobras na linha têm o segundo pico ao redor dos 13 segundos e um valor nominal maior do que a das outras. O segundo pico das manobras surpresa é temporalmente o mais lento, ocorrendo ao redor de 14 segundos após a falha do motor e um pouco menor do que o obtido nas manobras na linha.

Os valores normalizados das frequências cardíacas se aproximam do valor basal, referente aos instantes imediatamente precedentes à manobra após cerca de 40 segundos. Como existem dois máximos locais (picos) na variação da frequência cardíaca, optamos por analisar a área sob a curva para extrair informação a respeito do arousal dos pilotos. A região utilizada para o cálculo da integral foi demarcada pelas duas linhas vermelhas pontilhadas, que compreendem desde o momento da falha do motor até 40 segundos depois (Figura 21).

As curvas médias da frequência cardíaca normalizada de cada um dos voos, separadas por piloto, podem ser vistas na figura 22. Observamos uma grande variação na característica da resposta entre pilotos distintos, mas há um padrão similar entre voos do mesmo participante, tal como na atividade eletrodérmica. 
a)

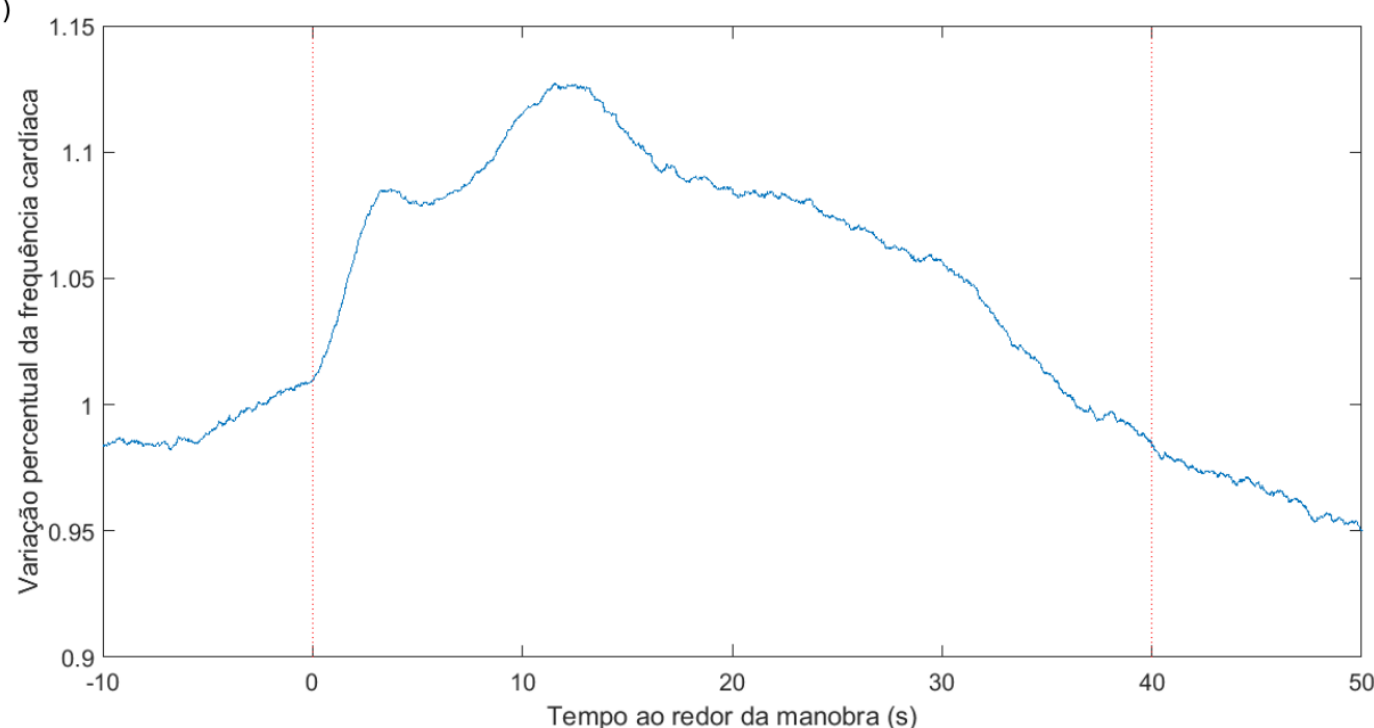

b)

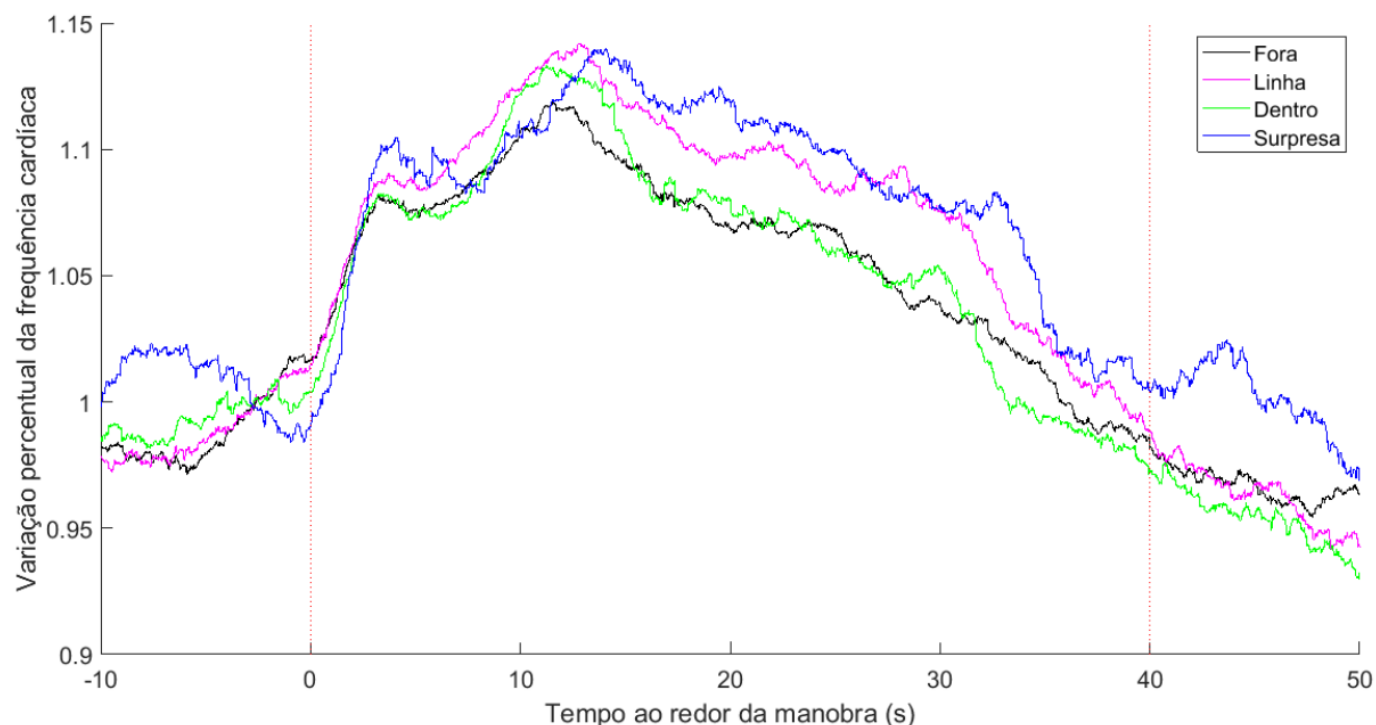

Em a) temos a média global de todas as manobras. Em b) as manobras separadas por local de execução.

Figura 21. Frequência cardíaca ao redor da falha do motor

Os valores médios das integrais e seu erro padrão são apresentados na figura 23. É possível perceber pouca variação nos valores médios obtidos e que o maior valor foi nas manobras realizadas na linha, o que não seria esperado, mas condizente com o maior pico na figura $21 \mathrm{~b}$. 

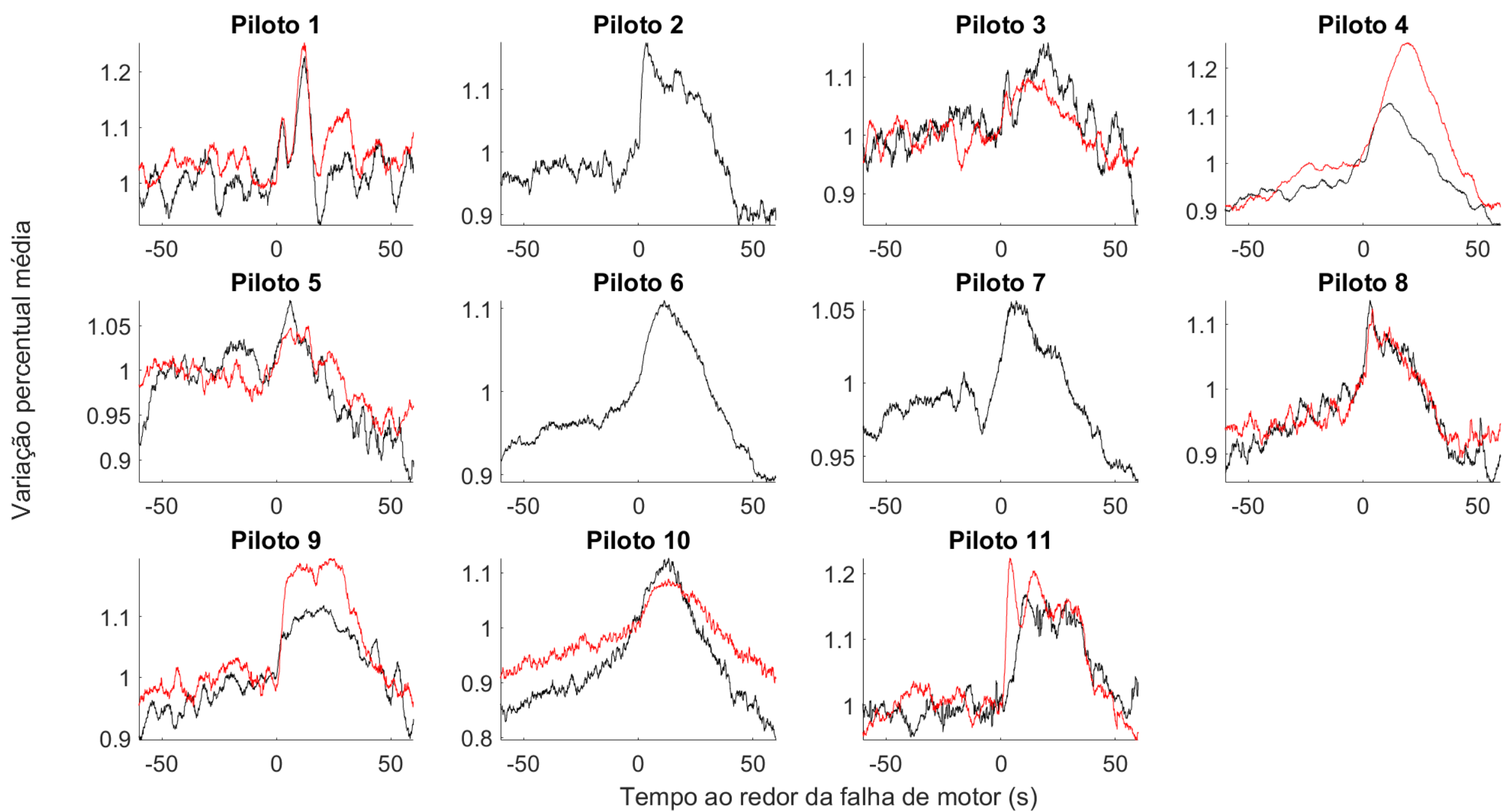

Observe a grande semelhança entre a resposta do mesmo participante em dois voos distintos.

Figura 22. Curvas de frequência cardíaca normalizada em relação aos cinco segundos anteriores a falha do motor por voo 


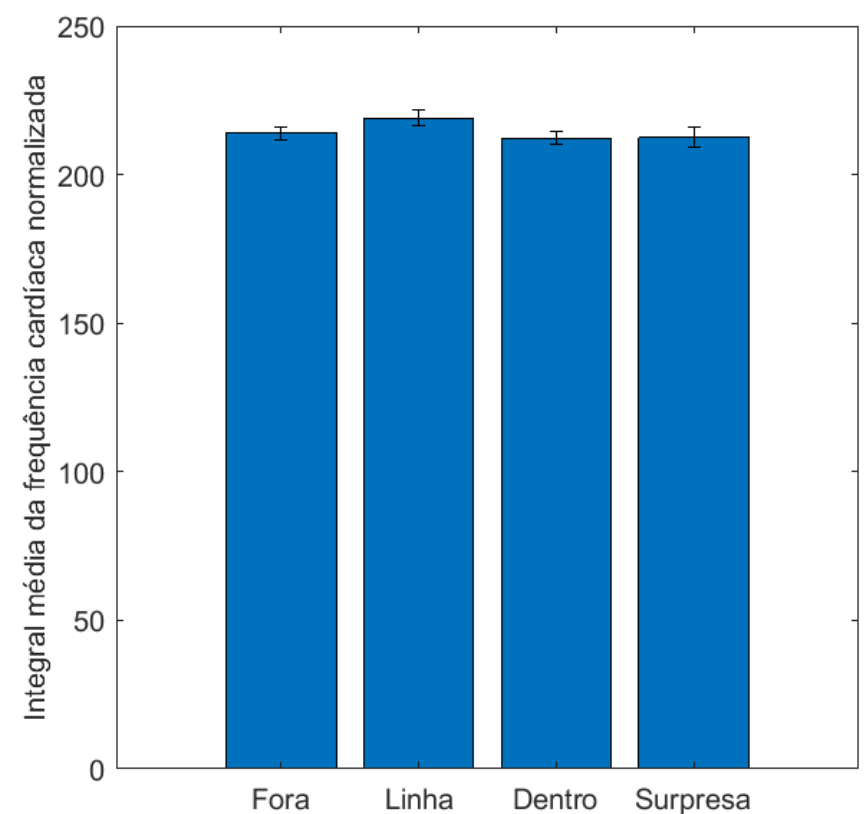

Figura 23. Integrais da frequência cardíaca ao redor das manobras

O modelo linear misto ponderado pelo local da manobra em relação à curva do homem morto (Equação 2) tomando as manobras fora da curva como referência não retornou diferença significativa para a integral da frequência cardíaca, conforme apresentado na figura 24.

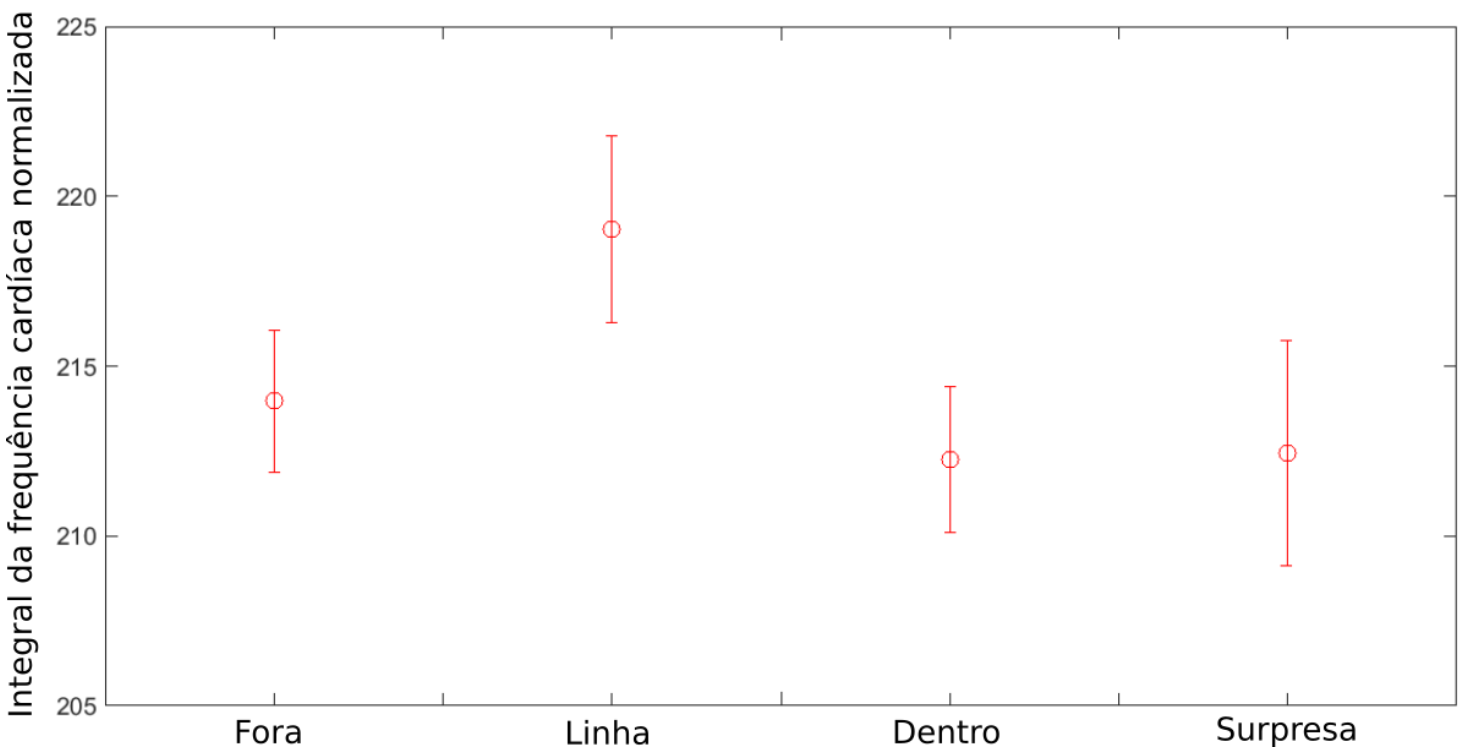

Não houve diferença estatística das manobras em relação às que ocorreram fora da curva do homem morto, o padrão de diferença utilizado pelo modelo linear misto (Eq. 2).

Figura 24. Valor médio e erro padrão das integrais da frequência cardíaca por local da manobra 


\subsubsection{Variabilidade da frequência cardíaca}

A partir da otimização dos parâmetros do modelo para minimizar o erro e a autocorrelação dos resíduos, os valores utilizados foram uma janela de 105 segundos, com ponderação do histórico de 0,98 e a ordem do modelo autorregressivo foi 12. O resultado foi bem diferente do esperado, com as razões indo até cerca de 3000 (Figura 25). O que nos mostrou que, mesmo com as otimizações efetuadas para encontrar os melhores parâmetros para o modelo, ele não foi adequado para nos mostrar as variações que ocorreram durante a execução das manobras.

Havia a possibilidade de algumas manobras terem sido mal ajustadas, e que uma análise de suas variações por local de manobra nos fornecesse algum tipo de informação. Entretanto, mesmo com esse agrupamento, o modelo não nos forneceu nenhuma informação relevante.

Esperávamos encontrar uma razão sistema simpático (baixa frequência) e parassimático (alta frequência) mais elevada logo após a falha do motor e depois, em torno de 10-12 segundos novamente, refletindo os picos encontrados na frequência cardíaca.

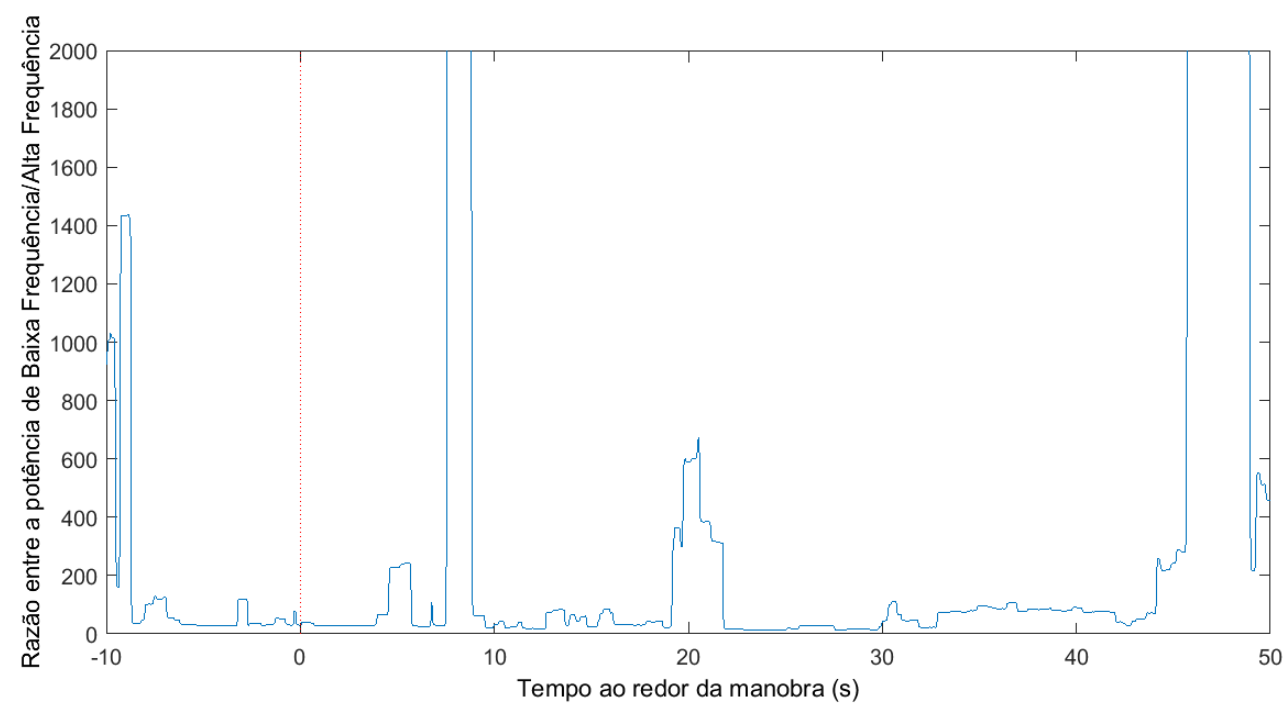

Figura 25. Resultado da relação entre as potências de alta e baixa frequência da variabilidade cardíaca obtidas com o modelo de processamento de pontos

Mas, como os valores pareciam estar contaminados por alguns outiliers, refizemos a análise da média retirando $10 \%$ das manobras, aquelas que 
tiveram em algum momento uma razão entre baixa e alta frequência acima de 550 . Então, das 225 iniciais, prosseguimos com a análise das 202 manobras.

Assim, ainda que não tenhamos encontrado uma maneira de realizar o ajuste mais adequado para esse modelo em todos os dados que coletamos, é possível observar que nos dados com melhor ajuste é possível encontrar dois picos de razão entre baixa frequência e alta frequência, conforme o esperado (Figura 26).

a)

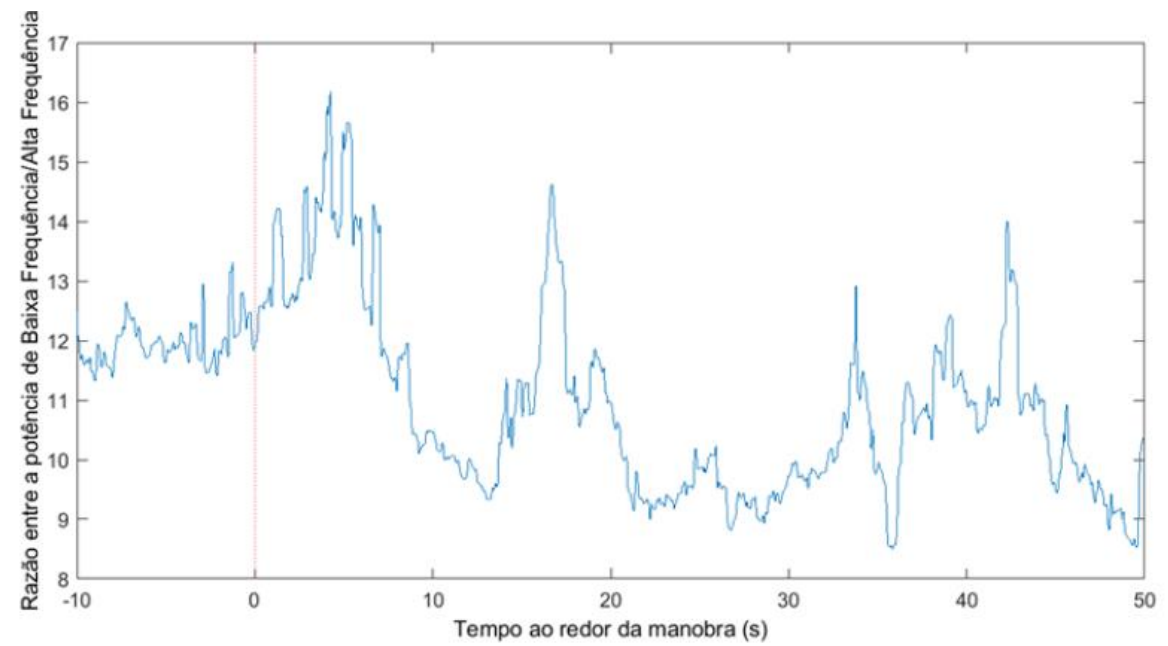

b)

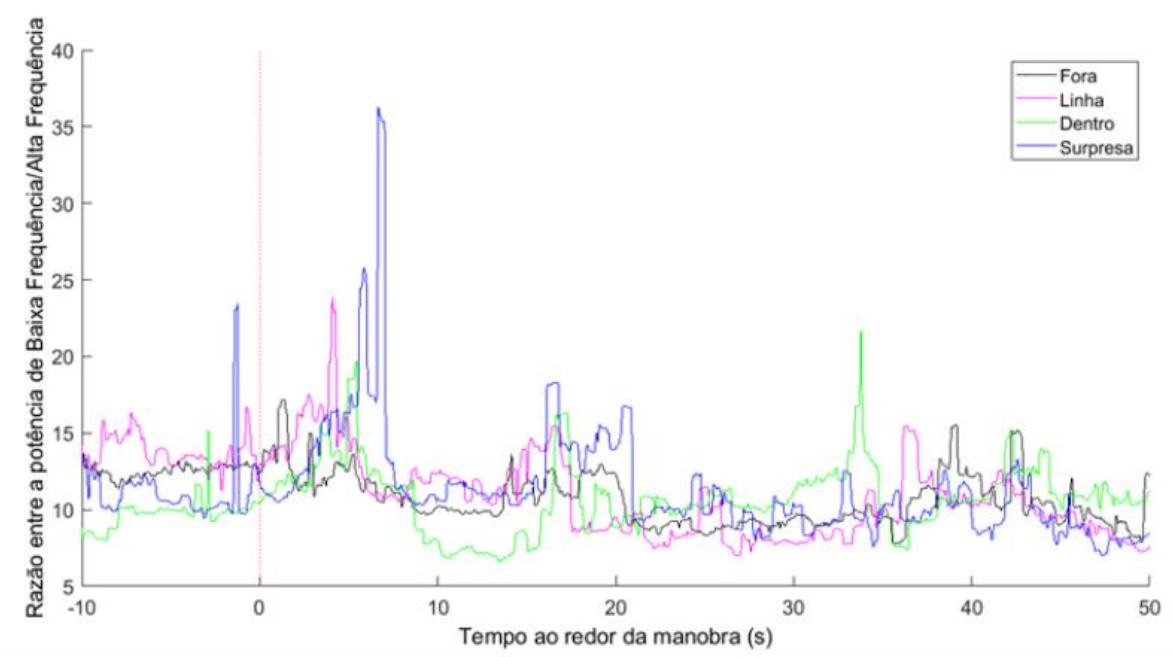

Foram retirados os $10 \%$ com maiores valores (acima de 550 , considerados mal ajustados pelo modelo). Em a) temos a média global das manobras. Em b) as médias agrupadas por local de ocorrência da falho do motor.

Figura 26. Relação entre as potências de alta e baixa frequência da variabilidade cardíaca obtidas com o modelo de processamento de pontos

Com base nesses resultados, não seguimos adiante com análises estatísticas em relação à variabilidade cardíaca em relação ao local de execução da manobra, mas pudemos observar uma concordância com os valores esperados em relação a variação da frequência cardíaca (Figura 21). 


\subsection{Atividade respiratória}

A observação do sinal bruto da respiração capturado pela cinta elástica ao redor do peito dos pilotos mostra que, após a manobra, há uma clara alteração no ritmo da respiração, conforme exemplificado na figura 27.

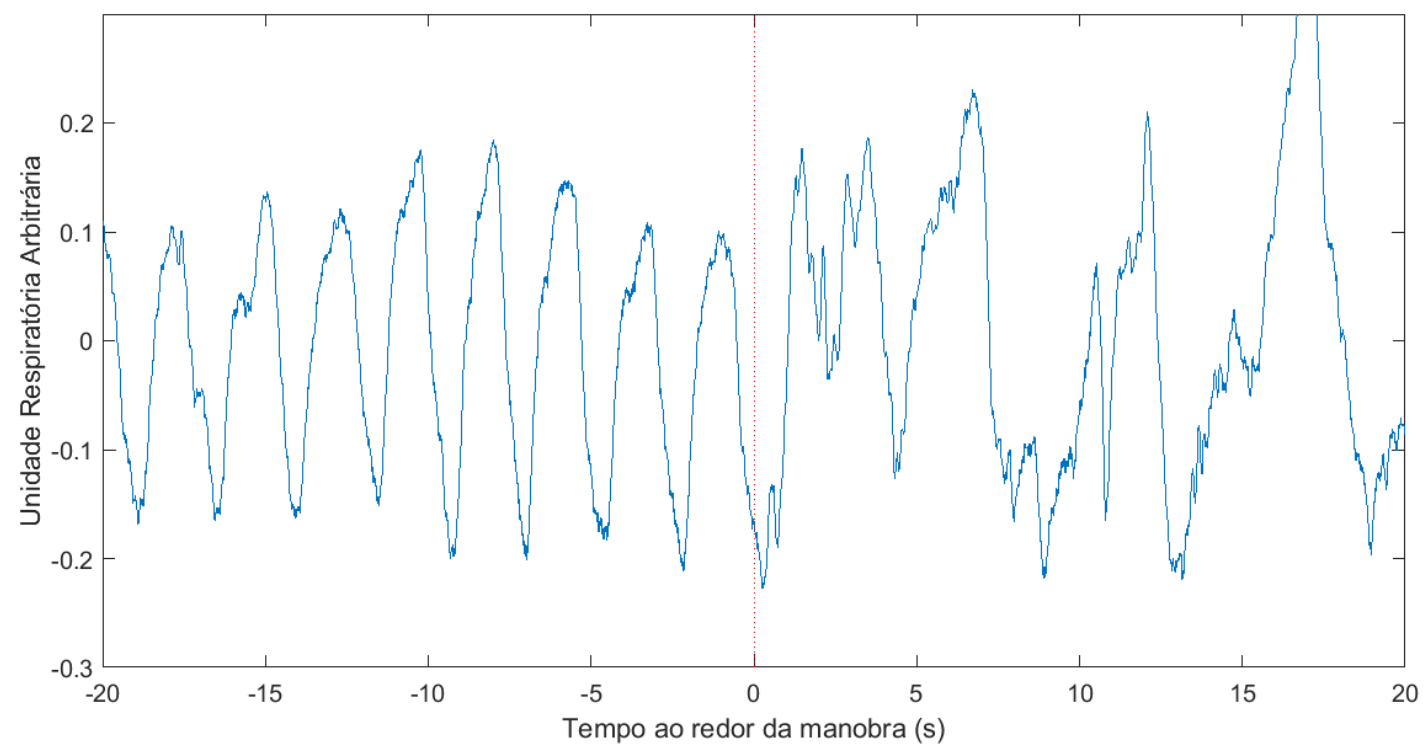

Observar a variação no sinal após a falha do motor.

Figura 27. Valor bruto do sinal de respiração de uma manobra ao redor da falha do motor

A análise da média dos sinais brutos nos mostra que, logo após a falha do motor, há um componente claro de expiração prolongada, conforme podemos observar na figura 28.

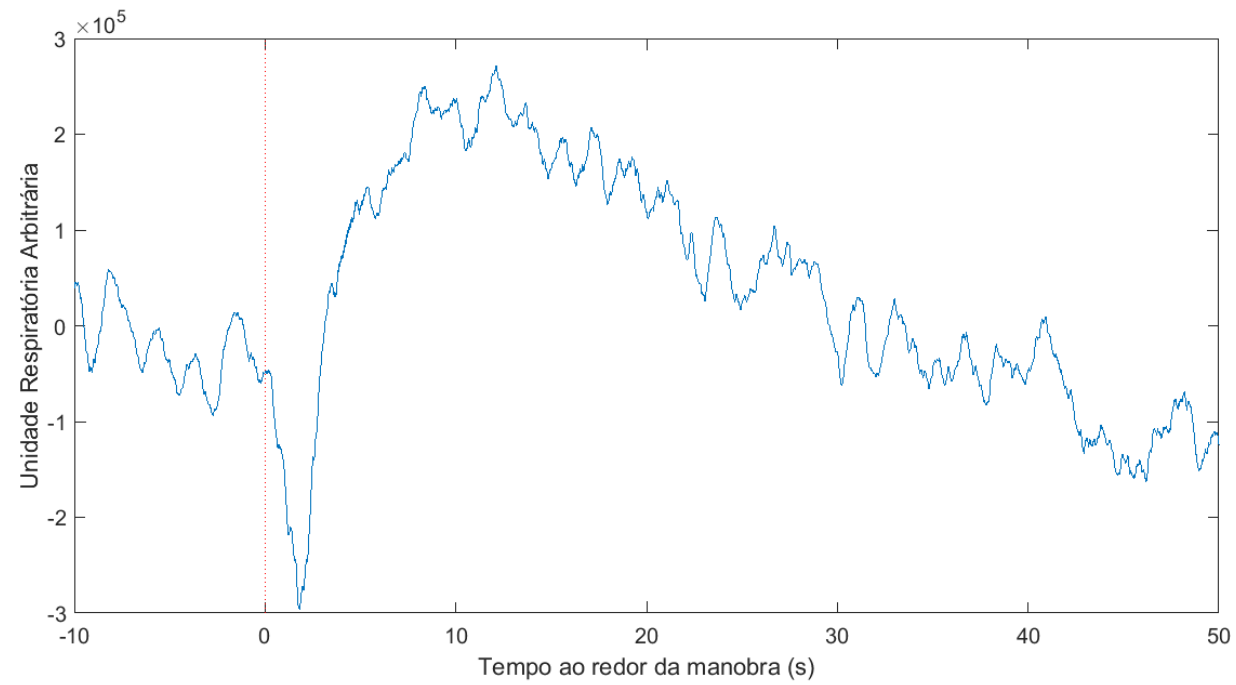

Observar a expiração após a falha do motor.

Figura 28. Valor bruto médio do sinal da respiração ao redor da falha do motor 
A análise da variação da frequência respiratória média de todas as manobras, através da frequência promediada, calculada com base no espectrograma de ondeletas (Figura 11) exibe uma variação negativa logo após a ocorrência da falha do motor e outra ao redor de 20 segundos (Figura 29a). Podemos observar que há um deslocamento do pico da frequência respiratória para alguns milissegundos antes da ocorrência da falha do motor, o que pode ser creditado ao fato de estarmos trabalhando com médias de valores de frequência muito baixos, e que mesmo ao utilizar uma ferramenta com maior precisão, como a de ondeletas, há um "espalhamento" da frequência para momentos adjacentes. É possível observar também que, ao redor de 19 segundos, há uma segunda queda na frequência respiratória.

Quando observamos as curvas agrupadas por local de manobra, é possível notar que, para todos os locais de manobra, houve uma queda na frequência respiratória muito similar logo após a manobra. Uma segunda queda clara pode ainda ser observada, com início em torno de 16 segundos nas manobras surpresa, ao redor de 19 segundos nas manobras fora, e em torno de 24 segundos nas manobras na linha. Este padrão não fica claro nas manobras dentro da curva.

O padrão de variação da respiração de cada piloto nos diferentes voos (Figura 30) sugere que não há uma similaridade dentro de um mesmo participante na execução de diferentes voos, como observado para a atividade eletrodérmica e para a frequência cardíaca. Não foram realizadas análises subsequentes a fim de separar alguma característica que pudesse ajudar a diferenciar o local de manobra. 
a)

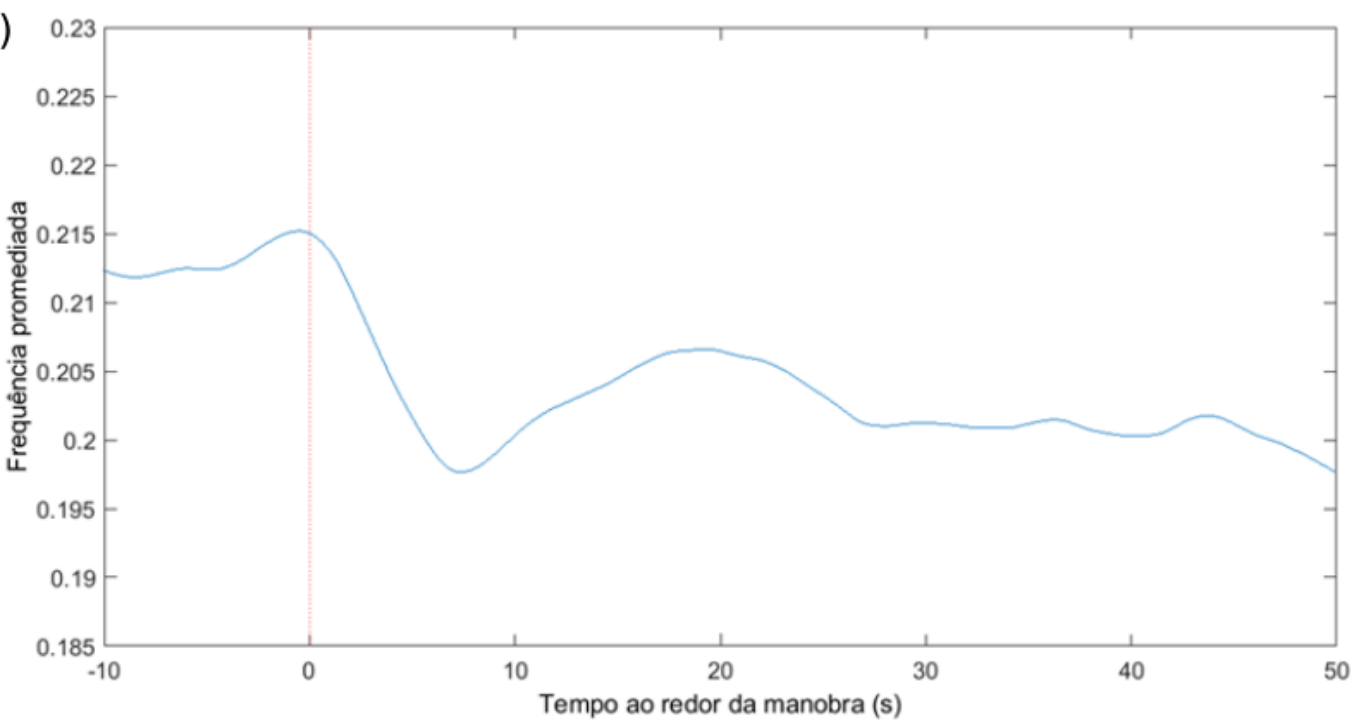

b)

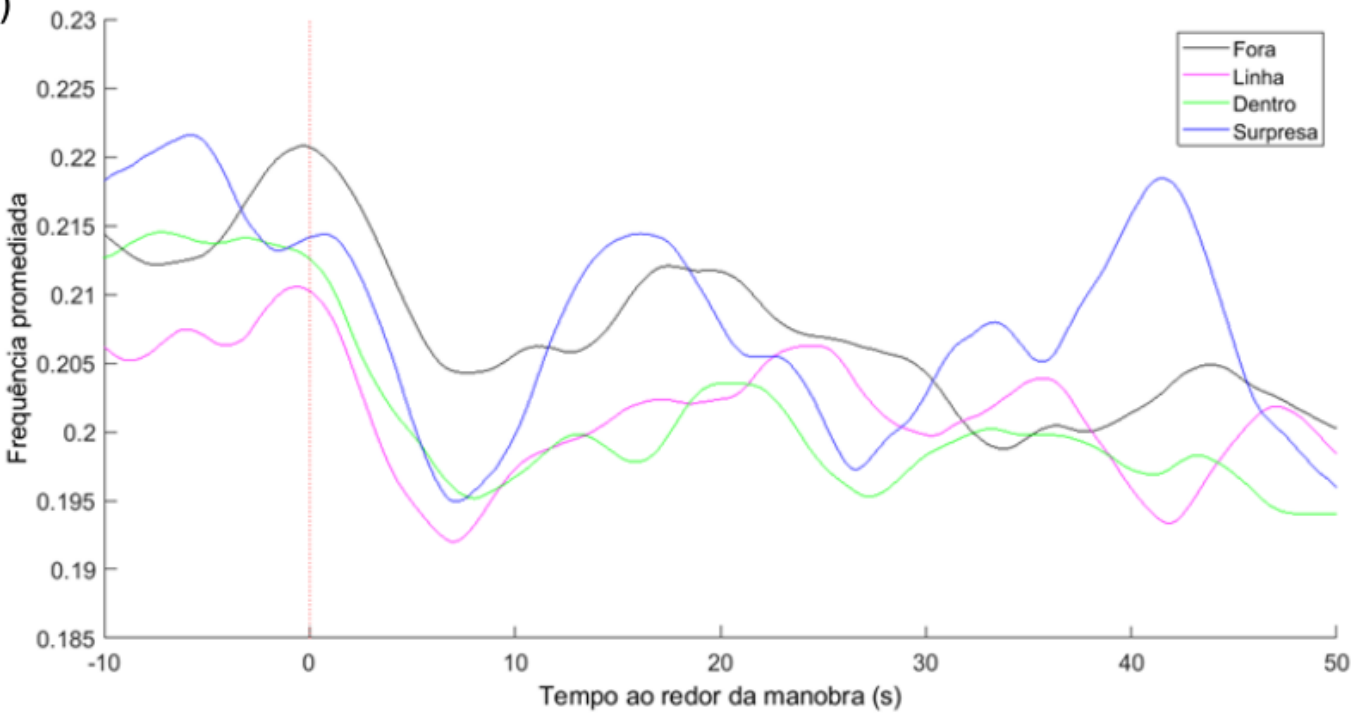

Em a) temos a variação global, de todas as manobras. Em b) a média por local de ocorrência da falha do motor.

Figura 29. Frequência respiratória promediada média 

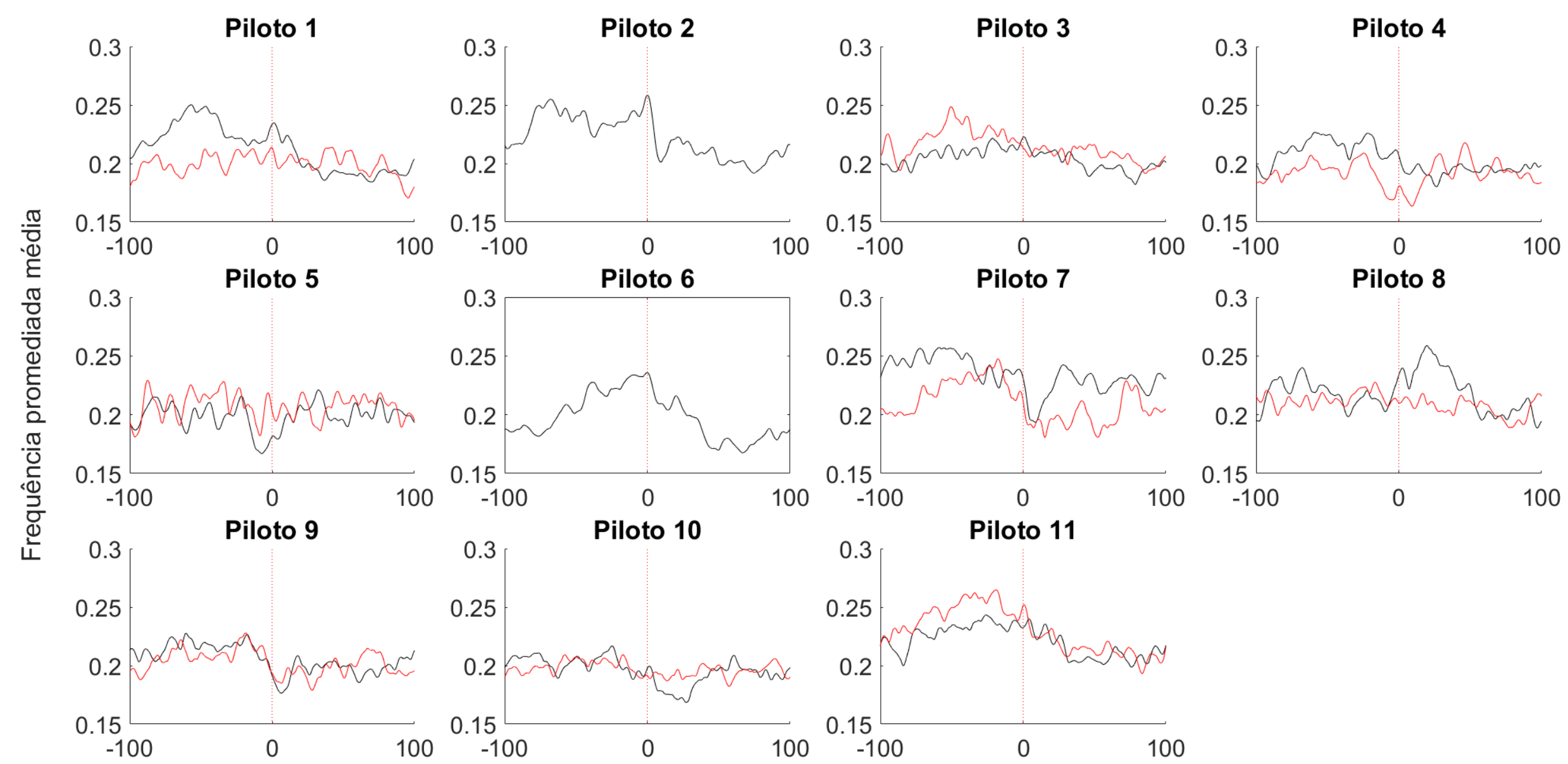

Tempo ao redor da falha de motor (s)

Figura 30. Frequência respiratória promediada média por voo de cada piloto 


\subsection{Frequência de piscadas}

Dos 20 voos gravados, foi possível obter uma componente independente com topologia e frequência de ocorrência compatíveis com piscadas em 18 deles (205 manobras). Em nove desses voos um dos canais teve que ser excluído.

O tamanho do bin que minimizou a função custo utilizada foi de 5 segundos. Na figura 31a, o histograma apresenta uma diminuição clara na frequência de piscadas, que foi confirmado pelo teste de Kruskal-Wallis $[H(23)=450,48$ e $p<0,01]$. Quando analisado para todas as manobras, o bin logo após a manobra é estatisticamente diferente de todos os outros bins. Além disso, o período de 55 segundos anteriores à falha do motor apresentou uma frequência de piscadas que é diferente daquela a partir de 25 segundos após a manobra.

a)
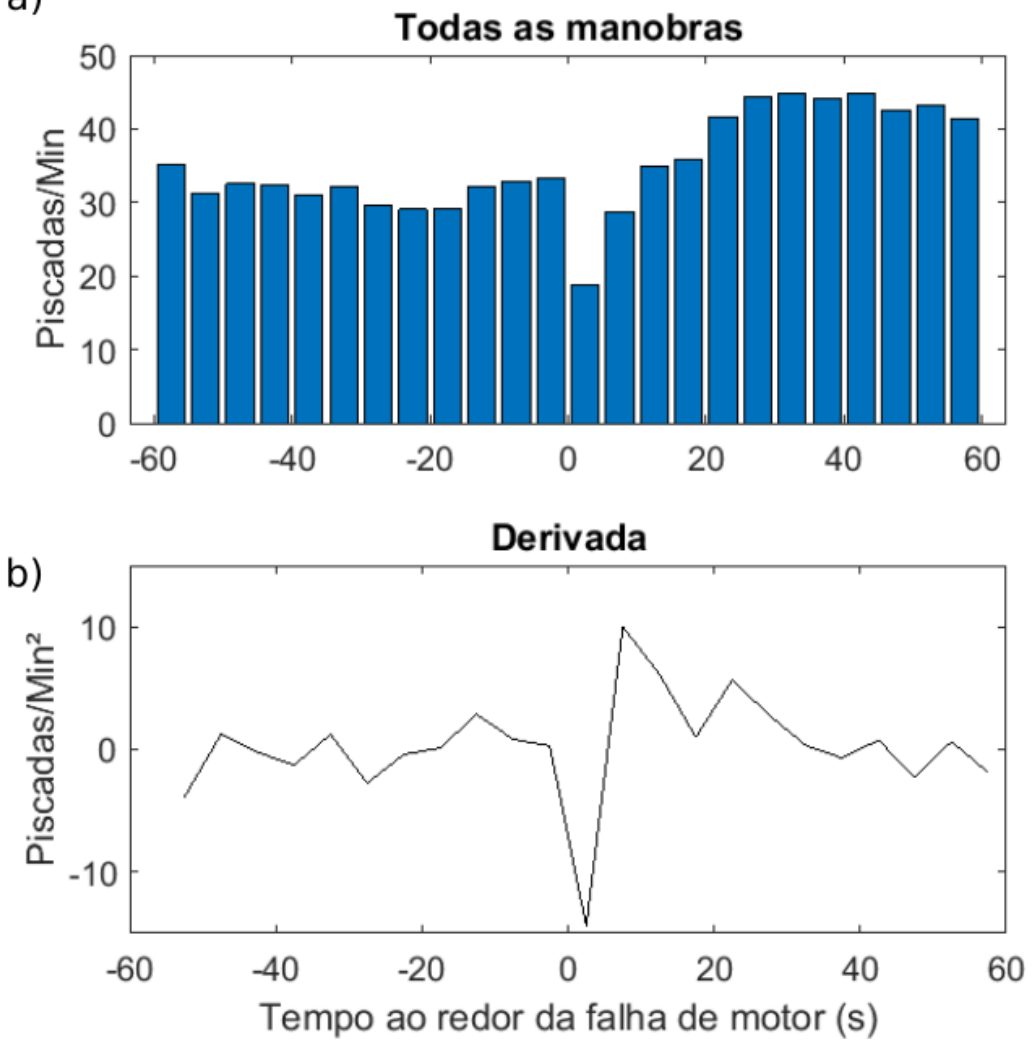

Figura 31. Frequência de piscadas média ao redor da manobra

Em seguida, as manobras foram agrupadas de acordo com o local de sua realização. E foram testados valores próximos de bins para representar o conjunto de dados. É possível observar que, independentemente do local da manobra, 
ocorreu uma supressão de piscadas após a falha do motor. Com o bin mantido em 5 segundos, há um segundo ponto de derivada negativa claro no bin centrado em 17,5 segundos para as manobras surpresa. Quando diminuímos o bin para 2 segundos, foi possível observar esse segundo ponto de derivada negativa em todos os grupos de manobras, sendo que fora, linha e dentro têm derivada negativa próximo a 13 segundos, e nas manobras surpresa, por volta de 17 segundos, conforme pode ser observar na figura 32.
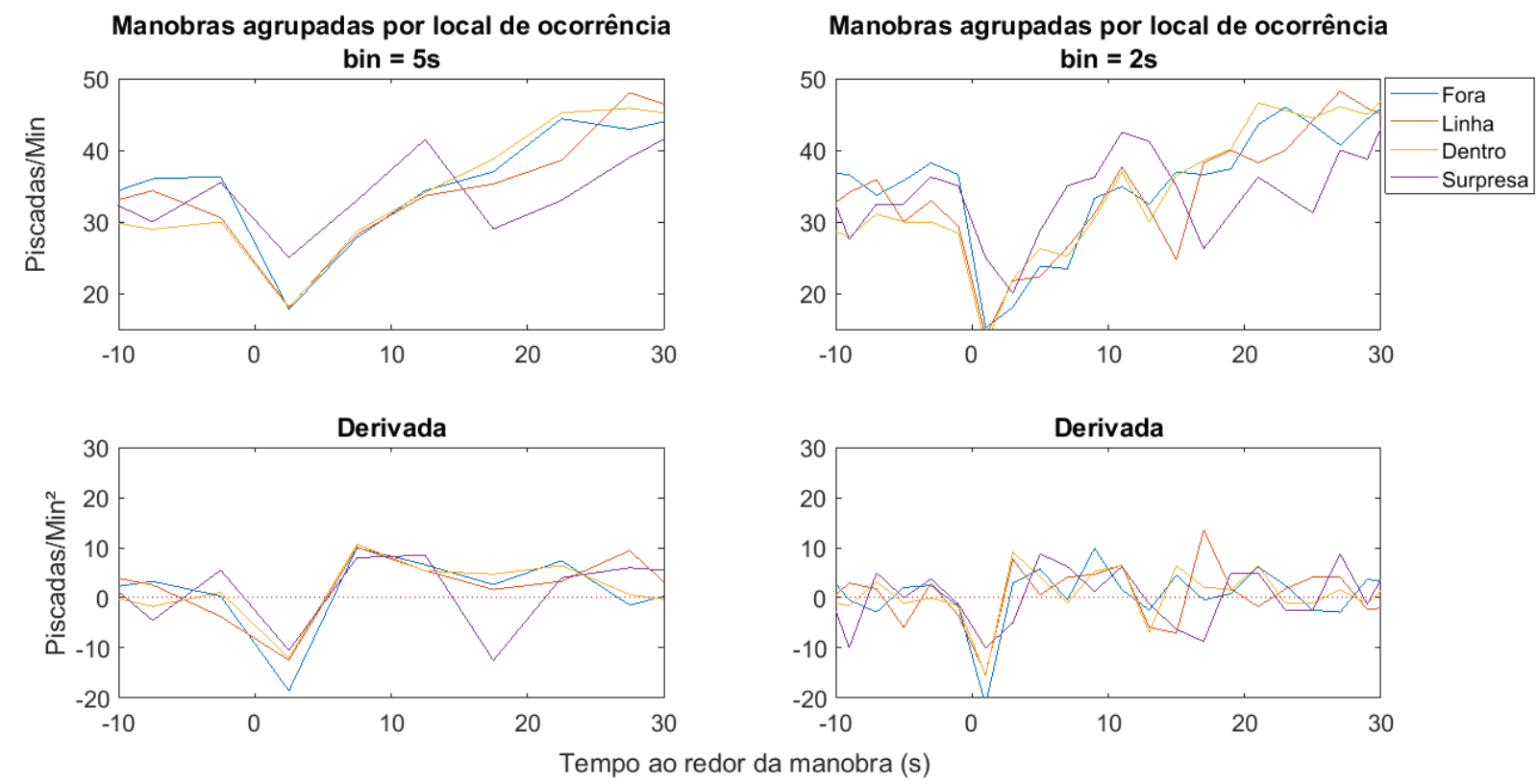

Figura 32. Número de piscadas e derivada com dois tamanhos diferentes de bins

A inibição de piscadas foi em seguida analisada a partir do teste de Kruskal-Wallis. Quando analisamos todas as manobras, obteve-se como resultados que, no bin logo após a falha do motor, há uma diferença estatística em relação ao restante do período analisado, com exceção dos dois bins subsequentes, e a série foi considerada não homogênea $[H(59)=627,77$ e $p<0,01]$. As manobras fora, na linha e dentro da curva do homem morto também foram consideradas não homogêneas $[H(59)=237,91$ e $p<0,01, \quad H(59)=261,12$ e $p<0,01$ e $H(59)=261,12$ e $p<0,01]$, respectivamente. Para as manobras surpresa, a hipótese de valores iguais não foi rejeitada $[H(59)=77,86$ e $p=0,0506]$, pois o bin após a manobra não foi considerado diferente dos outros. 


\section{DISCUSSÃO}

\subsection{Medidas subjetivas}

As medidas subjetivas de medição de carga de trabalho apresentaram resultados semelhantes entre si. Os padrões da carga de trabalho reportados em ambas as escalas apontaram para as características esperadas, sendo as menores cargas de trabalho associadas às manobras executadas fora da curva, e as maiores, nas executadas dentro da curva.

\subsection{Atividade eletrodérmica}

A primeira análise, do sinal bruto, mostrou uma modulação clara no sinal em resposta à manobra (Figura 15). Isso demonstrou a aquisição de um dado fisiologicamente parecido com o descrito na literatura (Figura 3), ainda que tenhamos colocado os eletrodos na parte dorsal, em vez de na palma da mão, como preconizado, ${ }^{(24)}$ a fim de evitar a pressão dos sensores com o manete do helicóptero. Além disso, a resposta da atividade eletrodérmica média dos pilotos (Figura 17) em dois voos diferentes mostrou uma assinatura de cada piloto muito similar mesmo em voos distintos, o que reforça a robustez do sinal gravado.

Um ponto a ser ressaltado é que, em geral, considera-se que a resposta a um estímulo é iniciada entre 1 a 5 segundos após a sua apresentação, a não ser em casos de uma resposta de sobressalto, mas o tempo de latência entre o estímulo e a resposta nunca pode ser menor que 0,5 segundos. ${ }^{(24)}$ Neste trabalho observamos que a latência entre o estímulo e a resposta em $9 \%$ das ocorrências foi menor do que 1 segundo, mas nunca inferior a 0,5 segundos. Porém, ressaltamos que ainda que nosso evento seja bem marcado pelos instrumentos de telemetria, a percepção do participante pode sofrer ligeiras variações temporais, o que traz imprecisões à esta demarcação. Cabe ressaltar que esse é um cenário real e que, em entrevistas com os pilotos, alguns relataram perceber a falha em um momento anterior ao alarme apenas pela mudança no barulho do motor, o que também poderia fazer com que a resposta eletrodérmica fosse eliciada numa janela inferior ao tradicional período de 1 segundo após o estímulo. 
Não foi possível utilizar a duração da resposta da atividade eletrodérmica, como tradicionalmente efetuado na literatura, uma vez que, neste trabalho avaliamos um cenário real, no qual o participante não retorna imediatamente às condições iniciais, como evidenciado pela presença de um segundo aumento na amplitude da atividade eletrodérmica antes do retorno ao valor basal (ou a 50\% do valor da amplitude, como sugerido na literatura). ${ }^{(24)}$

O nível tônico do sinal parecia um bom candidato para medição de carga de trabalho, pois já foi utilizado para avaliar diferentes níveis de dificuldade de uma tarefa secundária durante a direção de um automóvel em uma rodovia, mostrando-se uma medida sensível e que não atingiu um teto. ${ }^{(82)}$ Em outro contexto, a condutância da pele tônica apresentou uma relação linear crescente com o número de aeronaves que um controlador de tráfego aéreo operava. ${ }^{(83)}$ Mas, para a avaliação da execução da manobra de autorrotação, essa medida não se mostrou adequada devido ao curto período de tempo envolvido em sua execução.

O uso do modelo linear misto para a análise estatística sugere que a resposta da atividade eletrodérmica das manobras efetuadas, dentro da região demarcada pela curva do homem morto, e das manobras surpresa são estatisticamente diferentes daquelas oriundas das manobras executadas fora da curva (Figura 20). Este resultado está de acordo com o esperado nessas condições, já que elas são associadas a uma maior carga de trabalho. O resultado indica também que as diferenças de carga de trabalho foram grandes o suficiente para alterar os sinais, tal como demonstrado em um trabalho com aeronaves de asas fixas, em que a amplitude da atividade eletrodérmica não apresentou diferenças entre todos os pontos de voo, mas apenas diferenciou pontos de grande carga de trabalho (como pouso, decolagem e arremetidas). ${ }^{(23)}$

Maiores modulações na atividade eletrodérmica também foram obtidas utilizando-se a métrica da duração da resposta em testes realizados com motoristas de carros executando manobras de frenagem em diferentes velocidades, em que foi observado que, quanto maior a desaceleração necessária, maior a duração da atividade eletrodérmica. Isso ficou ainda mais evidente em paradas de emergência, nas quais a duração da resposta foi ainda maior, dada a mesma desaceleração. ${ }^{\left({ }^{84)}\right.}$

Além disso, a tendência à diminuição na amplitude da resposta eletrodérmica, evidenciada pelo coeficiente angular negativo na maioria dos gráficos da amplitude percentual ao longo das repetições (Figura 19), pode ser relacionada à 
habituação ou à fatiga. Ressalta-se que essa diminuição da amplitude da resposta já foi observada em uma tarefa de longa duração. ${ }^{(67)}$ Como o estímulo gerador da resposta da atividade eletrodérmica era breve e intenso (alarme de falha do motor), resultou em concomitante aumento da frequência cardíaca, com habituação após um pequeno número de repetições, esses resultados sugerem que as respostas associadas à manobra de autorrotação podem ser classificadas como respostas de sobressalto. ${ }^{(24)}$

Uma possível crítica a essa análise é a demarcação do ponto de máximo da resposta eletrodérmica ser realizada de maneira manual, o que pode incluir um viés no pesquisador que está realizando o processamento desse sinal. Essa é uma crítica levantada na literatura, e sua solução final não é conhecida. ${ }^{(24)}$ Há ainda um possível aumento da amplitude da resposta eletrodérmica quando ela é relacionada com uma ação motora. ${ }^{(24,38)}$ Mas, como todas as manobras envolviam uma ação muito semelhante, esse viés deveria ocorrer de maneira próxima à homogênea nas respostas gravadas. A possibilidade de contaminação do sinal por atividade muscular foi verificada através da inspeção visual de algumas respostas da atividade eletrodérmica e da atividade do eletromiograma do braço esquerdo dos pilotos, mas não se observou nenhum padrão característico.

Embora existam evidências indicando que as respostas da atividade eletrodérmica poderiam ser uma boa medida para avaliar a carga de trabalho, ${ }^{(84)}$ não há relatos em relação à efetividade dessa medida na caracterização de manobras de autorrotação ao redor da curva do homem morto, o que é uma das contribuições deste trabalho. Existem trabalhos indicando um efeito teto na medida, ${ }^{(44)}$ e estudos que afirmam a necessidade de um grande contraste entre as cargas de trabalho para que as diferenças nas respostas da atividade eletrodérmica sejam observáveis. ${ }^{(23)}$ Tal observação no entanto foi efetuada em estudos com aeronaves de asas fixas, e as diferenças foram evidentes apenas entre as partes mais demandantes do voo (decolagem, arremetida e pouso) em relação a todas as outras fases do voo. ${ }^{(23)}$ Assim, existia a possibilidade de que a diferença entre as cargas de trabalho exigidas nos diferentes pontos de execução da manobra (fora, linha, dentro e surpresa) não fossem contrastantes o suficiente para que isso se refletisse em diferenças nas amplitudes. 


\subsection{Atividade cardíaca}

A variação percentual da frequência cardíaca média após a falha do motor mostrou um padrão de resposta similar quando comparamos os resultados do mesmo participante (Figura 22) mas foram observadas diferenças notáveis ao compararmos indivíduos distintos. Esses resultados demonstram que a frequência cardíaca é um correlato robusto, mesmo em execuções diferentes da mesma atividade, mas que apresentam uma elevada variabilidade em uma população.

A dinâmica da frequência cardíaca mostrou, como o esperado, um aumento transiente, com uma volta ao valor basal em menos de um minuto, o que nos levou a buscar uma métrica para analisar suas propriedades que levasse isso em consideração. Por isso, optamos pela integral da variação percentual no período até 40 segundos após a falha do motor.

Ao analisarmos somente os valores médios das integrais da frequência, não observamos o padrão esperado, que consistia numa variação de acordo com o local de manobra que se correlacionasse com as medidas subjetivas. Isso significaria um aumento conforme a posição da manobra se direcionasse para o interior da região demarcada pela curva do homem morto. Houve apenas um pequeno aumento da integral para as manobras realizadas na linha da curva do homem morto em relação às demais.

Quando ponderamos o modelo linear misto pelos pontos de realização das manobras (Equação 2), não verificamos diferenças estatisticamente significativas entre as manobras executados fora da curva do homem morto em relação aos outros locais (Figura 24). Essa não diferenciação também foi observada em outros estudos que analisaram a frequência cardíaca e reportaram variações significativas apenas nos momentos de decolagens e pousos, sem conseguir diferenciar diferentes tarefas executadas durante os voos, reais ou simulados. ${ }^{(23,50,51)}$ Nos simuladores de tráfego aéreo com participantes experientes, observou-se também que a frequência cardíaca era sensível à análise do período de tarefa em relação ao repouso, mas não a manipulações na carga de trabalho. ${ }^{(65)}$

Apesar da hipótese inicial de uma modulação da frequência cardíaca que variasse com o tipo de manobra não ter sido observada, os resultados estão de acordo com a literatura, que afirma que é necessária uma variação de carga de 
trabalho muito grande para ser mensurado através da frequência cardíaca. ${ }^{(61)}$ Nossa expectativa inicial era que a execução da manobra fosse criar tal contraste na carga de trabalho e que pudesse ser caracterizada através dessa medida, mas não foi o resultado obtido.

Porém, como as medidas cardíacas não dependem do pesquisador para avaliação da ocorrência e amplitudes como na atividade eletrodérmica, elas podem ser consideradas mais robustas com relação a vieses do pesquisador.

Outro marcador que tentamos foi a variabilidade da frequência, mas não obtivemos sucesso para ajustar o modelo de processamento de pontos de maneira satisfatória. No entanto ao retirar algumas manobras com resultados sem validade fisiológica foi possível observar a ocorrência de uma predominância simpática (alta frequência) em relação ao parassimpático (baixa frequência) em dois momentos distintos da execução da manobra de pouso.

Análises mais detalhadas em cima de modelos que permitem uma estimativa rápida (da ordem de segundos ou milissegundos) poderiam ser muito uteis para avaliar o comportamento de pilotos com diferentes níveis de experiência. Em análises preliminares (não apresentadas neste trabalho pela falta de robustez estatística) observamos uma tendência de aumento maior da frequência cardíaca em pilotos mais experientes em relação aos pilotos com menor experiência. Mas ao final da manobra os pilotos mais experientes tendiam a retornar mais rápido à sua atividade basal. Isso sugere que pode haver uma atividade simpática maior no início da execução da manobra seguida por uma atividade maior do sistema parassimpático após o seu término.

\subsection{Atividade respiratória}

Os resultados da respiração evidenciaram os desafios para 0 processamento deste sinal em meio a um ambiente no qual os participantes falam, e ilustram a dificuldade em contornar este tipo de problema, uma vez que a aquisição é contaminada, como pode ser observado na quebra do padrão respiratório na figura 27.

Durante a realização da manobra, o efeito médio é de uma expiração longa, como pode ser observado na figura 28. 
Essa longa expiração resultou em uma diminuição instantânea da frequência do sinal da respiração, apesar dos relatos na literatura apontarem para um aumento na frequência respiratória ${ }^{(62,65-67)}$ quando tarefas com alta carga de trabalho são realizadas.

A análise do sinal respiratório médio (Figura 30) demonstrou diferenças tanto entre os participantes, como nos padrões do mesmo piloto, quando eles executaram mais de um voo. Dessa maneira, não existe uma robustez do sinal, com um padrão preservado para o mesmo participante em execuções distintas da mesma atividade, de maneira similar ao observado para a atividade eletrodérmica e para a frequência cardíaca (Figuras 17 e 22). Essa falta de robustez em repetições da atividade evidencia a dificuldade de extração de padrões confiáveis que caracterizem diferenças na carga de trabalho a partir deste sinal.

Além da fala intensa, após a conclusão da manobra de autorrotação, outras complicações advêm da baixa frequência da respiração, o que é um fator complicante para uma análise de sua variação frente a estímulos rápidos, tais como a falha do motor, já que estes eventos possuem grandes diferenças em suas escalas temporais. Ainda que tenhamos buscado por técnicas modernas como a transformada de ondeletas, não conseguimos avançar nas análises para além de perceber uma marcação clara no momento da falha do motor.

Uma sugestão para trabalhos futuros seria a busca por análises conjuntas da respiração e da frequência cardíaca, pois há indícios de que, em média, há uma segunda queda de frequência respiratória num período de tempo próximo (um pouco depois) do segundo pico de aumento de frequência cardíaca. Uma hipótese é que os pilotos (talvez intuitivamente) utilizem da interação entre batimentos cardíacos e respiração para diminuir a frequência cardíaca após os picos de carga de trabalho.

\subsection{Piscadas}

Neste trabalho foi possível observar uma diminuição na frequência de piscadas (Figuras 31 e 32), conforme o reportado pela literatura em momentos de maior demanda visual. ${ }^{(71,85)}$ Porém, observamos que esta grandeza passou por um aumento após a realização da manobra, o que pode estar ligado à fatiga, já que esse é 
considerado um marcador robusto de cansaço. ${ }^{(86-88)}$ Esses resultados mostram que o sinal adquirido, ainda que de forma indireta, corroboram com a literatura.

Entretanto, o que mais chama a atenção nesses resultados é a existência de dois vales para a frequência de piscadas ao longo do tempo. O primeiro, temporalmente coincidente com a realização da manobra, e o segundo, próximo à ocorrência do segundo pico de frequência cardíaca e da segunda queda na frequência respiratória.

Portanto, ainda que não seja possível diferenciar o nível de carga de trabalho a qual os pilotos estavam submetidos a partir dessa métrica, ela reforça a hipótese de que há um segundo momento de alta carga de trabalho após a falha do motor.

\subsection{Discussão sobre os resultados em conjunto}

Até onde pudemos verificar, a caracterização da variedade de sensores fisiológicos utilizadas neste trabalho e o fato de eles estarem sincronizados entre si em um ambiente de tamanha complexidade é inédito na literatura. Pudemos observar no conjunto dos dados que as aquisições foram bem-sucedidas no que tange à qualidade e robustez dos sinais, ainda que estivéssemos em uma situação real e em um ambiente desafiador, repleto de fontes externas de ruído. O objetivo de diferenciar os níveis de carga de trabalho ao qual os pilotos estão submetidos foi realizado parcialmente, porém foi possível determinar os sensores fisiológicos mais robustos e sensíveis para este fim. Assim, a principal contribuição deste trabalho tange a demonstração de viabilidade destes sensores e que as modulações que eles apresentam continuam observáveis em ambientes desafiadores. Como trabalhos futuros, acreditamos que estes sensores podem ser explorados em conjunto, uma vez que nossa aquisição foi sincronizada, na expectativa de extração de padrões mais sutis e não observáveis a partir da característica de um sensor individual. Apesar de termos realizado algumas tentativas neste sentido sem sucesso, acreditamos que análises multimodais podem enriquecer a descrição do fenômeno, especialmente se os dados fisiológicos puderem ser combinados com os dados de telemetria.

Além disso, foi possível observar, não apenas um, mas dois momentos de picos de resposta fisiológica a partir do resultado de alguns sensores. 
para a execução de pouso em autorrotação, os pilotos precisam iniciar a descida, e já próximos ao chão, realizar uma manobra conhecida como flare, quando a parte frontal da aeronave é levantada para realizar os últimos procedimentos de pouso. Portanto, atribuimos a segunda resposta observada, de 12 a 20 segundos após a falha do motor a esta atividade. Ressaltamos que todas as análises foram centradas no momento da falha do motor, e não no flare, mas que análises complementares em trabalhos futuros podem também explorar a robustez das modulações nesta e em outras janelas de tempo, e se existe alguma possível relação a ser estabelecida com a carga de trabalho. Tal relação traria grande auxílio na caracterização de uma missão de voo, já que auxiliaria a determinação de diferentes pontos de demanda cognitiva do piloto, o que não é possível de se realizar a partir de medidas subjetivas.

\subsection{Limitações}

A limitação mais clara deste trabalho é o baixo número de participantes e o relativo baixo número de manobras frente ao normalmente coletado na literatura para estudos de fisiologia. Essa limitação decorre do alto nível de treinamento necessário para que os pilotos possam participar desta campanha de voo, além dos elevados custos associados a cada hora de voo.

Outro ponto importante que ressaltamos foi a não inclusão de um medidor de temperatura nos pilotos, já que uma das medidas mais informativas utilizadas foi à atividade eletrodérmica, que é dependente da temperatura. 


\section{CONCLUSÕES}

1. Os sinais fisiológicos coletados foram viáveis no ambiente real analisado;

2. É possível observar diferenças na fisiologia dos pilotos em diferentes pontos da tarefa analisada, aumentando assim a resolução temporal de análise em relação às métricas subjetivas;

3. Apenas a atividade eletrodérmica mostrou uma associação clara de diferença entre os diferentes níveis de carga de trabalho ao qual os pilotos estavam submetidos. 


\section{REFERÊNCIAS}

1. Endsley MR. Design and evaluation for situation awareness enhancement. Proc Hum Factors Soc Annu Meet. 1988;32(2):97-101.

2. Endsley MR. Theoretical underpinnings of situation awareness: a critical review. In: Endsley MR, Garland DJ, editors. Situation awareness analysis and measurement. Mahwah: Lawrence Erlbauwn Associates; 2000. p. 3-28.

3. Endsley MR. Toward a theory of situation awareness in dynamic systems. Hum Factors. 1995;37(1):32-64. Figure 1, Model of situation awareness in dynamic decision making; p. 36.

4. Endsley MR, editor. Situation awareness and workload: flip sides of the same coin. 7th International Symposium on Aviation Psychology; 1993 Apr 26-29, Columbus: Ohio State University; 1993.

5. Matthews G, Reinerman-Jones LE, Barber DJ, Abich J 4th. The psychometrics of mental workload: multiple measures are sensitive but divergent. Hum Factors. 2015;57(1):125-43.

6. Galy E, Cariou M, Mélan C. What is the relationship between mental workload factors and cognitive load types? Int J Psychophysiol. 2012;83(3):269-75.

7. Cooper GE, Harper RP Jr. The use of pilot rating in the evaluation of aircraft handling qualities. Paris: Advisory Group for Aerospace Research and Development; 1969. Figure 7, Handling qualities rating scale; p. 12.

8. Roscoe AH. Assessing pilot workload in flight. Bedford: Royal Aircraft Establishment; 1984.

9. Roscoe AH, Ellis GA. A subjective rating scale for assessing pilot workload in flight: a decade of practical use. Farnborough: Royal Aerospace Establishment Farnborough; 1990.

10. Veillette PR. Human error cited as major cause of US commercial EMS helicopter accidents. Flight Saf Dig. 2001.

11. Abbeel P, Coates A, Hunter T, Ng AY. Autonomous autorotation of an RC helicopter. In: Khatib O, Kumar V, Pappas GJ. Experimental robotics: The Eleventh International Symposium. Springer; 2009. p. 385-94.

12. Shapley JJ, Kyker RA, Ferrell KR. The development of an improved method of conducting height-velocity testing on rotary wing aircraft. J Am Helicopter Soc. 1970;15(2):30-8. Figure 7, Proposed height-velocity diagram. p. 37.

13. Stanisławski J. Prediction of helicopter HV zone and cueing the emergency maneuver after power loss. Archive of Mechanical Engineering. 2010;57(1):21-44.

14. Wickens CD. Multiple resources and mental workload. Hum Factors. 2008;50(3):449-55.

15. Hancock PA, Chignell MH. Mental workload dynamics in adaptive interface design. IEEE Trans Syst Man Cybern. 1988;18(4):647-58.

16. Cain B. A review of the mental workload literature. Toronto: Defence Research And Development Canada; 2007. 
17. Rubio S, Díaz E, Martín J, Puente JM. Evaluation of subjective mental workload: a comparison of SWAT, NASA-TLX, and workload profile methods. Appl Psychol. 2004;53(1):6186.

18. Gao Q, Wang Y, Song F, Li Z, Dong X. Mental workload measurement for emergency operating procedures in digital nuclear power plants. Ergonomics. 2013;56(7):1070-85.

19. Johnson A, Widyanti A. Cultural influences on the measurement of subjective mental workload. Ergonomics. 2011;54(6):509-18.

20. Mehta RK, Parasuraman R. Neuroergonomics: a review of applications to physical and cognitive work. Front Hum Neurosci. 2013;7:889.

21. Teo G, Reinerman-Jones L, Matthews G, Barber D, Harris J, Hudson I, editors. Augmenting robot behaviors using physiological measures of workload state. 10th International Conference on Foundations of Augmented Cognition; 2016 Jul 17-22. New York: Springer-Verlag; 2016. p. 404-15.

22. Ahlstrom C, Kircher K, Fors C, Dukic T, Patten C, Anund A. Measuring driver impairments: sleepiness, distraction, and workload. IEEE Pulse. 2012;3(2):22-30.

23. Wilson GF. An analysis of mental workload in pilots during flight using multiple psychophysiological measures. Int J Aviat Psychol. 2002;12(1):3-18.

24. Boucsein W. Electrodermal activity: Springer Science \& Business Media; 2012. Figure 2.15, An ideal type-1 DC recorded exosomatic EDR and the parameters to be obtained from it (see text for explanations); p. 154.

25. Critchley HD. Electrodermal responses: what happens in the brain. Neuroscientist. 2002;8(2):132-42.

26. Vetrugno R, Liguori R, Cortelli $P$, Montagna $P$. Sympathetic skin response: basic mechanisms and clinical applications. Clin Auton Res. 2003;13(4):256-70.

27. Benedek M, Kaernbach C. A continuous measure of phasic electrodermal activity. J Neurosci Methods. 2010;190(1):80-91.

28. Figner $\mathrm{B}$, Murphy $\mathrm{RO}$. Using skin conductance in judgment and decision making research. In: Schulte-Mecklenbeck M, Kuehberger A, Johnson JG, editors. A handbook of process tracing methods for decision research: a critical review and user's guide. New York: Psychology Press; 2011. p. 163-84.

29. Sarchiapone M, Gramaglia C, losue M, Carli V, Mandelli L, Serretti A, et al. The association between electrodermal activity (EDA), depression and suicidal behaviour: a systematic review and narrative synthesis. BMC Psychiatry. 2018;18(1):22.

30. Thorell LH. Valid electrodermal hyporeactivity for depressive suicidal propensity offers links to cognitive theory. Acta Psychiatr Scand. 2009;119(5):338-49.

31. Ward NG, Doerr HO. Skin conductance: a potentially sensitive and specific marker for depression. J Nerv Ment Dis. 1986;174(9):553-9.

32. Thorell LH, Wolfersdorf M, Straub R, Steyer J, Hodgkinson S, Kaschka WP, et al. Electrodermal hyporeactivity as a trait marker for suicidal propensity in uni- and bipolar depression. J Psychiatr Res. 2013;47(12):1925-31. 
33. Turpin G. Effects of stimulus intensity on autonomic responding: the problem of differentiating orienting and defense reflexes. Psychophysiology. 1986;23(1):1-14.

34. Turpin G, Schaefer F, Boucsein W. Effects of stimulus intensity, risetime, and duration on autonomic and behavioral responding: implications for the differentiation of orienting, startle, and defense responses. Psychophysiology. 1999;36(4):453-63.

35. Barry RJ, Sokolov EN. Habituation of phasic and tonic components of the orienting reflex. Int J Psychophysiol. 1993;15(1):39-42.

36. Barry RJ. Scoring criteria for response latency and habituation in electrodermal research: a study in the context of the orienting response. Psychophysiology. 1990;27(1):94-100.

37. Siddle DA, Jordan J. Effects of intermodality change on electrodermal orienting and on the allocation of processing resources. Psychophysiology. 1993;30(5):429-35.

38. Maltzman I, Langdon B. Novelty and significance as determiners of the GSR index of the orienting reflex. Physiol Psychol. 1982;10(2):229-34.

39. Nikula R. Psychological correlates of nonspecific skin conductance responses.

Psychophysiology. 1991;28(1):86-90.

40. Damasio AR. Descartes' error: emotion, reason, and the human brain. New York: Avon Books; 1994.

41. Bechara A, Damasio H, Tranel D, Damasio AR. Deciding advantageously before knowing the advantageous strategy. Science. 1997;275(5304):1293-5.

42. Bechara A, Tranel D, Damasio H, Damasio AR. Failure to respond autonomically to anticipated future outcomes following damage to prefrontal cortex. Cereb Cortex. 1996;6(2):215-25.

43. Collet C, Petit C, Champely S, Dittmar A. Assessing workload through physiological measurements in bus drivers using an automated system during docking. Hum Factors. 2003;45(4):539-48.

44. Mehler B, Reimer B, Coughlin JF, Dusek JA. Impact of incremental increases in cognitive workload on physiological arousal and performance in young adult drivers. Transp Res Rec. 2009;2138(1):6-12.

45. Jamali HK, Waqar F, Gerson MC. Cardiac autonomic innervation. J Nucl Cardiol. 2017;24(5):1558-70.

46. Roscoe AH. Assessing pilot workload: why measure heart rate, HRV and respiration? Biol Psychol. 1992;34(2-3):259-87.

47. Charles RL, Nixon J. Measuring mental workload using physiological measures: a systematic review. Appl Ergon. 2019;74:221-32. Figure 1, The cardiac cycle; p. 222.

48. Hughes AM, Hancock GM, Marlow SL, Stowers K, Salas E. Cardiac measures of cognitive workload: a meta-analysis. Hum Factors. 2019;61(3):393-414.

49. Stuiver A, de Waard D, Brookhuis KA, Dijksterhuis C, Lewis-Evans B, Mulder LJ. Short-term cardiovascular responses to changing task demands. Int J Psychophysiol. 2012;85(2):153-60. 
50. Hankins TC, Wilson GF. A comparison of heart rate, eye activity, EEG and subjective measures of pilot mental workload during flight. Aviat Space Environ Med. 1998;69(4):360-7.

51. Tattersall AJ, Hockey GR. Level of operator control and changes in heart rate variability during simulated flight maintenance. Hum Factors. 1995;37(4):682-98.

52. Lahtinen TM, Koskelo JP, Laitinen T, Leino TK. Heart rate and performance during combat missions in a flight simulator. Aviat Space Environ Med. 2007;78(4):387-91.

53. Lee YH, Liu BS. Inflight workload assessment: comparison of subjective and physiological measurements. Aviat Space Environ Med. 2003;74(10):1078-84.

54. Dussault C, Jouanin JC, Philippe M, Guezennec CY. EEG and ECG changes during simulator operation reflect mental workload and vigilance. Aviat Space Environ Med. 2005;76(4):344-51.

55. Wilson GF, Purvis B, Skelly J, Fullenkamp P, Davis I, editors. Physiological data used to measure pilot workload in actual flight and simulator conditions. Proc Hum Factors Soc Annu Meet. 1987;31(7),779-83.

56. Veltman J. A comparative study of psychophysiological reactions during simulator and real flight. Int J Aviat Psychol. 2002;12(1):33-48.

57. Stuiver A, Brookhuis KA, de Waard D, Mulder B. Short-term cardiovascular measures for driver support: increasing sensitivity for detecting changes in mental workload. Int $\mathrm{J}$ Psychophysiol. 2014;92(1):35-41.

58. De Rivecourt M, Kuperus MN, Post WJ, Mulder LJ. Cardiovascular and eye activity measures as indices for momentary changes in mental effort during simulated flight. Ergonomics. 2008;51(9):1295-319.

59. de Waard D, Kruizinga A, Brookhuis KA. The consequences of an increase in heavy goods vehicles for passenger car drivers' mental workload and behaviour: a simulator study. Accid Anal Prev. 2008;40(2):818-28.

60. Van Roon AM, Mulder LJ, Althaus M, Mulder G. Introducing a baroreflex model for studying cardiovascular effects of mental workload. Psychophysiology. 2004;41(6):961-81.

61. Splawn JM, Miller ME, editors. Prediction of perceived workload from task performance and heart rate measures. Proc Hum Factors Ergon Soc Annu Meet. 2013;57(1):778-82.

62. Veltman JA, Gaillard AW. Physiological workload reactions to increasing levels of task difficulty. Ergonomics. 1998;41(5):656-69.

63. Porges SW, Byrne EA. Research methods for measurement of heart rate and respiration. Biol Psychol. 1992;34(2-3):93-130.

64. Bernardi L, Wdowczyk-Szulc J, Valenti C, Castoldi S, Passino C, Spadacini G, et al. Effects of controlled breathing, mental activity and mental stress with or without verbalization on heart rate variability. J Am Coll Cardiol. 2000;35(6):1462-9.

65. Brookings JB, Wilson GF, Swain CR. Psychophysiological responses to changes in workload during simulated air traffic control. Biol Psychol. 1996;42(3):361-77. 
66. Backs RW, Navidzadeh HT, Xu X, editors. Cardiorespiratory indices of mental workload during simulated air traffic control. Proc Hum Factors Ergon Soc Annu Meet. 2000; 44(13),8992.

67. Fairclough SH, Venables L. Prediction of subjective states from psychophysiology: a multivariate approach. Biol Psychol. 2006;71(1):100-10.

68. Recarte MA, Nunes LM. Mental workload while driving: effects on visual search, discrimination, and decision making. J Exp Psychol Appl. 2003;9(2):119-37.

69. Recarte MA, Pérez E, Conchillo A, Nunes LM. Mental workload and visual impairment: differences between pupil, blink, and subjective rating. Span J Psychol. 2008;11(2):374-85.

70. Hwang SL, Yau YJ, Lin YT, Chen JH, Huang TH, Yenn TC, et al. Predicting work performance in nuclear power plants. Saf Sci. 2008;46(7):1115-24.

71. Veltman JA, Gaillard AW. Physiological indices of workload in a simulated flight task. Biol Psychol. 1996;42(3):323-42.

72. Sirevaag EJ, Kramer AF, Wickens CD, Reisweber M, Strayer DL, Grenell JF. Assessment of pilot performance and mental workload in rotary wing aircraft. Ergonomics. 1993;36(9):1121-40.

73. Hess RA, Zeyada Y, Heffley RK. Modeling and simulation for helicopter task analysis. J Am Helicopter Soc. 2002;47(4):243-52.

74. Walker D. Multivariable control of the longitudinal and lateral dynamics of a fly-by-wire helicopter. Control Eng Pract. 2003;11(7):781-95.

75. Kumar MV, Suresh S, Omkar S, Ganguli R, Sampath P. A direct adaptive neural command controller design for an unstable helicopter. Eng Appl Artif Intell. 2009;22(2):181-91.

76. Bailey RE, Jackson EB, Bilimoria KD, Mueller ER, Frost CR, Alderete TS. Cooper-Harper experience report for spacecraft handling qualities applications. Hampton: National Aeronautics and Space Administration; 2009.

77. Delorme A, Makeig S. EEGLAB: an open source toolbox for analysis of single-trial EEG dynamics including independent component analysis. J Neurosci Methods. 2004;134(1):9-21.

78. Barbieri R, Matten EC, Alabi AA, Brown EN. A point-process model of human heartbeat intervals: new definitions of heart rate and heart rate variability. Am J Physiol Heart Circ Physiol. 2005;288(1):H424-35.

79. Barbieri R, Brown EN. Analysis of heartbeat dynamics by point process adaptive filtering. IEEE Trans Biomed Eng. 2006;53(1):4-12.

80. Daubechies I. Ten lectures of wavelets. Philadelphia: Society for Industrial and Applied Mathematics; 1992.

81. Shimazaki H, Shinomoto S. A method for selecting the bin size of a time histogram. Neural Comput. 2007;19(6):1503-27.

82. Mehler B, Reimer B, Coughlin JF. Sensitivity of physiological measures for detecting systematic variations in cognitive demand from a working memory task: an on-road study across three age groups. Hum Factors. 2012;54(3):396-412. 
83. Collet $C$, Averty $P$, Dittmar A. Autonomic nervous system and subjective ratings of strain in air-traffic control. Appl Ergon. 2009;40(1):23-32.

84. Collet C, Salvia E, Petit-Boulanger C. Measuring workload with electrodermal activity during common braking actions. Ergonomics. 2014;57(6):886-96.

85. Yan S, Wei Y, Tran CC. Evaluation and prediction mental workload in user interface of maritime operations using eye response. Int J Ind Ergon. 2019;71:117-27.

86. Stern JA, Boyer D, Schroeder D. Blink rate: a possible measure of fatigue. Hum Factors. 1994;36(2):285-97.

87. Kurylyak Y, Lamonaca F, Mirabelli G, editors. Detection of the eye blinks for human's fatigue monitoring. 2012 IEEE International Symposium on Medical Measurements and Applications Proceedings; 2012 May 18-19, Budapes: Institute of Electrical and Electronics Engeneers; 2012.

88. Morris TL, Miller JC. Electrooculographic and performance indices of fatigue during simulated flight. Biol Psychol. 1996;42(3):343-60. 


\begin{abstract}
Introduction: Helicopter flights must be located outside the so-called dead's man curve to allow safe landing in case of engine failure. This allows the autorotation maneuver to be performed safely. The standard for measuring workload during this maneuver consists of subjective measures, which are susceptible to various biases and report the average value of the workload during the maneuver. Objective measurement through physiological markers can help characterization over the duration of the maneuver execution, thus increasing the measurement resolution and may allow discriminate the moments of pilot's greatest demand. By better understanding the most demanding steps, pilots training can be improved. Objective: To study the feasibility of recording electrophysiological signals during self-rotation maneuvers in real flights. An attempt to analyze its correlations with the difficulty level of each maneuver (outside, in line or within the dead man's curve, or even surprise) during the self-rotating landing was also evaluated. Methods: Acquisition of electroencephalogram, electrocardiogram, electrodermal activity, respiration rate and electromyogram of eleven pilots during autorotation maneuvers at different points in relation to the dead's man curve. The electrodermal activity, electrocardiogram, respiration and blinking frequency of these pilots were analyzed. Results: Electrodermal activity, heart rate and blink frequency showed robust signals and patterns similar to those reported in the literature. The breath signal did not show a robust signal comparing 2 different pilot flights. The electrodermal activities elicited in the maneuvers within the curve and surprise were different from the maneuvers outside the curve. All signals collected, including breathing, had two distinct response modulation moments, one shortly after engine failure and another few seconds later. Conclusions: Physiological signals can be used even in a real environment with many noise sources. These analyzes showed that these signals can be useful to search for the moments of greatest demand of the pilots during this maneuver, which is not possible using the subjective measurements, which are most commonly used to evaluate this type of maneuver.
\end{abstract}

Keywords: Workload; Galvanic skin response; Heart rate; Respiratory rate; Blinking Rate 